\title{
استخدام بنك المعرفة المصري" EKB" لدى معلمي المدارس الثانوية وطلابها في محافظة القاهرة : المهرة دراسة ميدانية
}

\author{
د. نجوى شكري يمني أحمد

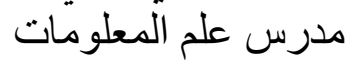 \\ قسم المكتبات - جامعة عين شمس علم
}

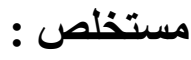

يرصد هذا البحث و اقع استخدام المعلمين، وطلاب المدارس الثانوية لبنك المعرفة المصري

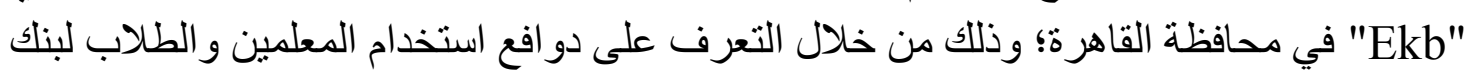

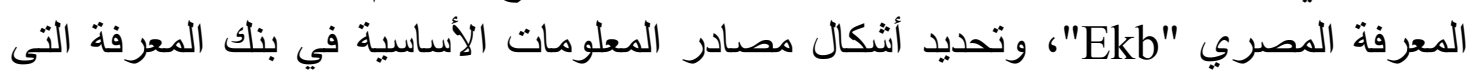

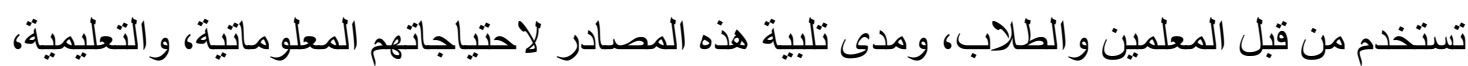

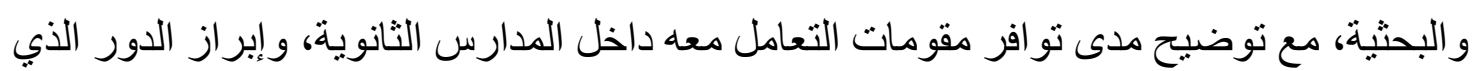

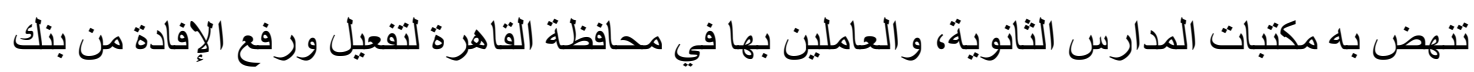
المعرفة المصري "Ekb"، مع الكثف عن المعوقات التى تحول دون استخدام بنك المعرفة المصري "Ekb" من قبل المعلمين والطلاب للتغلب عليها لتطوير وتعزيز أقصى إفادة منه،

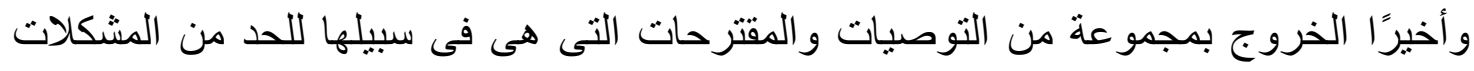

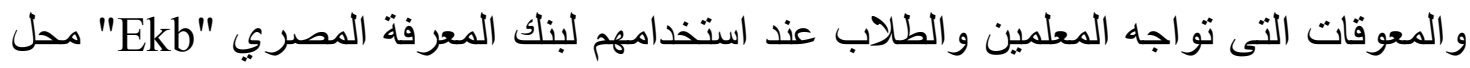
الدراسة المعوفات

/ / تمهيـــ

بنك المعرفة المصري (Egyptian Knowledge Bank) هو المشروع الذي تتبناه القيادة السياسية وتشرف عليه وزارة التربية والتعليم وعلى رأسها د. طارق شوقي وزير التربية 


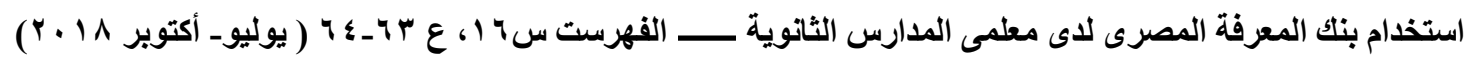

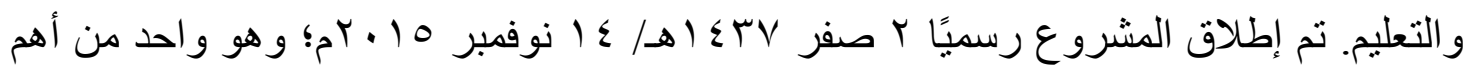
و أكبر بنوك المعرفة الموجودة على مستوى العالم؛ نظرًا لما يحتويه من مصادر إلكترونية تعليمية

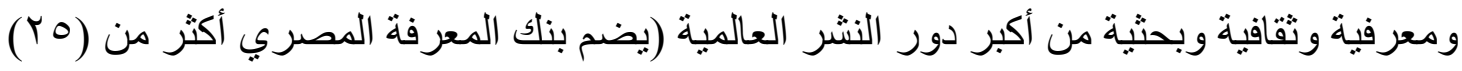
ناشرًا من صفوة الناشرين الدوليين على مستوى العالم مثل: Britannica، National، (Oxford University Press. ،Elsevier ،Willy ،Springer ،Geographic عبر الإنترنت مجانًا؛ حيث يوفر بنك المعرفة المصري "EKB" مقاطع فيديو، ومقالات، وموارد

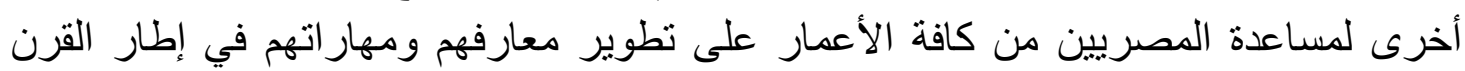
الحادي و العثرين.

ويحتوي بنك المعرفة المصري "EKB" على أربعة مكونات/ بوابات رئيسية وفقًا

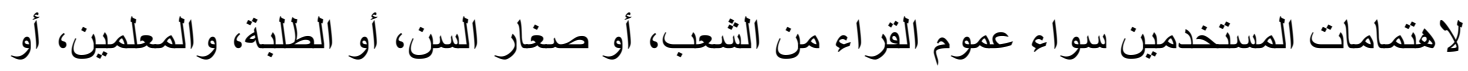

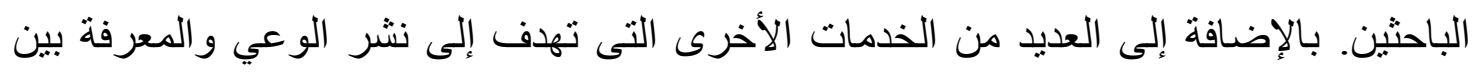
أفر اد الثعب، و الارتقاء بجودة مخرجات البحث العلمي إلى مستوى التنافسية الدولية . تحتوي البوابة الخاصة بعموم القراء على المصادر المعرفية المحلية والإقليمية، و العالمية

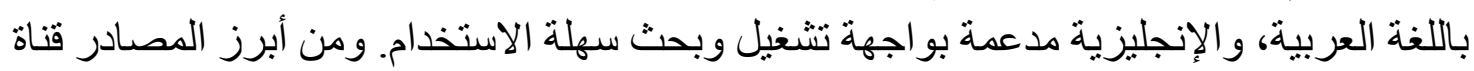

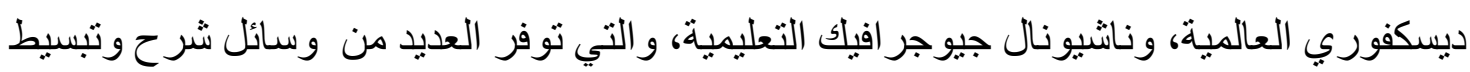
العلوم المختلفة في صور ها المقروءة و المسمو عة و المرئية، كما تحتوي على موسو عة بريتانيكا

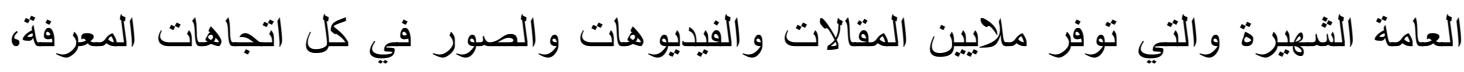
بالإضافة إلى أمهات الكتب التراثية والأدبية من المكتبة البريطانية باللغة العربية و العديد من

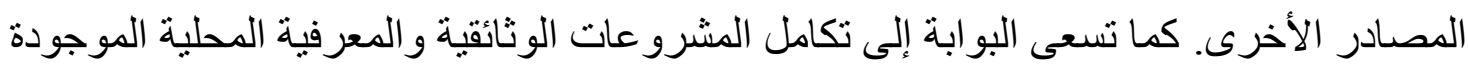
في الجهات و الهيئات المحلية كمكتبة الإسكندرية، والأزهر الثريف الثريف وغير ها. وللطلبة بو ابة خاصة سهلة الاستخدام تحتوي على نظام بحث موحد مرن الاستخدام للبحث

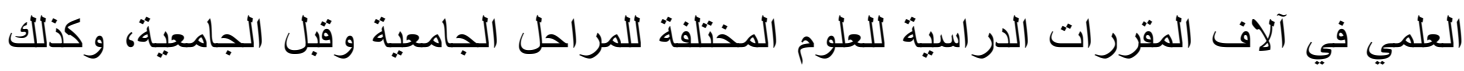
الكتب المرجعية من كبرى دور النشر العاملة في هذا المجال. وبالنسبة للبو ابة الخاصة بالباحثين فهي تحتوي على أحدث ما وصل إلبه العلم من اكتشافات

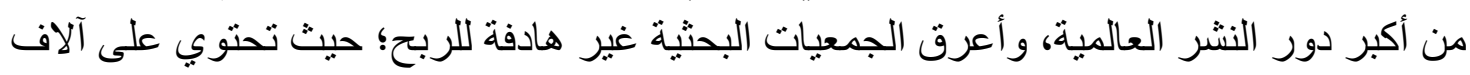
الدوريات العلمية المتخصصة ذات معاملات التأثير المرتفعة في المجالات البحثية المختلفة، بالإضافة إلى مئات الآلاف من الكتب والمراجع العامة والمتخصصة، وكذلك قواعد البيانات

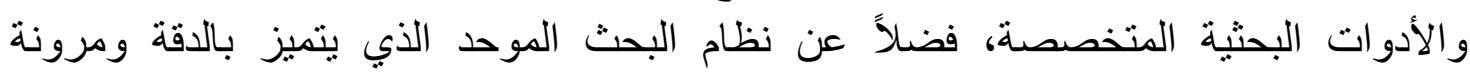
الاستخدام، ونظام التصفح الموضوعي لكافة التخصصات. جاءت أيضًا البوابة بنظام لتدعيم اتخاذ القرارات الطبية وفقًا للمواصفات العالمية واستنادًا إلى الطب القائم على الدليل، وكذلك 
خبر ات المتخصصين دعمًا لجهود الارتقاء بالر عاية الصحية و العلاجية لجمهورية مصر العربية. كما يستكمل بنك المعرفة بوابة خاصة لصغار السن مدعمة بنظام بسيط ، وتصميم متميز للأطفال؛ تحتوي البوابة على العديد من القصص والألعاب التعليمية مدعمة بالوسائل السمعية (البصرية) (1). (1)

وتهدف شركة Discovery Education إلى إمداد بنك المعرفة المصري بمحتوى تعليمي قيم وذي مستوى عالمي لطلاب المر احل الابتدائية، والإعدادية، و الثانوية؛ حيث تسعى من خلاله إلى توفير آلاف من مقاطع الفيديو المتنوعة و التي بدور ها سوف تؤدي إلى تحويل دروس العلوم

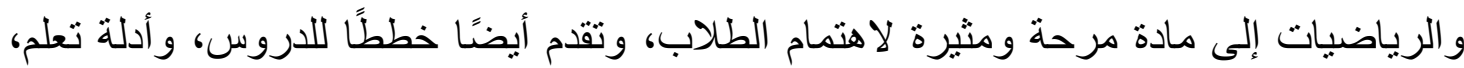

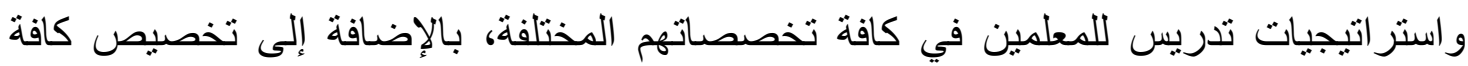

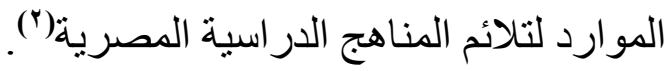
وتحقيقًا للهدف المنشود من أكبر مكتبة إلكترونية في العالم والتي تتمثل في بنك المعرفة المصري (EKB)، قام توجيه عام المكتبات في مديرية التربية و التعليم بالقاهرة بوضع نشرة

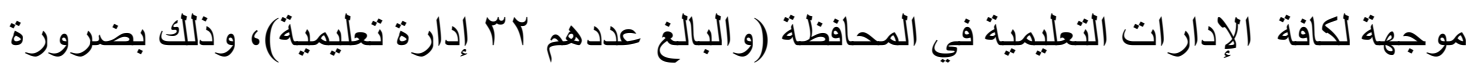
عمل محاضر ات وورش عمل للمعلمين و الطلاب للتعريف بينك المعرفة المصري و التسجيل فيه، بالإضافة إلى صدور نشرة أخرى تفيد بضرورة وجود جهاز حاسب آلي مزود بخدمة الإنترنت

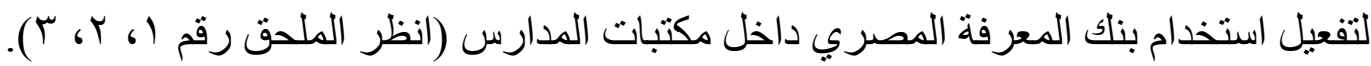

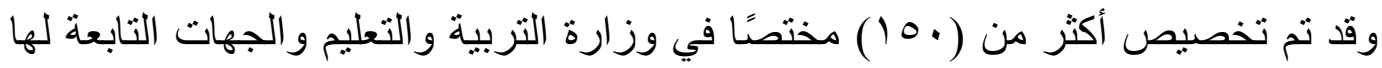
للوصول بمشروع بنلك المعرفة المصري لأعلى مستويات النجاح. وكان الناتج عقد أكثر من (•9) جلسة تدريب في المدارس مما أسفر عن تدريب ما يزيد عن ؟ ؟ ألف معلم وأخصائي مكتبات (محمد العربي مدرب المدارس الخاص ببنك المعرفة (المصري). ونتيجة لتلك المجهودات السابقة، حققت منصة ويب بنلك التعليم المصري نجاحًا كبيرًا لافنًا؛

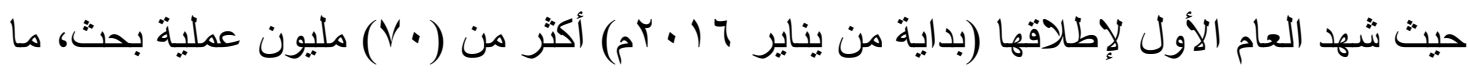

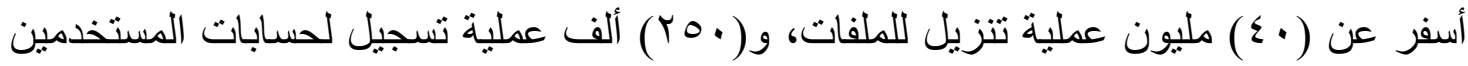
في ويب بنك المعرفة المصري، وقد اتسع نطاق قاعدة المستخدمين ليضم الطلاب، والأطفال، و الباحثين، و المهتمين بالقر اعة و الاطلاع(محمود داوود، مدير التدريب و التسويق في بنك المعرفة

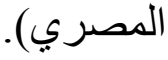
كما عقت وزارة التربية والتعليم، مجموعة من الاتفاقات مع العديد من المكتبات لتقديم خصومات لمن لديه حساب على بنك المعرفة المصري، وذللك في إطار اهتمام الوزارة بالتشجيع

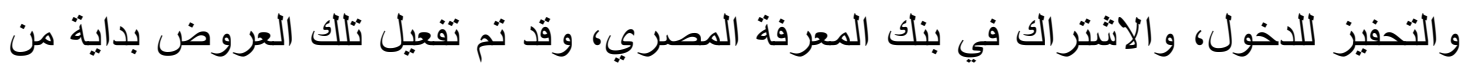

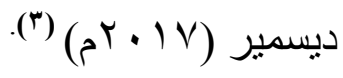




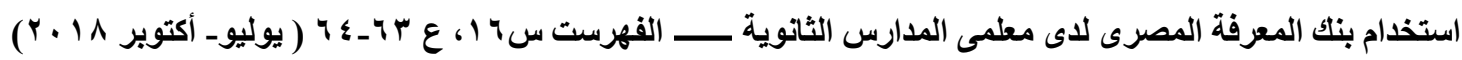

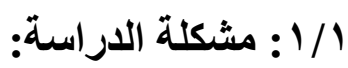

في سياق التطورات الحديثة و الر اهنة في عصر المعلومات وتقنياته، وفي ظل إتاحة أكبر مصادر المعرفة على الإنترنت وهو بنك المعرفة المصري "EKB"؛ حيث يعطي المعلمين و الطلبة فرصة الحصول على مواد مجانية للتعليم والأبحاث العلمية في جميع أنحاء العالم،

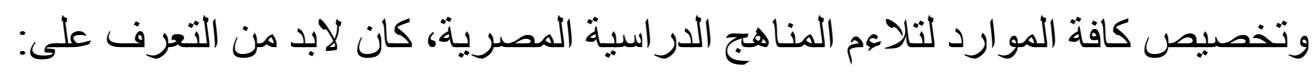
ا ـ استخدام بنلك المعرفة المصري لدى معلمي المدارس الثانوية وطلابها في محافظة القاهرة. r ـ مدى تأثثير هذا الثكل التكنولوجي الجديد على الجانب التعليمي لدى المعلمين والطلاب.

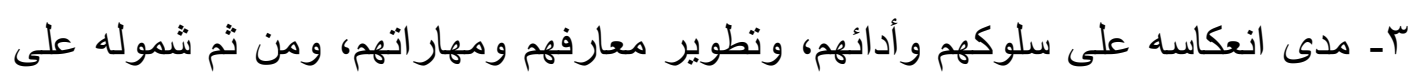
المنظومة التعليمية.

وذلك في ظل رفض الكثير من الطلاب وأولياء الأمور التسجيل عليه لفكرة رفض تطبيقه عليهم أو على أبنائهم في مرحلة مصيرية في حياتهم كالثانوية العامة؛ وهو ما يمثل جرس إنذار لجميع القائمين على منطومة التعليم لإيجاد طريقة وحل فوري لهذه المشكلة أنها.

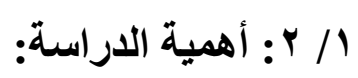

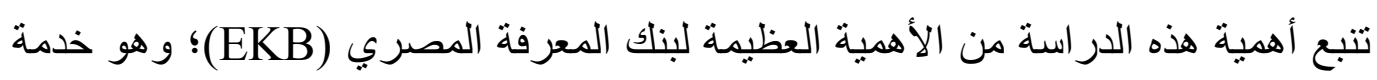
مجتمع مصري يتعلم ويفكر ويبتكر ، ويمكن بلورة هذه الأهمية من خلال النقاط التالية: أولاً: تعد دراسة استخدام بنك المعرفة المصري لدى معلمي المدارس الثانوية وطلابها في محافظة القاهرة موضو عًا بكرًا لم يسبق تناوله لهاه في البيئة العربية.

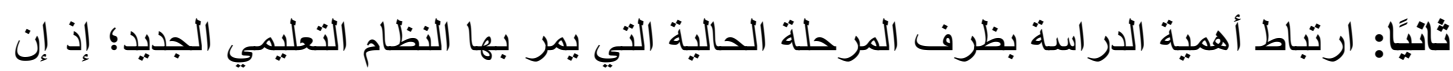
هناك علاقة وثثقة بين هذا النظام وبنك المعرفة المصري (EKB) في كونه محورًا أساسيًا

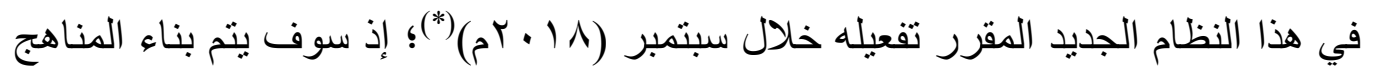
الجديدة و إتاحتها من خلاله، كما سيكون المرجع الرئيسي لطلاب الثانوية العامة بنظاميها

$$
\text { الجديد. }
$$

ثالثًا: تقديم صورة واضحة المعالم للاستخدام والتفاعل الفعلي لبنأك المعرفة من جانب المعلمين والطلاب داخل المدارس الثانوية في محافظة القاهرة. رابعًا: الإسهام في الكثف عن المعوقات التي تمنع المعلمين و الطلاب من استخدام بنك المعرفة

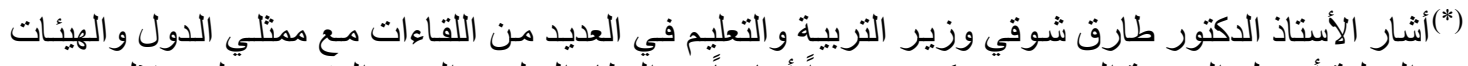

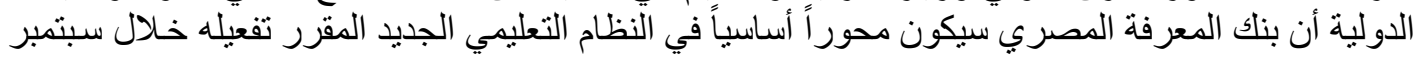


المصري (EKB)، و الصعوبات التي تواجهم أثناء استخدامهم للمصادر الإلكترونية بداخله. خامسًا: التغذية المرتدة التي يمكن الإفادة منها في التطوير المستقبلي لإعداد الدورات وكافة

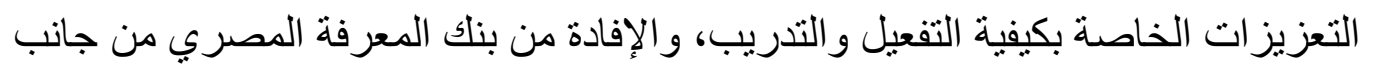

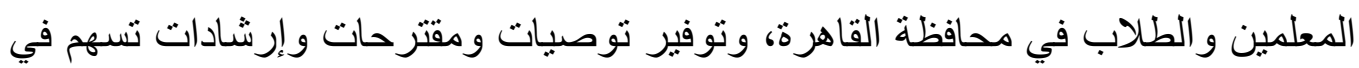

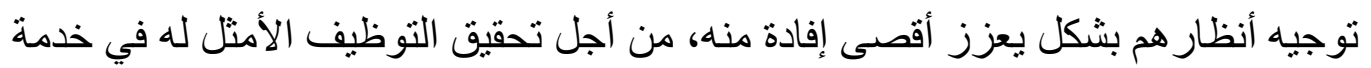

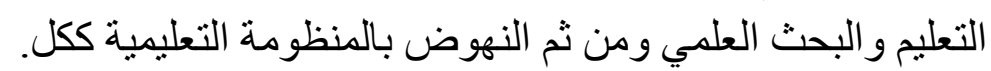
سادسًا: للباحثين المهتمين بإجر اء در اسات نوعية مماثلة على بنلك المعرفة المصري (EKB) داخل جمهورية مصر العربية.

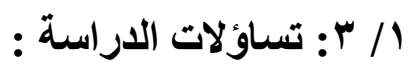
إذا كانت تكنولوجيا التعليم هي الاختيار الاستر اتيجي للنهوض بالعملية التعليمية في مصر ، وفي ظل وجود بنك المعرفة المصري؛ الذي يمثل أكبر مكتبة إلكترونية على مستوى العالم فهل

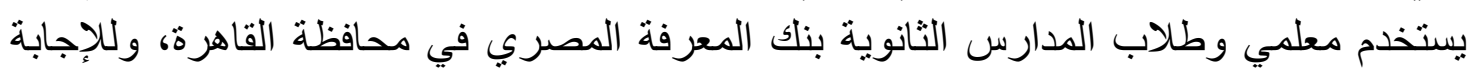
على هذا التساؤل الرئيسي سوف تحاول الدر اسة الإجابة على التساؤلات التالية: ا ـ ما و اقع استخدام المعلمين وطلاب المدارس الثانوية لبنك المعرفة المصري (EKB) في محافظة القاهرة؛

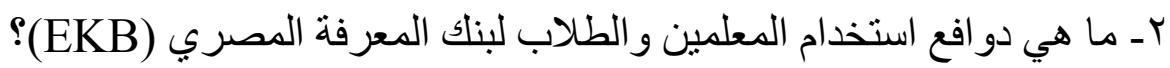

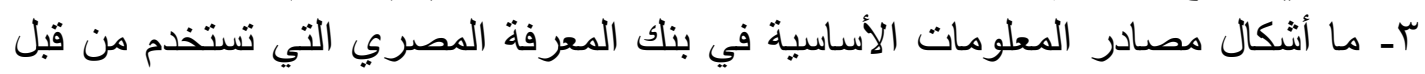

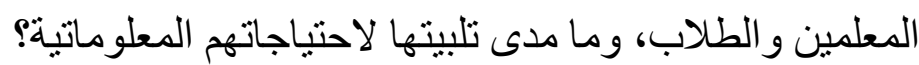

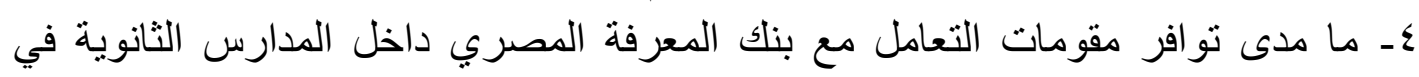

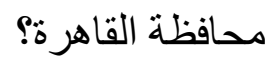
هـ هل هنالك دور تتهض به مكتبات المدارس الثانوية في محافظة القاهرة لتفعيل ولرفع

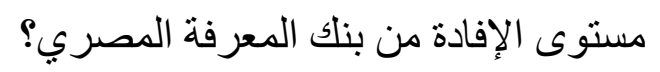

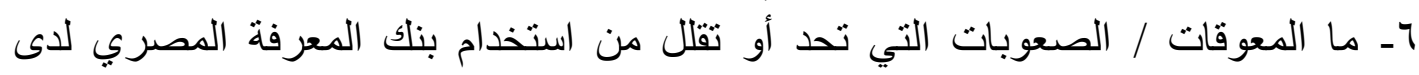

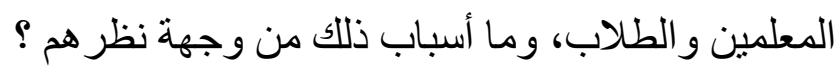
V- ما أهم مقترحات المعلمين و الطلاب لتطوير الإفادة من بنلك المعرفة المصرئ فمري.

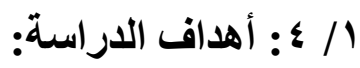
( ) رصد و اقع استخدام المعلمين وطلاب المدارس الثانوية لبنك المعرفة المصري (EKB) في محافظة القاهرة. 


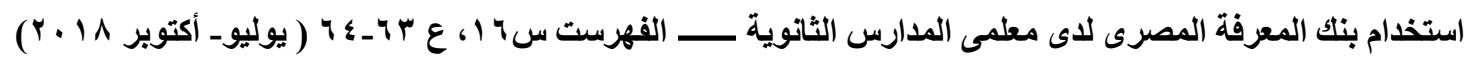

r) التعرف على دو افع استخدام المعلمين و الطلاب لبنك المعرفة المصري (EKB).

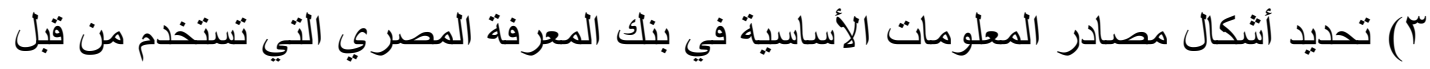
المعلمين و الطلاب ومدى تلبية هذه المصادر لاحتياجاتهم المعلوماتية و التعليمية و البحثية.

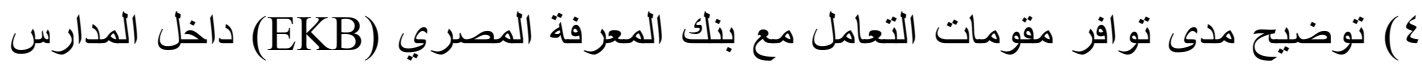
الثانوية في محافظة القاهرة. 0) إيراز الدور الذي تنهض به مكتبات المدارس الثانوية العامة والعاملون بها في محافظة

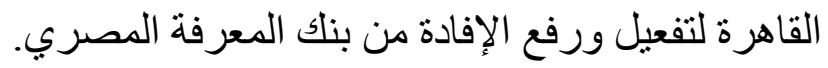
ج) كثف المعوقات التي تحول دون استخدام بنك المعرفة المصري من قبل المعلمين و الطلاب للتغلب عليها لتطوير وتعزيز أقصى إفادة منه.

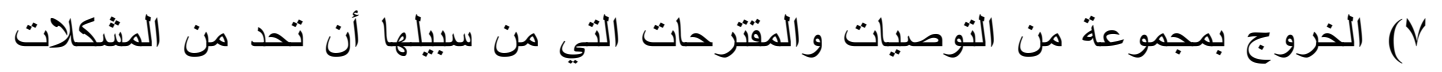

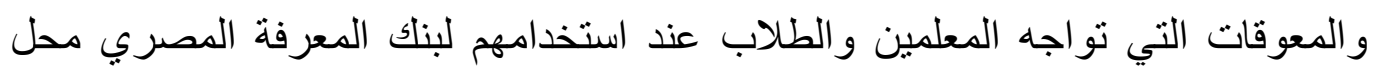
الدراسة.

/ / / م ه مصطحات الدراسة:

Electronic resources المصادر الإكترونية 1/0/1

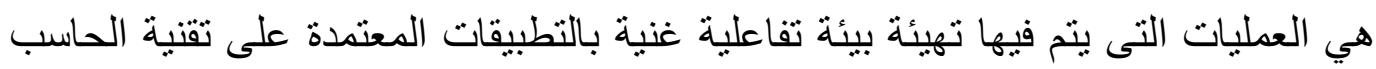
عبر الوسائط الإلكترونية؛ وهي إما متصلة مباثرة بالحاسب مثل الأقر اص المدمجة، أو عن بعد

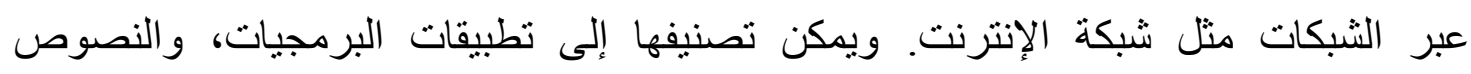

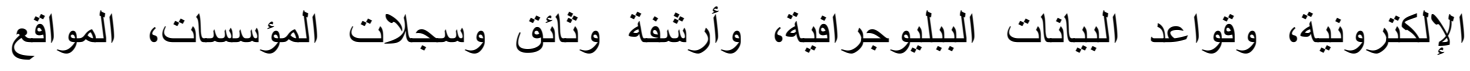
الإلكترونية، الكتب الإلكترونية، ومجموعة من الدوريات. وليس بالضرورة أن تثوفر المصادر

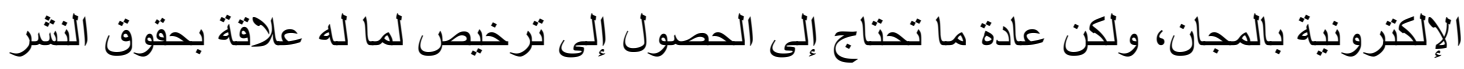

و الملكية. (ن)

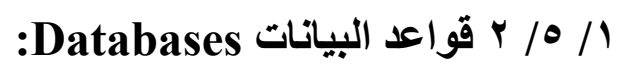

تحتوي على مجمو عة من التعليمات المنظمة التى تمثل قاعدة بيانات متكاملة لأداء عمل ماء و هي مجموعة بيانات من الحقائق مؤلفة من ملفات متر ابطة الثكل، وجزء من من البيانات أو كل

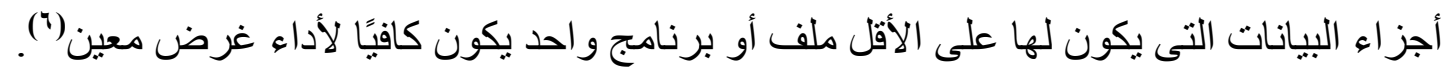

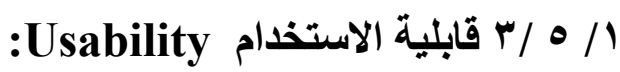

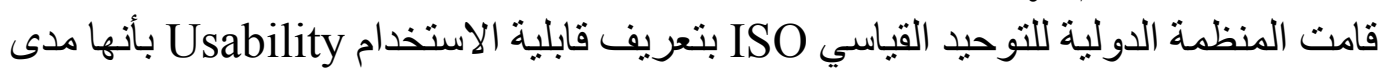

إمكانية استخدام منتج معين بواسطة مستخدمين محددين لإنجاز أهداف معينة بكفاءة وفعالية

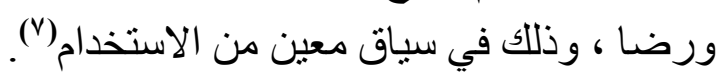

ويحدد هذا التعريف أركان قابلية الاستخدام في ثلاثة عناصر : الكفاءة و الفعالية و الرضا، كما 
يؤكد على ضرورة وضع الهدف من قاعدة البيانات، و المستخدمين منها، وسيأخذ الاستخدام محل الا عتبار.

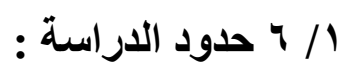

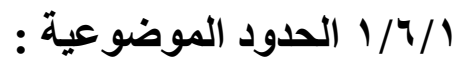

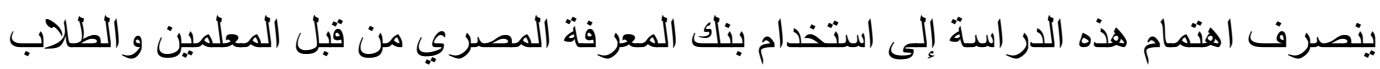

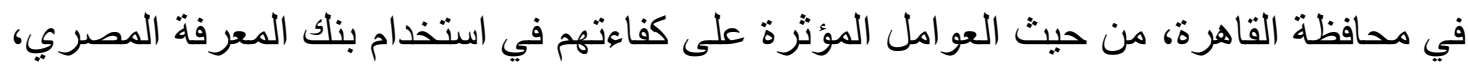
و الصعوبات و المشكلات التى تو اجههم ، فضلاً عن در اسة واقع الاستخدام في المدارس الثانوية فية عينة الدراسة . واستو

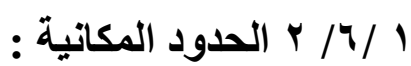

تتركز الدراسة في رصد وقع استخدام المعلمين والطلاب لبنك المعرفة المصري في

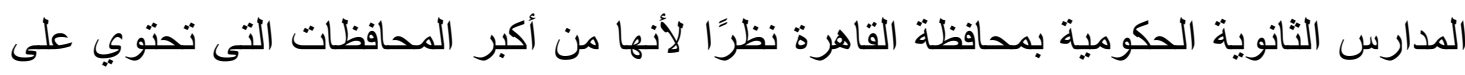

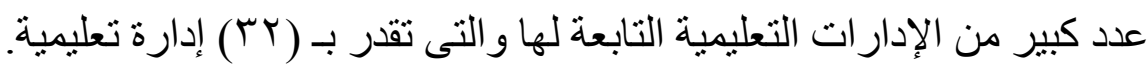

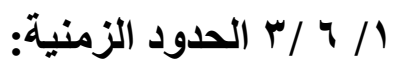

تم إجر اء وتطبيق هذه الدر اسة في الفصل الدراسي الثاني في الفترة من 10 فبرداير إلى 10

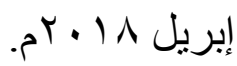

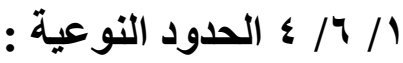

ينصب اهتمام هذه الدراسة على أحد أهم دعائم مصادر المعلومات "وهي مصادر

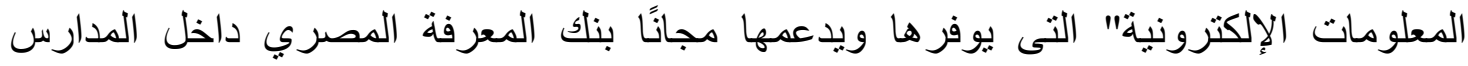
الثانوية .

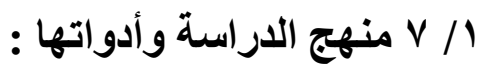
: 1/V/1

تعتمد هذه الدراسة ـ بحكم طبيعتها ولتحقيق أهدافها السابق ذكر ها ـ على المنهج المسحي

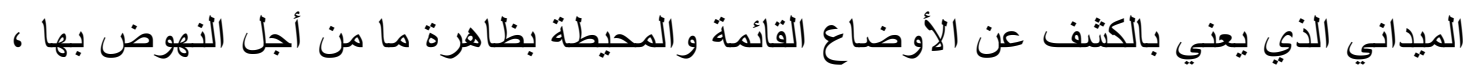

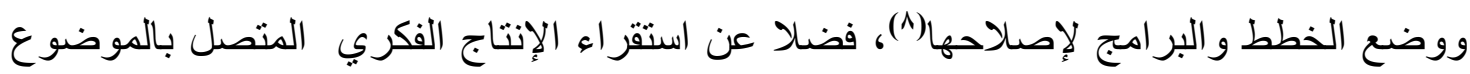

وتحليله(9). (19)

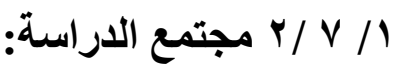

ينقسم مجتمع الدر اسة إلى فئتين و هما:

ا ـ المعلمون (ذكور / إناث) في المدارس الثانوية الحكو مية بمختلف تخصصاتهم الموضو عية

بداخل محافظة القاهرة. 


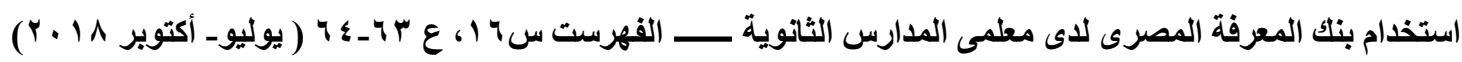

r ـ الطلبة (ذكور / إناث) في المدارس الثانوية الحكومية في محافظة القاهرة متمثلون في الفرقة

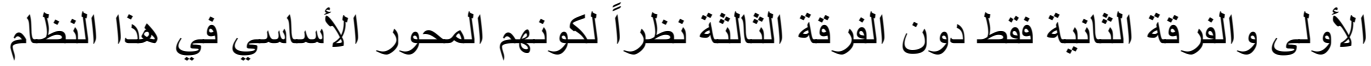

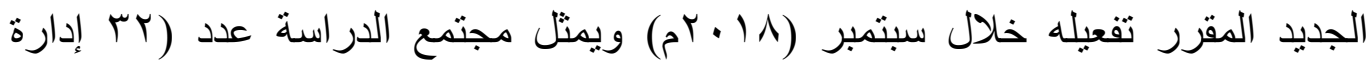
تعليمية)، ثم تخصيص هذه الإدارات التعليمية المختلفة في محافظة القاهرة ما بين (إدارة شمال، جنوب، شرق، وغرب)؛ وذلك لمحاولة تغطية الاستخدام و الإفادة في المحافظة. ويوضح الجدول رقم (1 ـ ( ) النالي مجتمع الدراسة من الطلاب و المعلمين و المدارس في

الإدارة المختلفة داخل محافظة القاهرة.

\section{جدول (1 ) مجتمع الدراسة}

\begin{tabular}{|c|c|c|c|c|c|}
\hline النطاق الجغرافي( القاهرة) & الإدارة & b & النطاتى الجغرافي( القاهرة) & الإدارة & b \\
\hline 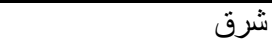 & القاهزة الجديدة & IV & شمال & روض الفرج & 1 \\
\hline غرب & وسط القاهرة & 11 & شمال & الساحل & $r$ \\
\hline غرب & عابنين & 19 & شمال & شُبرا & $r$ \\
\hline غرب & غرب القاهرة & $r$. & شمال & الثرابية & $\xi$ \\
\hline غرب & باب الثعرية & YI & شرق & المطرية & 0 \\
\hline غرب & غرب مدينة نصر & Tr & شرق & السلام & 7 \\
\hline جنوب & التنين & Tr & شرق & الو ايلي & V \\
\hline جنوب & السيدة زبنب & $r \varepsilon$ & 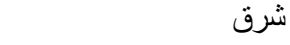 & الزيتون & $\Lambda$ \\
\hline جنوب & مصر القيمة & To & شرق & مصر الجيلية & 9 \\
\hline جنوب & البساتين ودار السلام & rq & شرق & شرق مدينة نصر & 1. \\
\hline جنوب & الخليفة والمقطم & TV & شرق & عين شمس & 11 \\
\hline جنوب & المعادي & rᄉ & شرق & المرج & IT \\
\hline جنوب & المعصرة & rq & شرق & حدائق القبة & 14 \\
\hline جنوب & منشية ناصر & r. & 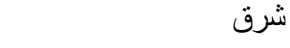 & الزاوية الحمراء & $1 \varepsilon$ \\
\hline جنوب & حلوان & T & شرق & النزهة & 10 \\
\hline جنوب & المستقبل & Tr & شرق & الثروق & 17 \\
\hline
\end{tabular}

| 1/1 / عينة الار اسلة: تنقسم عينة الدر اسة إلى فئتين:

نظرًا لكثرة وتفرق أفر اد مجتمع الدراسة على ذلك النحو (ب إدارة إدة تعليمية في محافظة القاهرة ) - بما لا يمكن معه إخضاعهم لتلك الدراسة، لجأت الباحثة إلى أسلوب العينة العمدية 
(المقصودة) Purposive Sample بالنسبة للمدارس التي تمثل مجتمع الدراسة بحيث تم اختيار

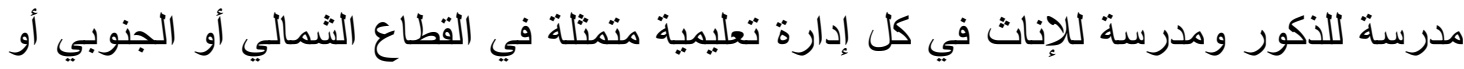

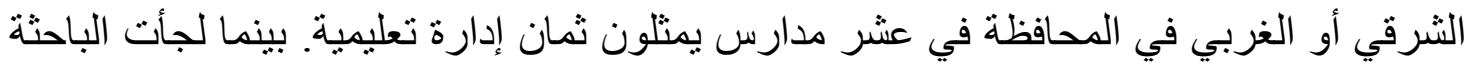

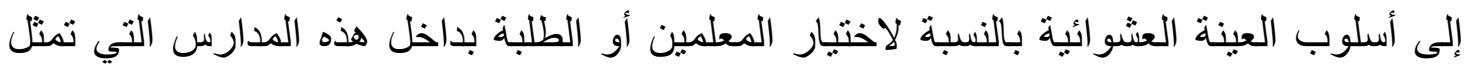
الإدارات التعليمية المختلفة في المحافظة. وبناءً على ذلك قامت الباحثة بتحديد حجم العينة في الإدارات المختلفة وحصر أعداد المعلمين و الطلاب محل الدر استة.

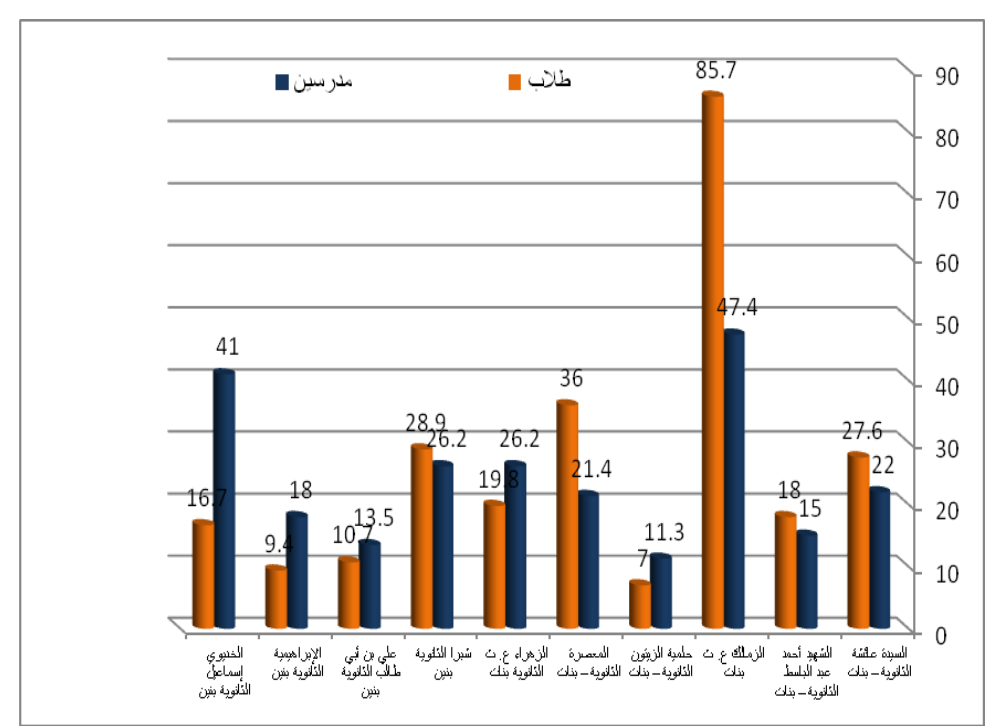

شكل (1) رسم بيانى يوضح العينة الكلية للاراسة 


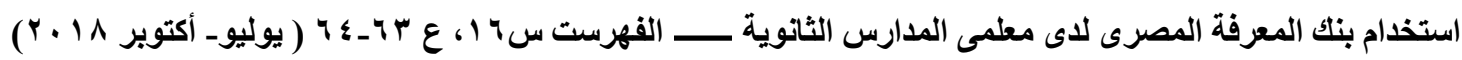

جدول (r) العينة الكلية للار اسة

\begin{tabular}{|c|c|c|c|c|c|c|c|c|c|c|c|c|c|}
\hline \multicolumn{3}{|c|}{ المعلمون } & \multicolumn{3}{|c|}{ المجموع } & \multicolumn{3}{|c|}{ الفرقة الثانية } & \multicolumn{3}{|c|}{ الفرقة الأولى } & \multirow{2}{*}{ الإدارة / الدر اسينة } & \multirow[t]{2}{*}{ ? } \\
\hline$\%$ & $\varepsilon$ & ع. & $\%$ & $\varepsilon$ & ع. ع & $\%$ & $\varepsilon$ & ع. & $\%$ & $\varepsilon$ & ع. & & \\
\hline \multicolumn{14}{|c|}{ إدارة روض الفرج - شمال القاهرة } \\
\hline & 17 & 01 & TY & 7. & TVT & r4 & $r$. & $11 \mathrm{~V}$ & $\begin{array}{l}19 \\
r .\end{array}$ & $r \cdot$ & 107 & الثانوية - عائشة & 1 \\
\hline & $\overline{Y r}$ & TYY & 10 & $\overline{1 \cdot r}$ & $7 \wedge \varepsilon$ & $\overline{Y Y}$ & 77 & $\Gamma \cdot \varepsilon$ & 9 & $\overline{4}$ & rA. & 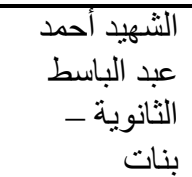 & r \\
\hline & TY & $\sqrt{17}$ & YY.Y & $1 \pi \xi$ & 01. & rA & 77 & TrA & To & 71 & TVY & شبين ا الثانوية & $\Gamma$ \\
\hline \multicolumn{14}{|c|}{ إدارة المعصرة جنوب القاهرة } \\
\hline & 11 & 0. & Y.. & $1 \cdot \varepsilon$ & $\varepsilon \wedge 0$ & 19 & $\varepsilon V$ & Tol & $\begin{array}{l}\text { rE } \\
r .\end{array}$ & OV & TTE & الثناتوية - & $\varepsilon$ \\
\hline \multicolumn{14}{|c|}{ إدارة جلوان جنوب القاهرة } \\
\hline & r) & 1.7 & Y૫.Y & 1.9 & हा। & $r$ & $\varepsilon \varepsilon$ & 119 & rq & 70 & TYY & بنات الثانوية ع. & 0 \\
\hline \multicolumn{14}{|c|}{ إدارة السيدة زينب جنوب القاهرة } \\
\hline & 17 & 97 & \&1 & ITr & $r \ldots$ & $\varepsilon \wedge$ & 71 & $1 \leqslant Y$ & ro & 00 & 101 & الخاعماعيل & 7 \\
\hline \multicolumn{14}{|c|}{ إدارة عين شمس - شرق القاهرة } \\
\hline & IV & $r \leqslant r$ & $11 . r$ & Tro & 11. & $\pi$ & 77 & Orr & $\begin{array}{l}1 . \\
r .\end{array}$ & 09 & ov1 & 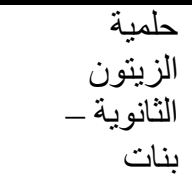 & v \\
\hline \multicolumn{14}{|c|}{ إدارة المرج شرق القاهرة } \\
\hline & 11 & $1 \cdot r$ & 15.0 & $T V Y$ & $\begin{array}{r}T r V \\
r\end{array}$ & $1 \leqslant$ & $\lambda r$ & 077 & 14 & 9. & $V \cdot V$ & طبنين الثانوية & $\Lambda$ \\
\hline \multicolumn{14}{|c|}{ إدارة غرب القاهرة } \\
\hline & $r \varepsilon$ & $r \wedge$ & $\varepsilon V . \varepsilon$ & $\overline{T \varepsilon}$ & $1 \% 0$ & 79 & $r \wedge$ & 00 & $\begin{array}{l}\text { Tr } \\
0 .\end{array}$ & $r q$ & $\Lambda$. & الز بنات عالك ع. & 9 \\
\hline \multicolumn{14}{|c|}{ إدارة عابدين غرب القاهرة } \\
\hline & IV & $1 \wedge$. & 11 & $1 \pi 0$ & V7. & TV & vo & rA. & $\begin{array}{l}\text { Tr } \\
0 .\end{array}$ & 7. & $\varepsilon \wedge$. & الثاإبر اهيمية بنين & 1. \\
\hline
\end{tabular}


تم إضافة (r) مدرسة للبنات لتساوي وتكافئ الأعداد بالنسبة للطلبة الذكور . 1 / م أدوات جمع البيانات:

مثل الاستبيان أداة جمع المادة العلمية الرئيسية من مجتمع الدراسة من المعلمين، و الطلبة، وسانده المقابلة الثخصية و الملاحظة المباشرة - وقد تم بناء الاستبيان في صورته المبدئية وتكون من (Y ) سؤ الاً موز عة على محورين رئيسين:

المحور الأول: البيانات الأساسية والتي تتضمن البيانات الثخصية و المهنية. المحور الثاني: رصد واقع الاستخدام والإفادة من بنك المعرفة المصري (EKB) وقد أعقب بناء الاستبيان عرضه على مجموعة من الأساتذة المتخصصين لجمع الآراء وطرحه في في لإني صياغتها النهائية "انظر الجدول رقم (ب). جدول (r) قائمة أسماء المحكمين

\begin{tabular}{|c|c|}
\hline التخصــــ & الاســــــم \\
\hline قسم المكتبات - كلية الآداب - جامعة القاهرة & أ.د.د. أسامة السيد \\
\hline قسم المكتباتـ كلية الآداب - جامعة عين شمس & أ.د. ثناء إبر اهيم موسى فرحات \\
\hline قسم المكتباتـ كلية الآداب - جامعة عين شمس & أ.د. رؤوف عبد الحفيظ هلال \\
\hline قسم المكتبات ـ كلية الآداب - جامعة عين شمس & أ.د. علي شاكر \\
\hline قسم علم النفس - كلية الآداب - جامعة عين شمس & أ.ـد. أحمد خيري حافظ \\
\hline قسم علم الاجتماع - كلية الآداب - جامعة عين شمس & أ.د. عبد الوهاب جوده \\
\hline
\end{tabular}

وقامت الباحثة بتوزيع هذه الاستبيانات بنفسها على المعلمين والطلبة في المدارس عينة الدر اسة، وقد تم تفريع وترميز وتكويد البيانات الواردة في الاستبيان ووضعها في جداول للوصول

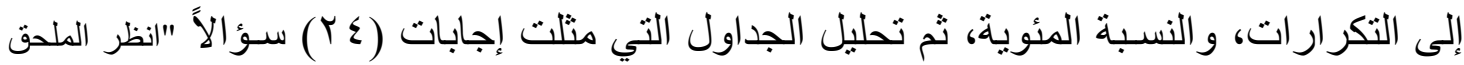

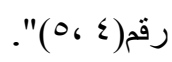
1/1/1 إجراءات وأساليب التحليل الإحصائي:

تم تفريغ البيانات عن طريق البرنامج الإحصائي المعروف برنامج الحزم الإحصائية للعلوم الاجتماعية Statistical Package For Social Sciences، وتم التحليل الإحصائي باستخدام الحاسب الآلي من خلال برنامج الحزم الإحصائية . .SPSS V. Y، وتعد هذه الخطوة - تفريغ

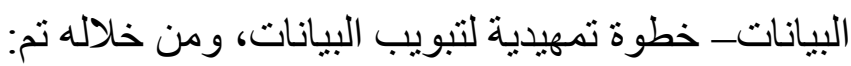

\section{الاختبار ات الإحصائية المستخدمة :}

اختبار ألفاكرونباخِ Cronbach's alpha لقياس ثبات وصدق محتوى استبيان الدراسة؛ حيث يوضح مدى إمكانية الاعتمادية على نتائج قائمة الاستبيان، ومدى إمكانية تعميم نتائجها على مجتمع الدر اسة؛ حيث إن معامل الفا يقع بين ( •، ( ) فإذا كانت قيمة معامل ألفا أكبر من لإنه 


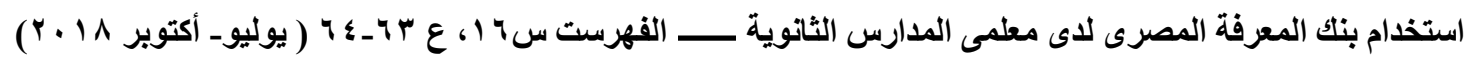

$$
\begin{aligned}
& \text { أ وتساوى 7. · أمكن الاعتماد على عينة البحث وتعميم نتائجها على مجتمع الدر اسة. } \\
& \text { ـ التكرارات و النسب المئوية لمعرفة خصائص الاعص عينة الدر اسة. }
\end{aligned}
$$

ه المتوسط و الانحر اف المعياري باستخدام اختبار T test لمعرفة اتجاه آر اء عينة الدر اسة.

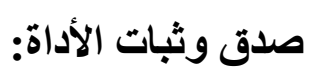

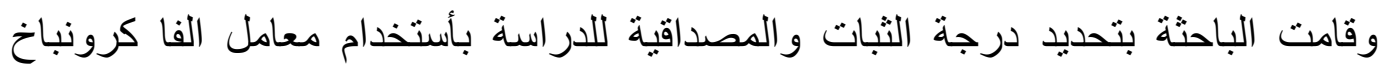

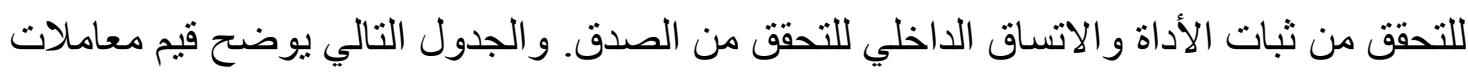

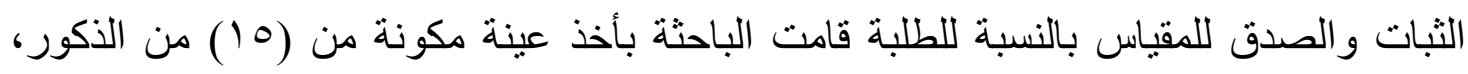

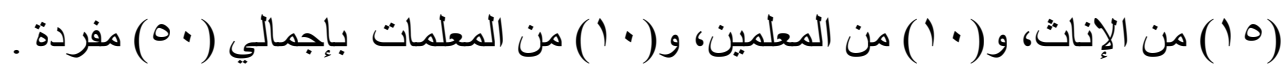
جدول (ع ) معامل الثبات و الصدق الصن

\begin{tabular}{|c|c|c|}
\hline المقياس & \multicolumn{1}{|c|}{} \\
\hline
\end{tabular}

المصدر : من مخرجات البرنامج

( 9 / المراجعة العلمية:

يحفل الإنتاج الفكري العربي والأجنبي بالدر اسات حول الاستخدام والإفادة من المصادر الإلكترونية للمعلومات سواء المتاحة على الاسطوانات الضوئية المكتنزة أو المتاحة من خلادل

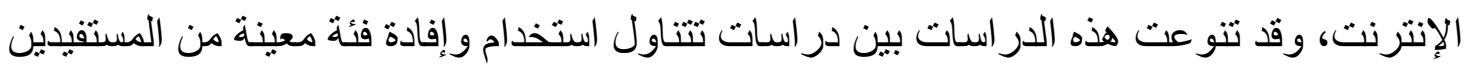

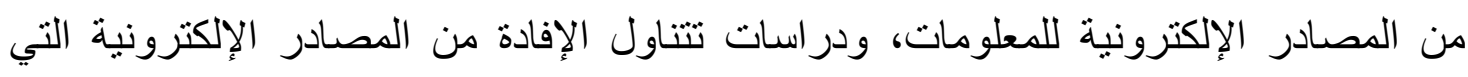
تنتجها مكتبات بعينها. وسوف نستعرض هذه الدر اسات من الأقدم للأحدث حتى يتسنى لنا رصد الأند

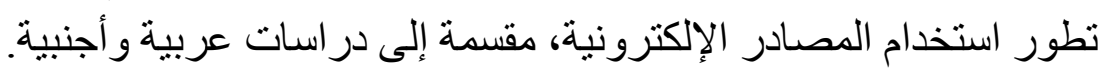

أولاً: الاراسات العربية:

لعل من أهم ما قدم من دراسات عربية للإفادة من مصادر المعلومات. د دراسة (نوال عبد

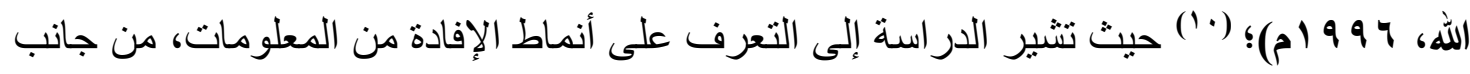

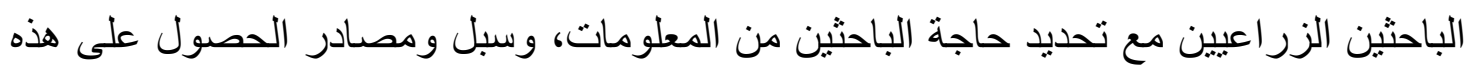

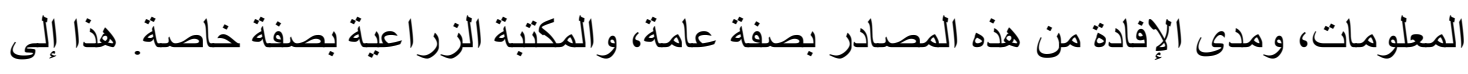

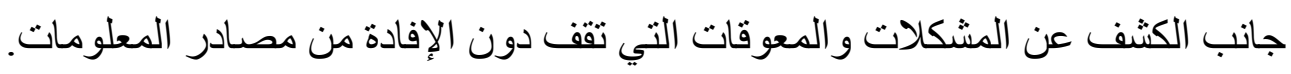
و هدفت در اسة (أمل كرم خليفه، ا . . بم)(' "). إلى معرفة مدى الاستفادة من المو اد السمعية

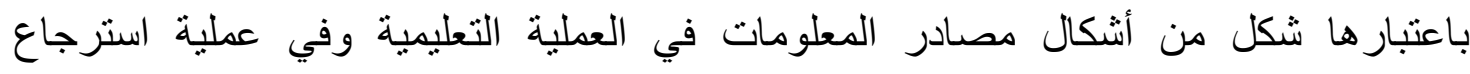

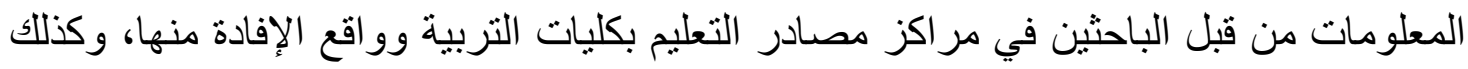
الإسهام في تحسين الخدمات التي من شأنها إنتاج وعرض مصني مصنادر المعلومات التي لها علاقة 
بالمنهج الدر اسي الجامعي. وقد اعتمدت في هذه الدراسة على المنهج الوصفي التحليلي. وتركزت در اسة (الخليفي، r . . rم)(r') حول الإفادة من الخدمات الإلكترونية التي تقدمها

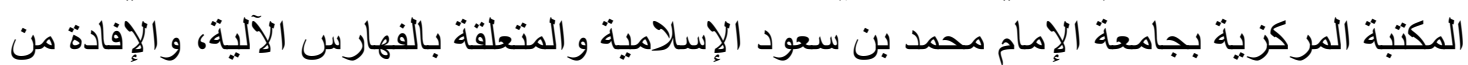

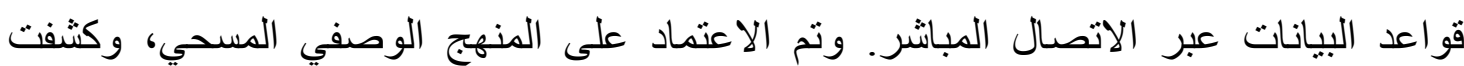

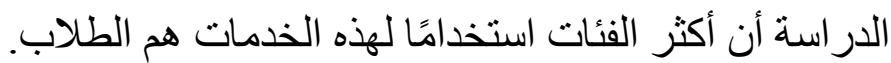

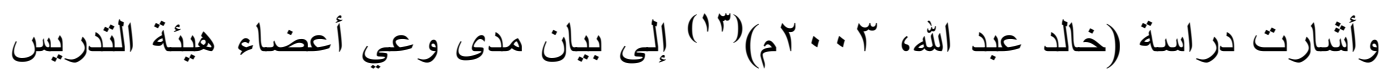

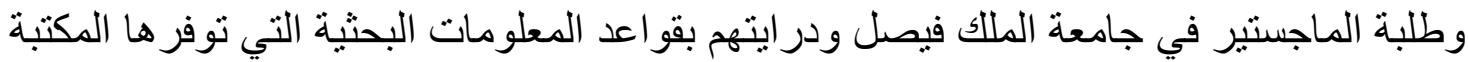
المركزية، وتفهم مدى استخدامهم واستفادتهم من هذه القو اعد، ومدى مشاركة عينة البحث في في

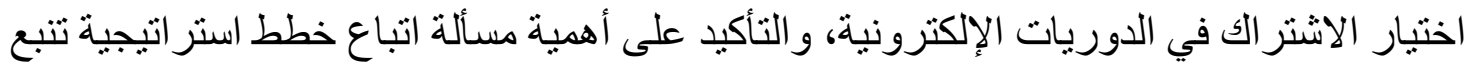
من در اسة احتياجات المستفيد من البحثية في عملية اختيار الاشتر الك في قو اعد البيانات، وتقييم استراتيجية المكتبة فيما يخص برامج التدريب، ونسويق خدمة البحث في قواعد المعلومات،

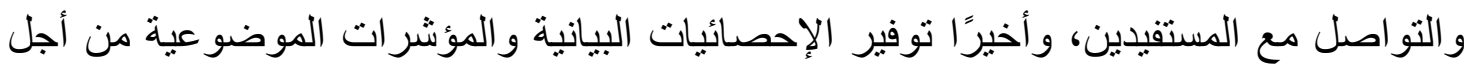
صياغة استر اتيجية مستقبلية للمكتبة المركزية في جامعة الملك فيصل.

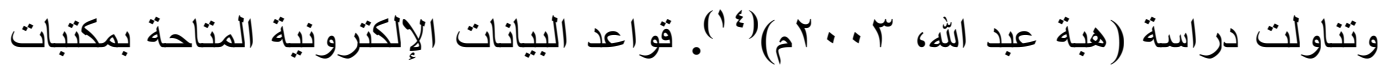

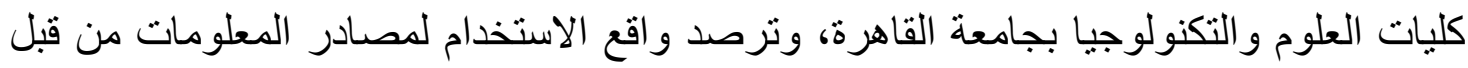

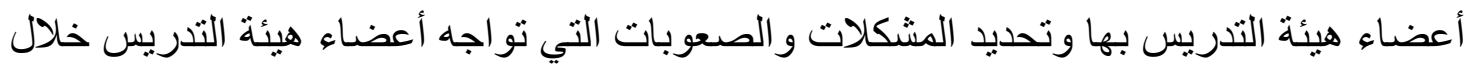
استخدامهم لمصادر المعلومات الإلكترونية وتحديد وبيان أهم العوامل المؤثرة على كفاءة

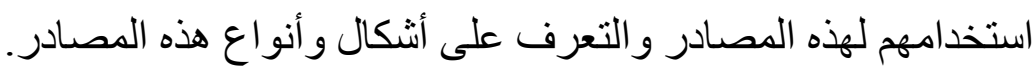

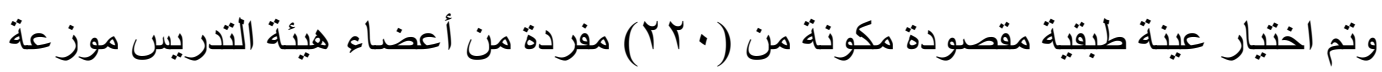

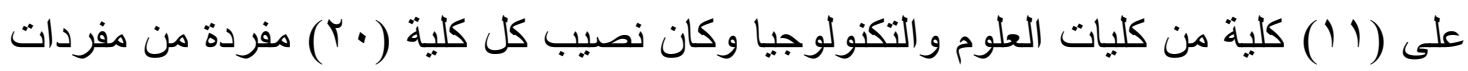
العينة.

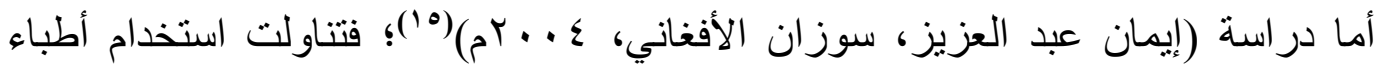

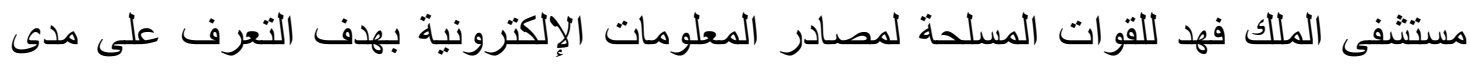

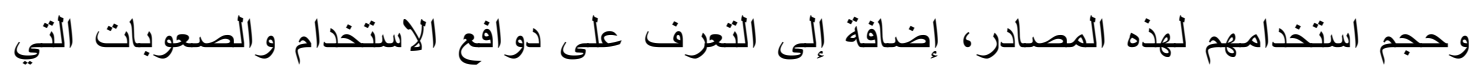
تو اجه الأطباء في الإفادة من هذه المصادر.

وتسعى دراسة (فلاح دحام، ه . . rم)("') إلى تحديد استخدام الفئات التدريسية وطلبة الدر اسات العليا بالجامعة المستتصرية لثبكة الانترنت، و التعرف فلى على مدى الاستفادة منها و معدل الاستخدام، وتحديد طر ائقه ومحركات البحث المستخدمة وأهم المصادر التي تم الحصول عليها

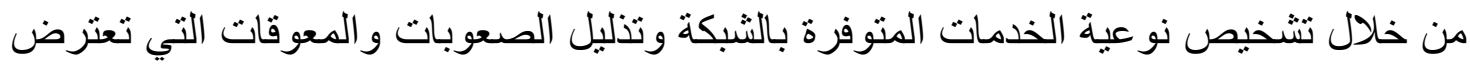

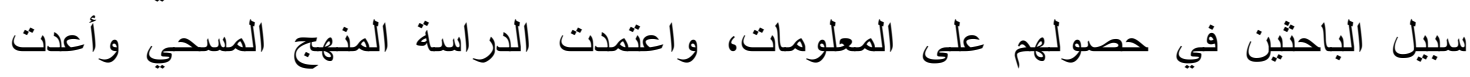




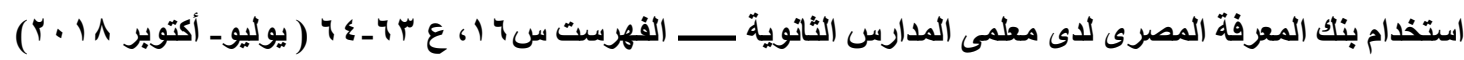

استمار ات استبانة وز عت على عينة حجمها (Y (Y) مستفيدًا باحثًا.

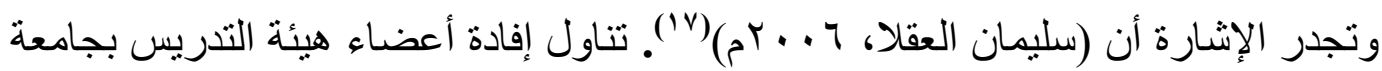
الملك سعود من مصادر المعلومات الإلكترونية التي توفر ها مكتبات الجامعة، ونم استخدام المنهج الوصفي التحليلي، وكانت أبرز معوقات الإفادة من هذه المصادر هو تغير اسم المستفيد ورقم الدخول السري باستمر ار و غز ارة المعلومات المسترجعة.

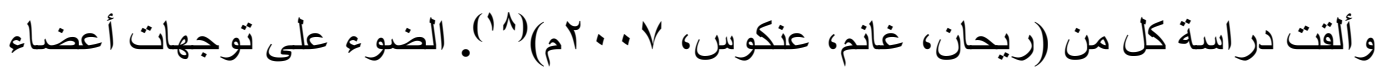
هيئة التدريس لكلية العلوم الإنسانية و الاجتماعية بجامعة مشوري قسنطينة بالجز ائر نحو استخدام

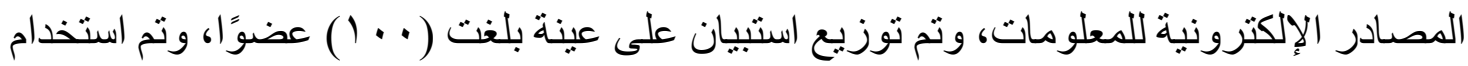

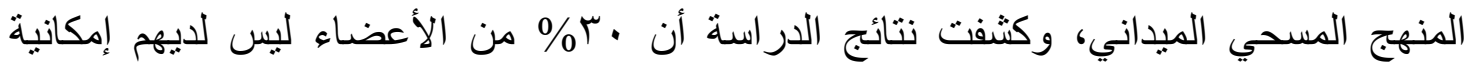
استعمال جهاز الحاسب، (0\%\%) يعتمدو ا على المصادر الإلكترونية مقارنة بالورقية.

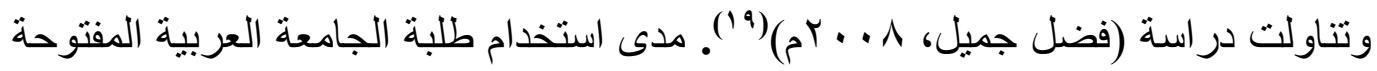

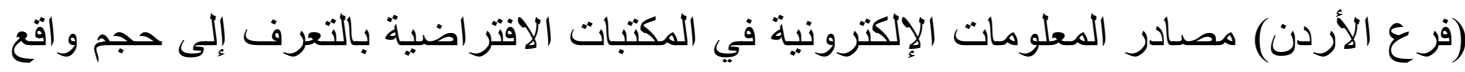

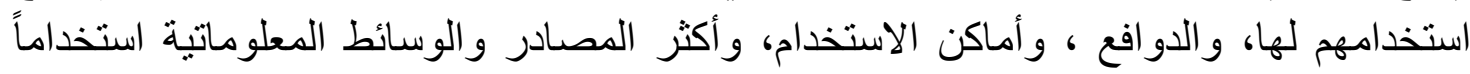

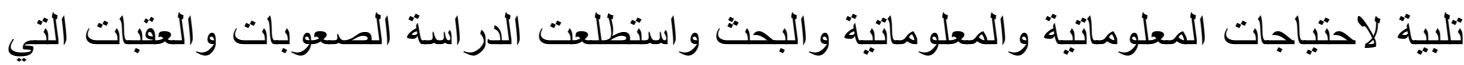

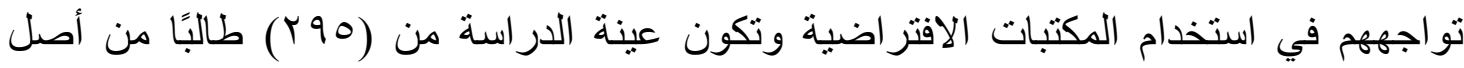

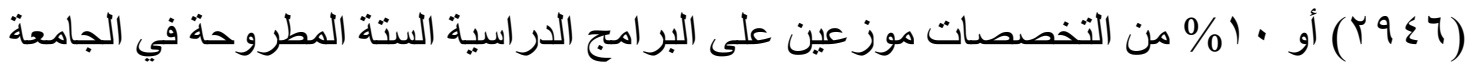

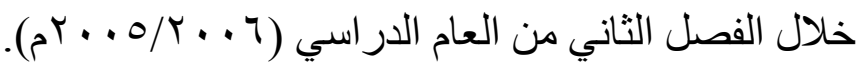

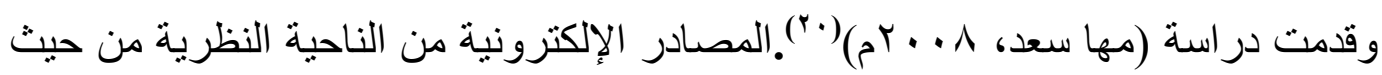
تعريفها، و أنو اعها و أجهزة التشغيل الخاصة بها، وكذللك التعرف على أنماط إفادة الباحثين من تللك المصادر ، وقد استخدمت الباحثة المنهج الوصفي التحليلي.

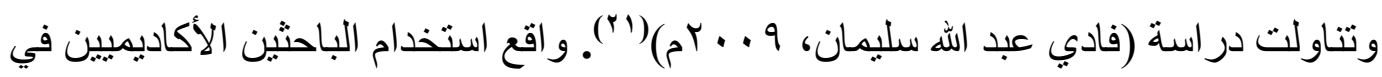

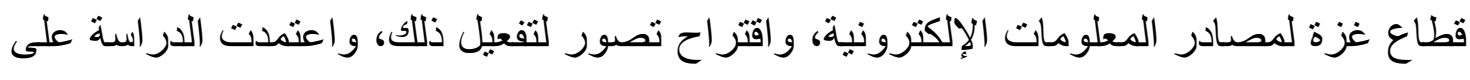

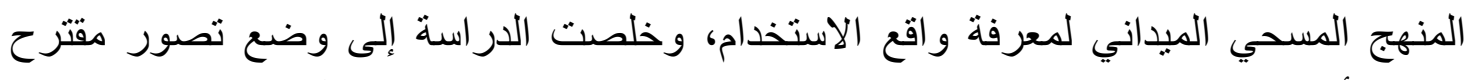

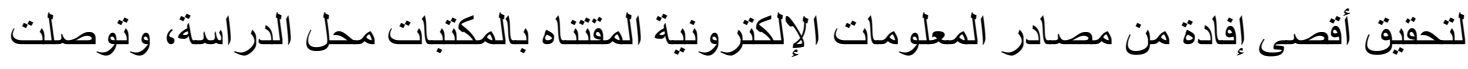
إلى أن درجة إفادة المصادر الإلكترونية في المكتبات بالنسبة للمستفيدين كانت جيدة بدرجة كبيرة.

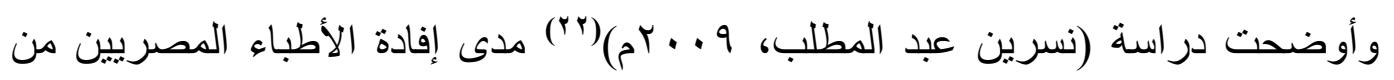
المعلومات المتاحة على شبكة الإنترنت، وتحديد سلوكه كباحثين عن المعلومات الصحية المتاحة

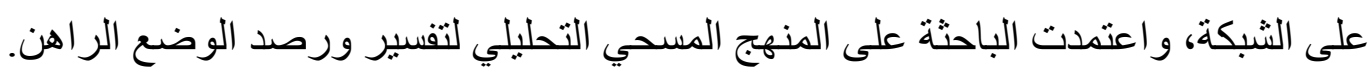

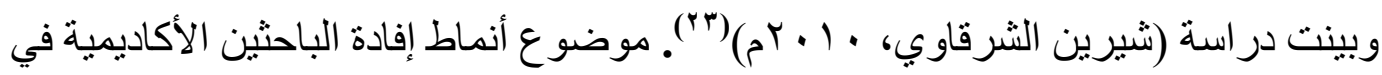

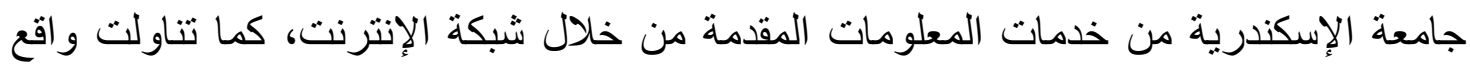


الاستخدام من قبل الباحثين وما هي معلومات هذا الاستخدام، واعتمدت الباحثة في در استها على المنهج التحليلي.

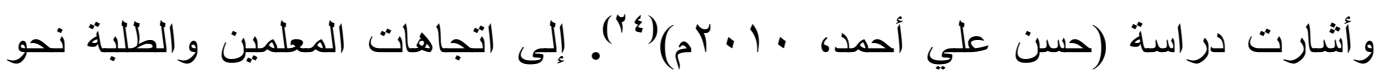

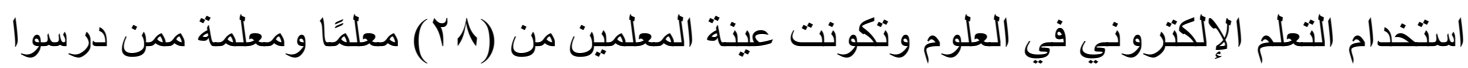

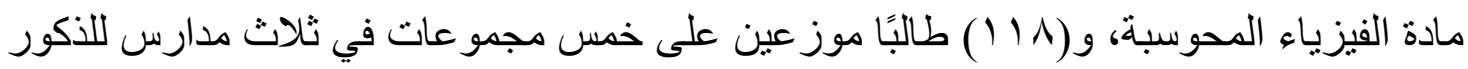
في محافظة الكرك.

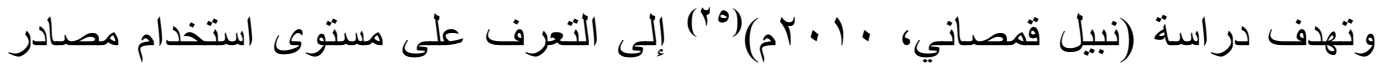

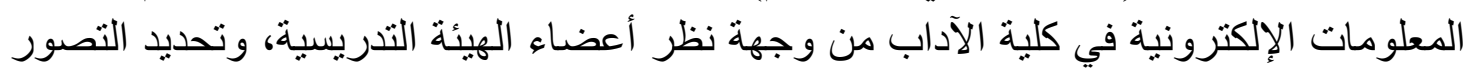
في استخدام مصادر المعلومات الإلكترونية، وتم استخدام المنهج الوثائقي المسحي لجمع البيانات

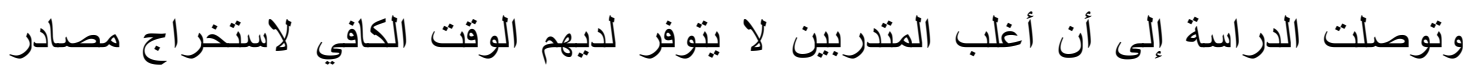

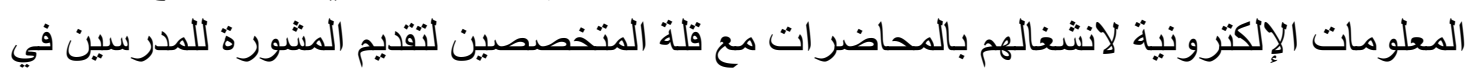
حالة تعذر الوصول لأي معلومة.

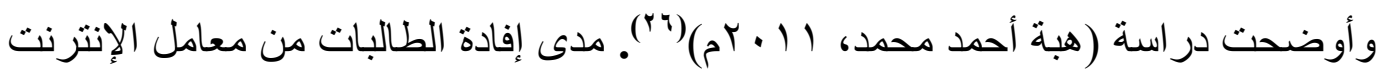
في المدارس الثانوية للبنات في محافظة الغربية و اعتمدت الدراسة على المنهج المدان المسحي الميداني.

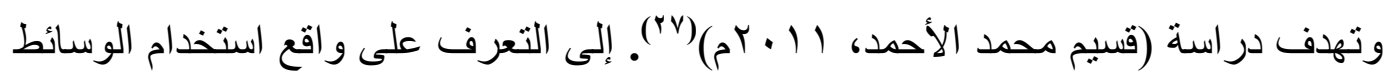

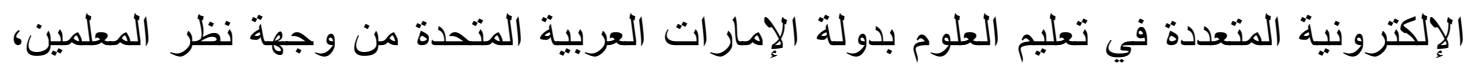

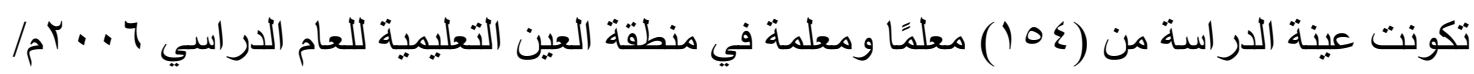

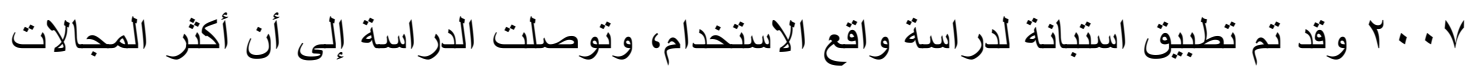

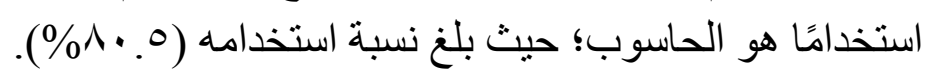

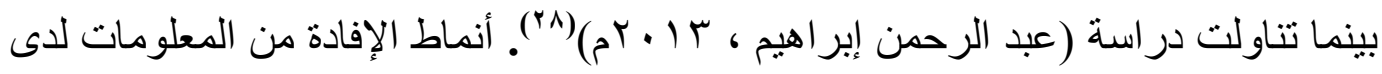
المعلمين في محافظة الإسكندرية وما هي المؤسسات التي تؤهل المعلمين، وكيفية إعدادهم

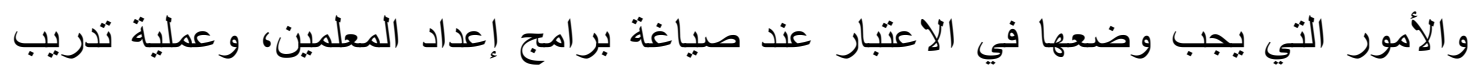

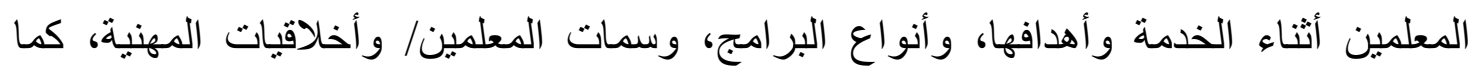
تناولت الدراسة مدى إفادة المعلمين من مرافق المعلومات من خلال خدمات المعلومات التهات التي تقدمها المر افق، ومدى كفاية عدد الساعات لتقديم خدمات المعلومات من المعلمين، ومدى الإفادة

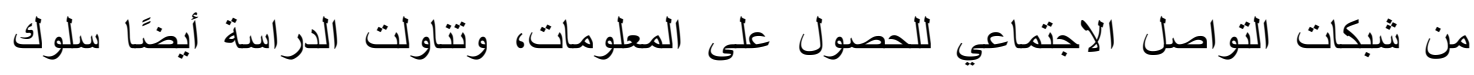

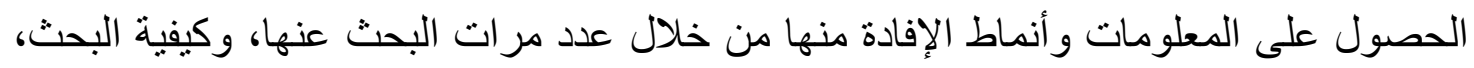

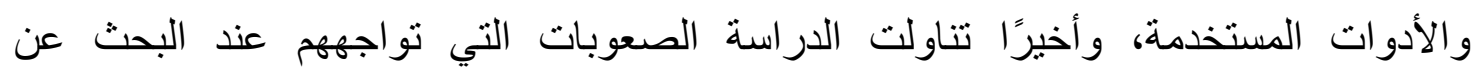
المعلومات ومقترحاتهم للتغلب عليها ثم خاتمة ضمت أهم النتائج التي تم التوصل إليها خلال تلات الدر اسة. 


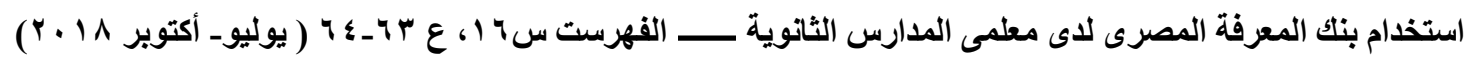

ويتبين من در اسة (منى هادي، ـ ( • Yم)(Y9). معرفة أهمية مصادر المعلومات الإلكترونية

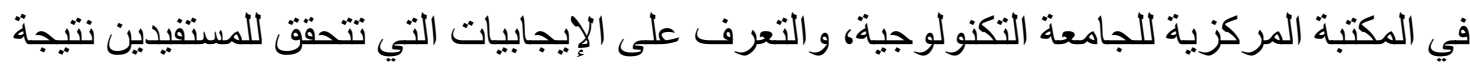

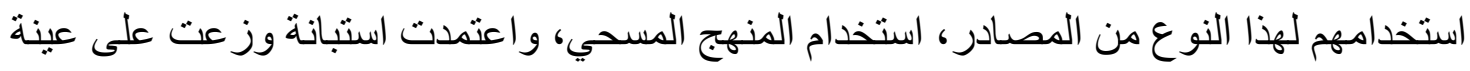
عثو ائية من المستفيدين بلغ عددهم ( • (0) مستفيدًا.

ثاتيًا: الدراسات الأجنبية:

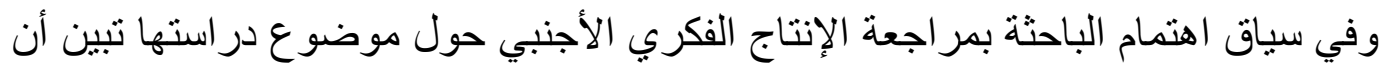

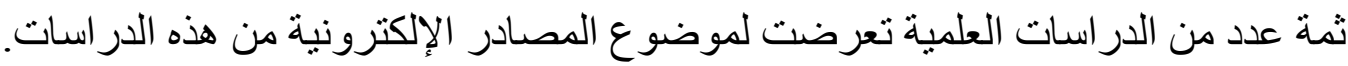
وتشير در اسة جوديث أز آدمز وشارون س. بونك (·r) . Judith a. adams \& Sharon

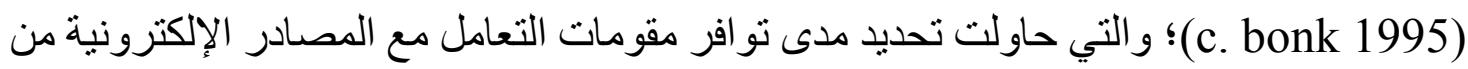

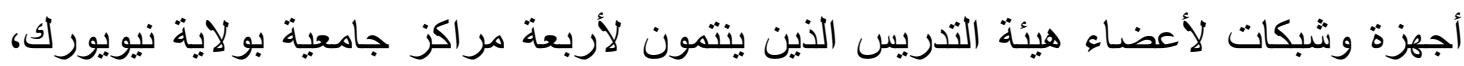

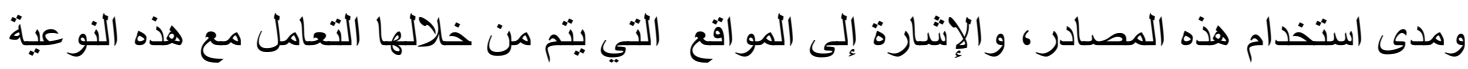

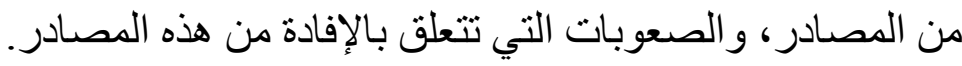

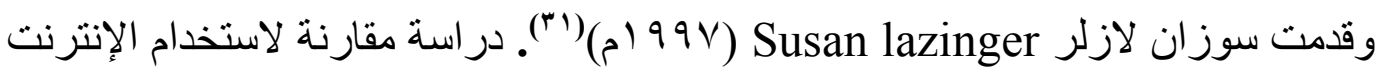
بين قطاعات مختلفة من أعضاء هيئة التدريس في الجامعة العبرية في القدس بهدف التحقق من

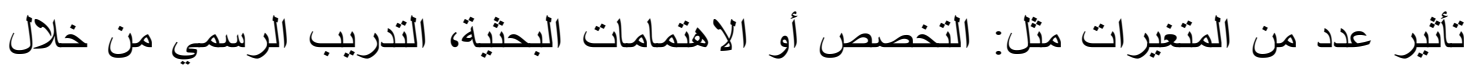
الدور ات التدريبية وورش العمل، التعلم الذاتي من خلال الأدلة والكتب التعريفية، الاستخدام العام للحاسبات، مدى الحاجة إلى المعلومات التي توفر ها الإنترنت وقد تم إرسال استبيان لعدد (1) (9)

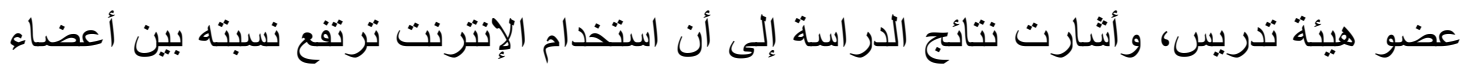
هيئة التدريس في العلوم والزراعة أكثر من أعضاء هيئة التدريس في الإنسانيات و العلوم الاجتماعية.

كما أجريت الر ابطة الكندية لمكتبات الكليات و المكتبات الفنية ( Canadian University (and College Libraries, 1997 إلى أن 0^\% من المكتبات الكندية تقدم خدمات الإنترنت للطلاب و أعضاء هيئة التدريس إلا أنها

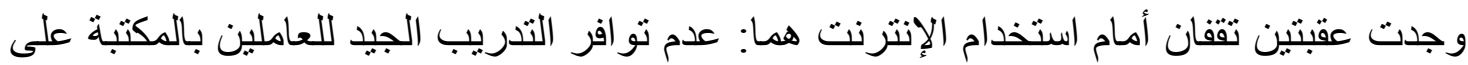
طر ائق البحث الإلكتروني، و عدم تو افر الإمكانيات المادية لتلبية احتياجات المستخدمين للمكتبة من

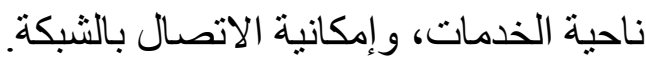
اهتمت بعض الدراسات أيضًا بمدى استخدام موارد المعلومات الإلكترونية على اختلاف صيغها من طرف الباحثين من أعضاء هيئة التدريس و الطلبة.

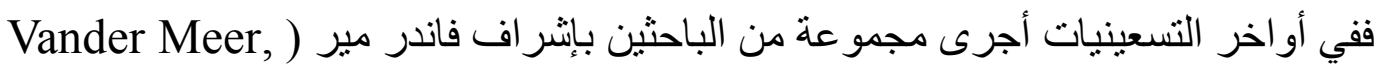

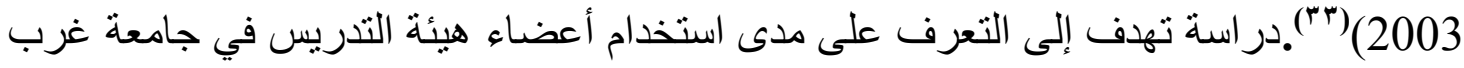


ميشيخان لمصادر المعلومات الإلكترونية، وقد شملت هذه الدر اسة (ع اب ) عضو هيئة تدريس في

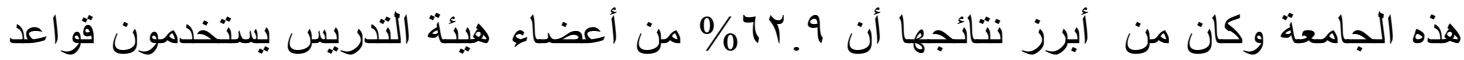

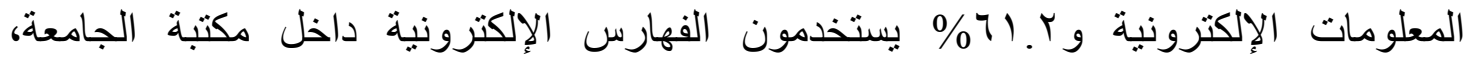

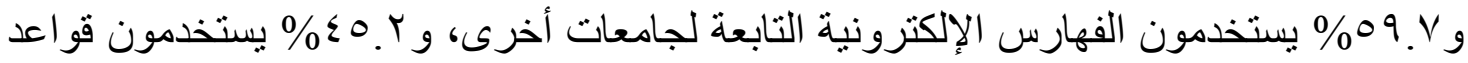

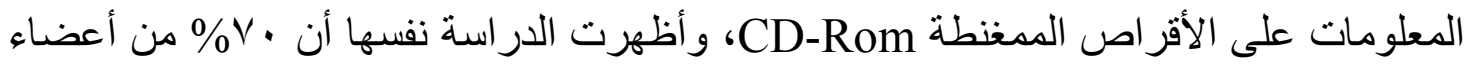

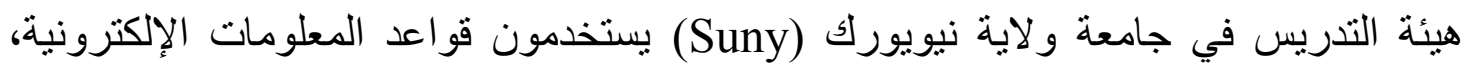
و • 9 \% يستخدمون فهارس المكتبة الإلكترونية.

و على مستوى استخدام أعضاء هيئة التدريس لقو اعد المعلومات المتخصصة أظهرت نتائج

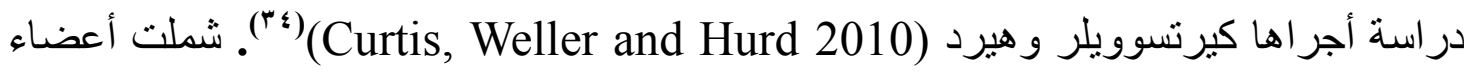

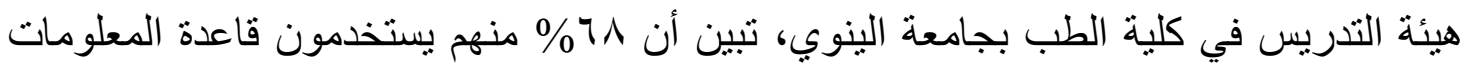

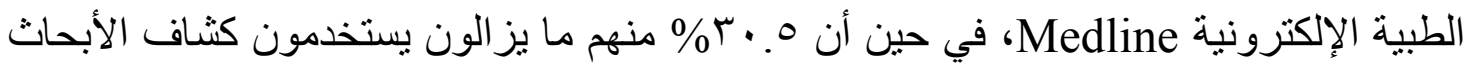
الطبية المطبوع Index Medicus، و أفاد أعضاء هيئة التدريس الذين شملهم البحث أنهم يفضلون استخدام قو اعد المعلومات الإكترونية من مكاتبهم أكثر من الذهاب إلى المكتبة. أما فيما يخص الدراسات التي أجريت للتعرف على مدى استخدام الطلاب في الجامعات لقو اعد المعلومات فتذكر الدراسة التي أعدها بر اد ماكدونالد وروبرت دانكلبرغر ( Brad Mac (Donald and Robert Dunkelberger, 2012 الدراسة (Y Y ) ) طالبًا، وخلصت إلى أن تنامى عدد القو اعد التي توفر النص الكامل للمستفيدين ضمن مجمل قو اعد البيانات التي تشترك فيها الجامعة_، بالإضافة على إمكانية استخدام محركات

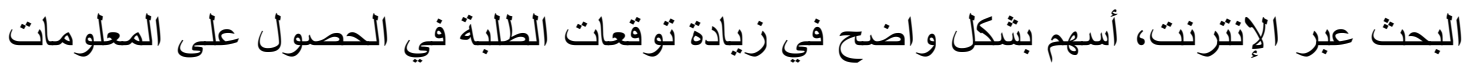
المفيدة لأبحاثهم، كما أن وجود النص الكامل لمقالات الدوريات الإلكثرونية أدى وظيفة مهمة في تشكيل طبيعة أبحاثهم وقد أكدت هذه الدراسة ما استتنجه الباحثان من خلال معاينتهما الميدانية لقسم الخدمة المرجعية؛ إذ تبين لهما إن استخدام قواعد المعلومات طغى على استخدام الطلبة لمصادر المعلومات التقليدية. وفيما يخص المفاضلة بين استخدام مقالات الدوريات المطبو عة وتللك الإلكترونية، أجرت

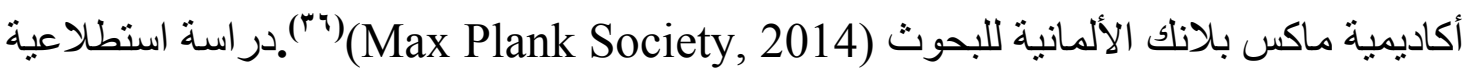
رصدت فيها رأي ( للمجلات الإلكترونية من قبل الباحثين الذين شملتهم الدراسة، و أبدوا رغبتهم في عدم العودة إلى لى إنى استخدام على النسخ المطبو عة.

وعن أسباب هذا التطور السريع في استخدام قواعد الدوريات الإلكترونية في مكتبات جامعة غرب ألينوي، ذكر الباحثان جملة من العوامل، أهمها ما شهدته الجامعة من تحديث لبناها 


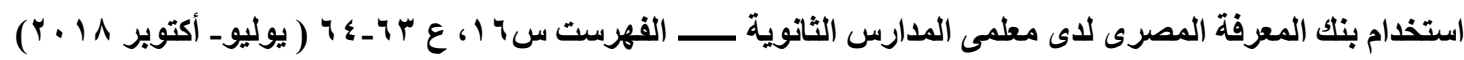

التحتية من شبكات، وزيادة في عدد أجهزة الحاسب في المكتبات ومعامل الطلاب، بالإضافة إلى مجانية خدمة الطباعة داخل الجامعة.

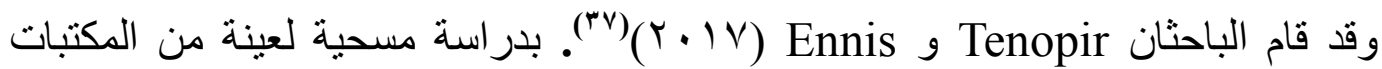

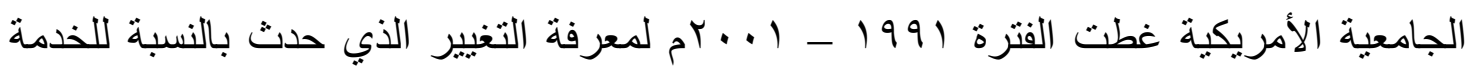
المرجعية الرقمية، وتوصلت الدراسة إلى عدة نتائج منها أن محركات البحث قد أصبحث أكثر الصريه

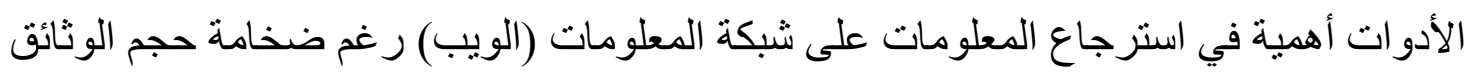

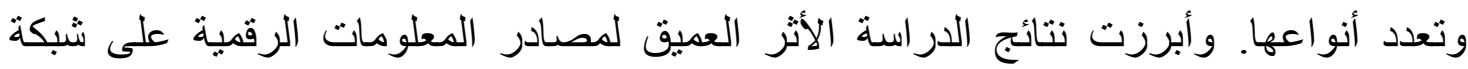
المعلومات (الويب) بالخدمات البحثية المتميزة التي يقدمها. أوجه التثابه والاختلاف بين الدراسات السابقة والدراسة القائمة: أوضحت الدراسات السابقة سواء كانت العربية أو الأجنبية الدور الهام الذي تلعبه المصادر الإلكترونية في دعم البحث العلمي، و الارتقاء به ومن ثم النهوض بالمنظومة التعليمية ككل .

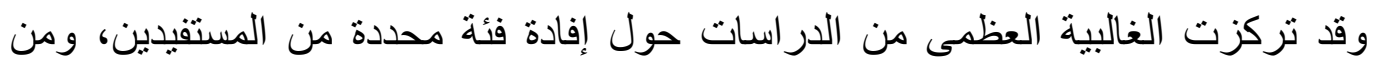

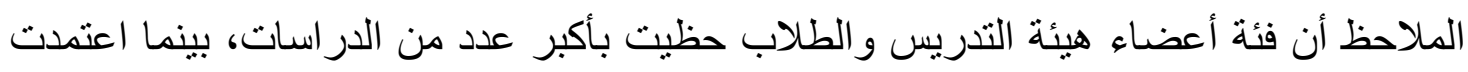
الدر اسة القائمة على فئة المعلمين والطلبة في المدارس الثانوية الحكومية؛ وهي تعد أول در استة

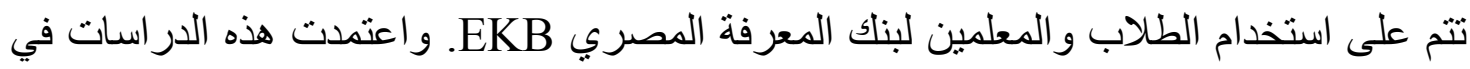

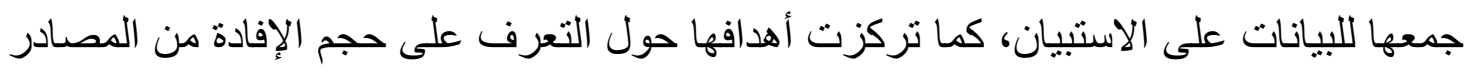

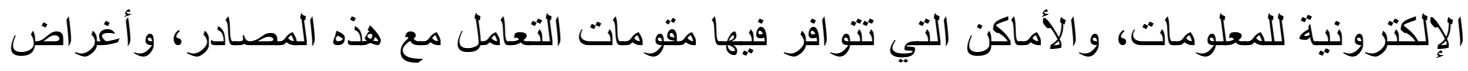

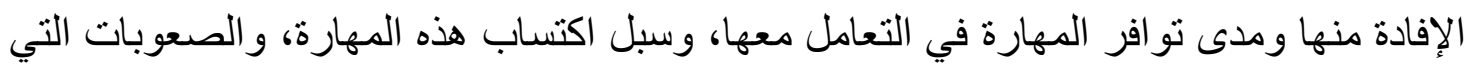

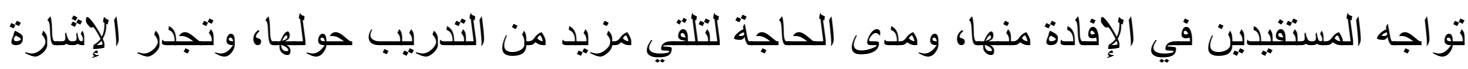

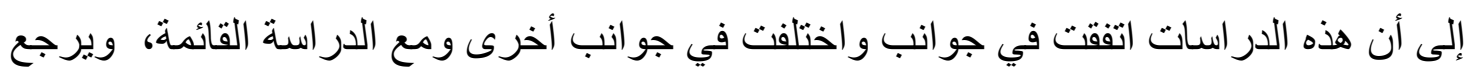
ذلك بالدرجة الأولى إلى تصميم الاستبيان و الاختيار ات التي تم وضعها في الأسئلة المغلقة. r/ 1 / المحور الأول : البيانات الديموجرافية والمهنية: يهدف هذا المحور إلى بيان البيانات الديموجر افية والمهنية لعينة الدراسة الكلية من أجل الجل

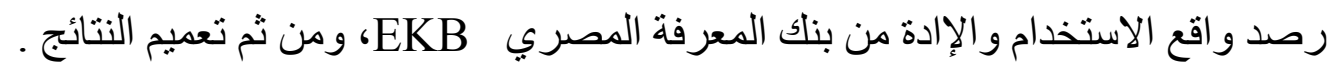
أ) الطلاب (الأكور والإناث): توزع المشاركون في الدر اسة على خمس فئات عمرية كما يتضح من الجدول رقم (ه). 
جول (0) الفئة العمرية للطلاب

\begin{tabular}{|c|c|c|c|c|c|c|c|}
\hline \multicolumn{2}{|c|}{ الإجملي } & \multicolumn{2}{|c|}{ طلبة إناث } & \multicolumn{2}{|c|}{ طلبة ذكود } & \multirow{2}{*}{ الفئة العمرية } & \multirow[t]{2}{*}{ p } \\
\hline$\%$ & $\varepsilon$ & $\%$ & $\varepsilon$ & $\%$ & $\varepsilon$ & & \\
\hline$r . \wedge$ & roq & 10. & 179 & 17.1 & 19. & 10 سنة & 1 \\
\hline r৯.r & $\varepsilon r$. & 19.5 & Y19 & $11 . V$ & YII & 717 سنة & $r$ \\
\hline rV.V & Tाr & $1 \leq .0$ & $17 \varepsilon$ & $1 T . Y$ & $1 \leq 9$ & Vنة IV & $r$ \\
\hline r.r & $r 7$ & 1.1 & 14 & $1 . r$ & $1 \varepsilon$ & 1/ سنة & $\varepsilon$ \\
\hline $1 \ldots$ & $11 Y A$ & 0. & $07 \varepsilon$ & 0. & $07 \varepsilon$ & لفى & الإج \\
\hline
\end{tabular}

وتدل هذه النسب في الجدول رقم (0) على التقارب الثنديد بالنسبة للذكور والإناث

المشاركين في الدر اسة وذللك للحصول على نسب حقيقية حول استخدام بنك المعرفة.

ب/ / الفئة العمرية للمعلمين:

يتضح من الجدول رقم (7) أن المشاركين في الدر اسة تم توزيعهم على أربع فئات عمرية،

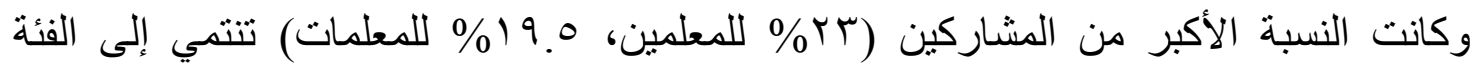

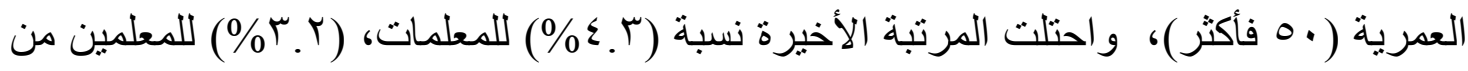

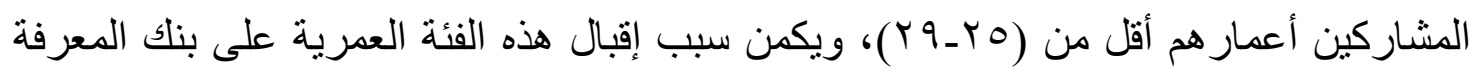

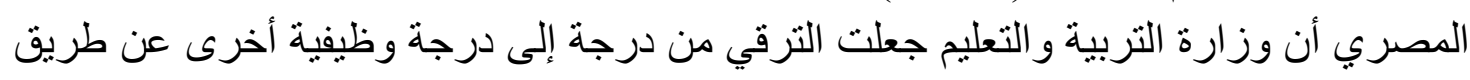

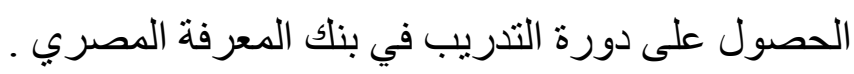

\section{جول (؟) الفئة العمرية للمعلمين}

\begin{tabular}{|c|c|c|c|c|c|c|c|}
\hline \multicolumn{2}{|c|}{ الإجمالي } & \multicolumn{2}{|c|}{ المطمات } & \multicolumn{2}{|c|}{ المطلمون } & \multirow{2}{*}{ الفئة العمرية عينة الدراسة } & \multirow[t]{2}{*}{ م } \\
\hline$\%$ & $\varepsilon$ & $\%$ & $\varepsilon$ & $\%$ & $\bar{\varepsilon}$ & & \\
\hline$\vee .7$ & $1 \varepsilon$ & $\varepsilon . \mu$ & $\Lambda$ & $r . r$ & 7 & اقل من OY_q & 1 \\
\hline YI. & $r q$ & $1 Y .7$ & rr & ᄉ. 7 & 17 & מن •rqur & $r$ \\
\hline rq & Or & ד. & ro & $10 . Y$ & YA & من · §q_ & $\mu$ \\
\hline$\varepsilon Y . r$ & $\vee \wedge$ & 19.0 & T4 & $r r$ & $\varepsilon r$ & من ·0 فأكثر & $\varepsilon$ \\
\hline $1 \ldots$ & $1 \wedge \varepsilon$ & 0 . & 94 & 0. & 94 & الىى & \\
\hline
\end{tabular}

r/ / / الخبرة في التّريس :

تشكل الخبرة في التدريس لأكثر من (آT) عام النسبة الأكبر من المشاركين بنسب بلغت

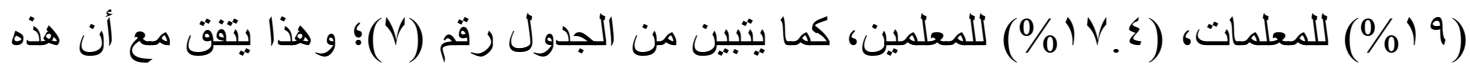
الفئة هي النسبة الغالبة للمشاركين الذين تتر اوح أعمار هم من ( •0 فأكثر)، كما تم الإشارة سابقًا، 


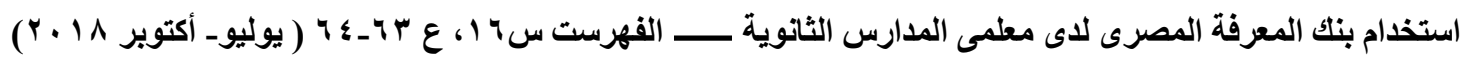
وجاءت أقل النسب للخبرة أقل من( • () سنوات بنسب (7.7\%) للمعلمات و (0.0\%) للمعلمين. جدول (V) الخبرة في التدريس

\begin{tabular}{|c|c|c|c|c|c|c|c|}
\hline \multicolumn{2}{|c|}{ الإجمالي } & \multicolumn{2}{|c|}{ مطمات } & \multicolumn{2}{|c|}{ معلمين } & \multirow{2}{*}{ الخبرة في التدريس عينة الدراسة } & \multirow[t]{2}{*}{ r } \\
\hline$\%$ & $\varepsilon$ & $\%$ & $\varepsilon$ & $\%$ & $\varepsilon$ & & \\
\hline Ir & Yr & 7.7 & IT & 0.0 & 1. & اقل من • 1 & 1 \\
\hline$\Gamma$. & 07 & 17.1 & Tा & $1 T .7$ & ro & من · - •r & $r$ \\
\hline r. & $T V$ & 19 & $\mu_{0}$ & $1 V . \varepsilon$ & $T r$ & من آ - •r & $r$ \\
\hline Y1.7 & $r q$ & $V .7$ & $1 \varepsilon$ & $1 \pi .0$ & Yo & أكثر من آ & $\varepsilon$ \\
\hline $1 \ldots$ & $1 \wedge \varepsilon$ & 0. & 94 & 0. & $9 Y$ & & \\
\hline
\end{tabular}

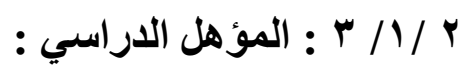

يتبين من الجدول رقم (^ ) تنوع الدرجات العلمية للمشاركين في الدر اسة ما بين دكتور اه، وماجستير، بكالوريوس أو ليسانس، ودبلوم الدراسات العليا، ويحمل العدد الأكبر من المشاركين

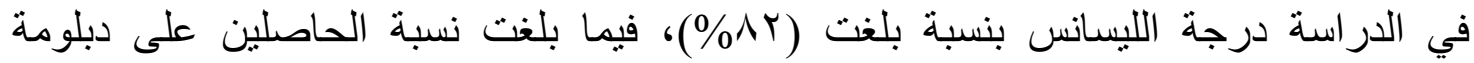
الدراسات العليا (^.؟1\%) ويأتي في المرتبة الأخيرة المعلمون الحاصلون على ماجستير ودكتور اه بنسبة (7 . \% \%) من إجمالي المشاركين في الدر اسة.

جدول (^) المؤهل

\begin{tabular}{|c|c|c|c|c|c|c|c|}
\hline \multicolumn{2}{|c|}{ الإجملي } & \multicolumn{2}{|c|}{ مطمات } & \multicolumn{2}{|c|}{ معلمون } & \multirow[b]{2}{*}{ المؤهل } & \multirow[t]{2}{*}{$\bar{p}$} \\
\hline$\%$ & $\varepsilon$ & $\%$ & $\varepsilon$ & $\%$ & $\varepsilon$ & & \\
\hline$\overline{\Lambda T}$ & 101 & $\varepsilon Y . r$ & $\mathrm{v \wedge}$ & rq.V & $V T$ & بكالوريوس أو ليسانس & 1 \\
\hline 17.1 & 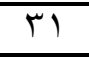 & $\vee .7$ & $1 \varepsilon$ & 9.1 & IV & دبلوم عالي & $r$ \\
\hline .7 & $T$ & - & - &. .7 & $T$ & ماجستير & $r$ \\
\hline$\cdot .7$ & $T$ & & & .7 & $T$ & دكتور اه & $\varepsilon$ \\
\hline $1 \ldots$ & $\overline{1 \wedge \varepsilon}$ & $1 \ldots$ & 94 & $1 \ldots$ & 94 & & \\
\hline
\end{tabular}




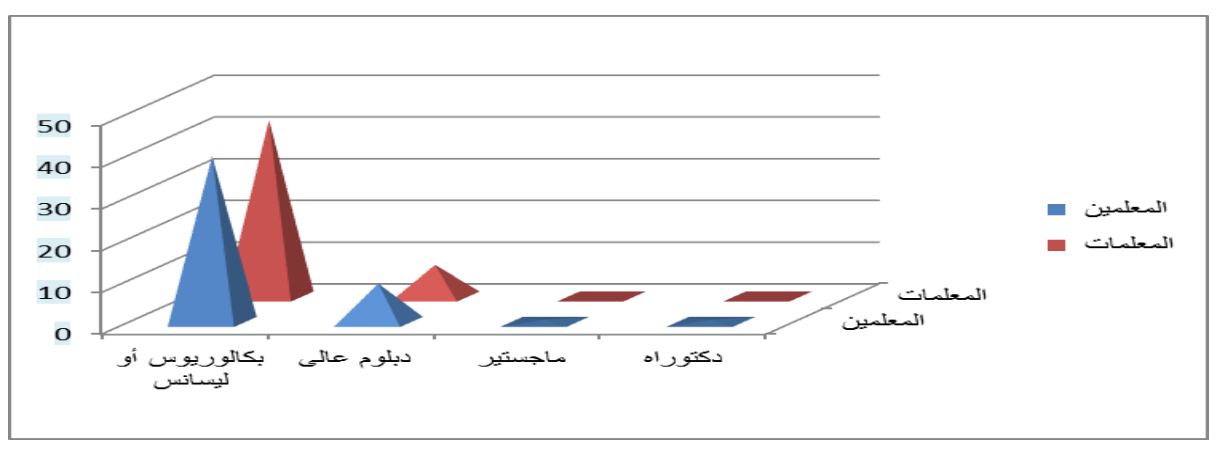

شكل رقم (ץ) آ المؤهل

r / / / ع التخصص العلمي:

يتبين من الجدول التالي أن تخصص العلوم الطبيعية يشكل النسبة الأكبر من أفراد العينة بنسبة كلية بلغت(ع. (ب\%)؛ وهذا مؤشر هام يوضح تركيز بنك المعرفة المصري علي العلوم

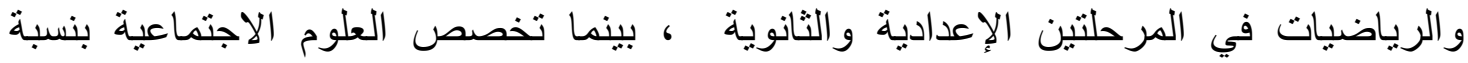

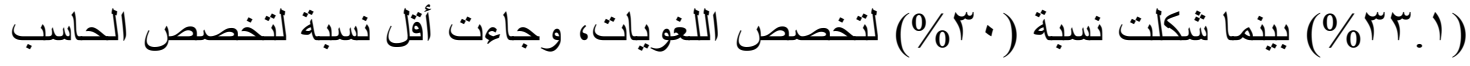

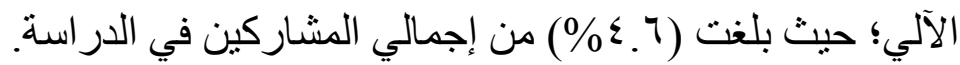
جول (9) التخصص العلمي

\begin{tabular}{|c|c|c|c|c|c|c|c|}
\hline \multicolumn{2}{|c|}{ الإجمالي } & \multicolumn{2}{|c|}{ المطمات } & \multicolumn{2}{|c|}{ المطمون } & \multirow{2}{*}{ الاراسة } & \multirow[t]{2}{*}{ م } \\
\hline$\%$ & $\varepsilon$ & $\%$ & $\varepsilon$ & $\%$ & $\varepsilon$ & & \\
\hline M. & OV & 10.0 & $r q$ & 10.4 & $r \wedge$ & علوم طبيعية & $r$ \\
\hline I. & 71 & 19.0 & $r 4$ & $1 \pi .4$ & ro & علوم اجتماعية & 1 \\
\hline$\varepsilon .7$ & 11 & r.o & 0 & $r . r$ & 7 & حاسب آلي & $r$ \\
\hline$r$. & 00 & 11.9 & $\overline{Y Y}$ & $1 V .9$ & $r T$ & لغويات & $\varepsilon$ \\
\hline $1 \ldots$ & $\overline{1 \wedge \varepsilon}$ & 0. & 94 & 0. & 94 & مالى & \\
\hline
\end{tabular}

ب / / / الإدارة التعليمية:

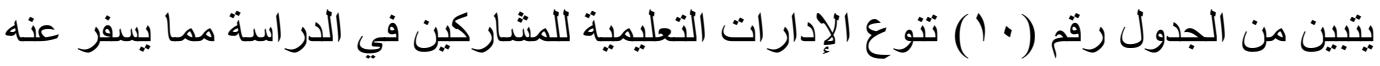
تغطية شاملة للاستخدام و الإفادة من بنك المعرفة داخل محافظة القاهرة وكانت النسب الأكبر في

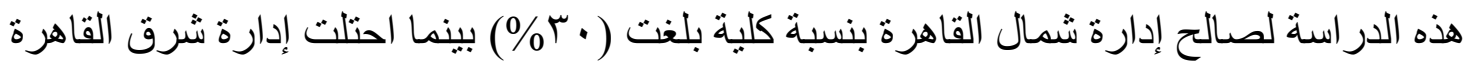

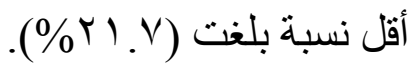




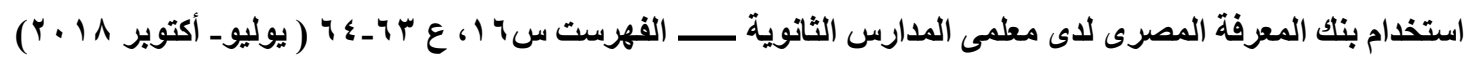

جدول ( · ( ) الإدارية التعليمية

\begin{tabular}{|c|c|c|c|c|c|c|c|}
\hline \multicolumn{2}{|c|}{ الإجمالي } & \multicolumn{2}{|c|}{ معلمات } & \multicolumn{2}{|c|}{ مطلمون } & \multirow{2}{*}{$\begin{aligned} \text { المنطقة التعليمية } & \\
& \text { الاراسة }\end{aligned}$} & \multirow[t]{2}{*}{ r } \\
\hline$\%$ & $\varepsilon$ & $\%$ & $\varepsilon$ & $\%$ & $\varepsilon$ & & \\
\hline$\Gamma$. & 00 & 10.4 & $r \wedge$ & $1 \leqslant .7$ & $T V$ & شمال & 1 \\
\hline$T \xi \varepsilon$ & $\varepsilon 0$ & 10.4 & $r \wedge$ & Q.Y & IV & جنوب & $r$ \\
\hline YI.V & $\varepsilon$. & $1 \cdot . \varepsilon$ & 19 & 11.2 & YI & شُرق & $r$ \\
\hline$r r . q$ & $\varepsilon \varepsilon$ & 9.1 & IV & $1 \leq .7$ & $r V$ & غرب & $\varepsilon$ \\
\hline $1 \ldots$ & $1 \wedge \varepsilon$ & 0. & 94 & 0. & 94 & & \\
\hline
\end{tabular}

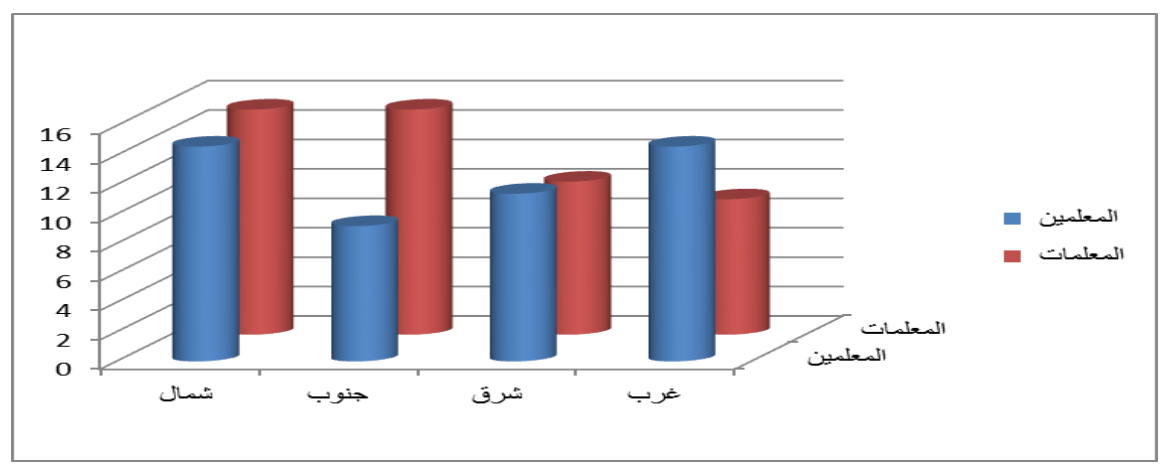

شكل (ب) الإدارية التعليمية

r/ 1 المحور الثاني : رصد واقع الاستخدام والإفادة من بنك المعرفة: ب / / 1/ مدى امتلاك جهاز حاسب آلي: جدول (1 1) مدى امتلاك جهاز حاسب آلي

\begin{tabular}{|c|c|c|c|c|c|c|c|c|c|}
\hline \multicolumn{2}{|c|}{ معلمات } & \multicolumn{2}{|c|}{ معلمين } & \multicolumn{2}{|c|}{ طلبة إناث } & \multicolumn{2}{|c|}{ طلبة ذكور } & \multirow{2}{*}{ المقترحات } & \multirow[t]{2}{*}{ 5 } \\
\hline$\%$ & $\varepsilon$ & $\%$ & $\varepsilon$ & $\%$ & $\varepsilon$ & $\%$ & $\varepsilon$ & & \\
\hline$\varepsilon \varepsilon$. & $\Lambda Y$ & $\varepsilon \wedge$ & $\wedge \wedge$ & $\varepsilon \varepsilon$. & $0 . Y$ & s. & $\leqslant 00$ & نعم & 1 \\
\hline 0.5 & 1. & r. & $\varepsilon$ & 0.5 & $7 Y 1$ & 9.1 & 1.9 & $y$ & $r$ \\
\hline $1 \ldots$ & $9 r$ & $1 \ldots$ & $9 r$ & $1 \ldots$ & $07 \varepsilon$ & $1 \ldots$ & $07 \varepsilon$ & الإجمالي & \\
\hline
\end{tabular}

يتضح من الجدول السابق أن الغالبية العظمى من أفراد عينة الدراسة المتمثلة في الطلبة

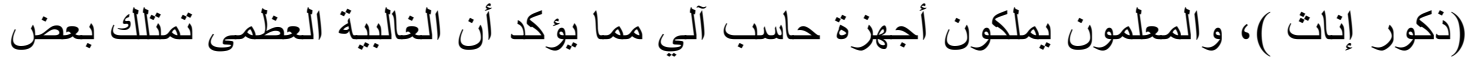

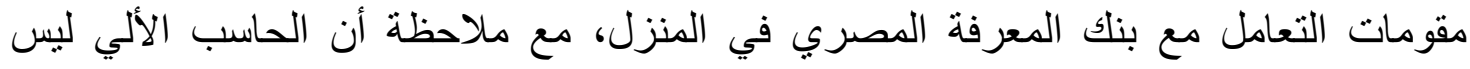
الوسيلة الوحيدة للوصول إلى بنك المعرفة المصري، فهنالك مثلا أجهزة الموبايل و التابلت. 


\section{r / / r مهارات استخدام الحاسب الآلي والإنترنت:}

يظهر الجدول رقم (Y I) أن الغالبية العظمى من أفر اد عينة الدر اسة بالنسبة للطلبة يتمتعون

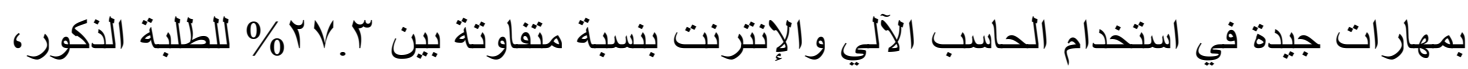

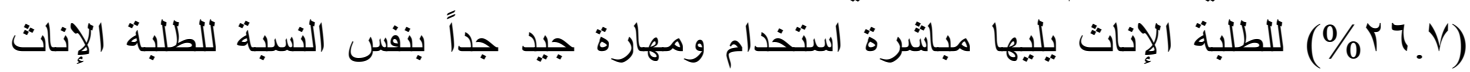

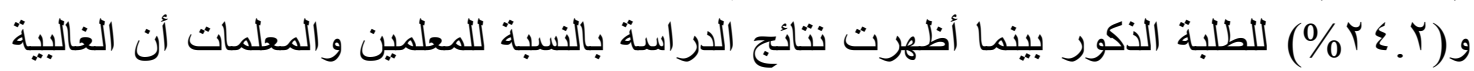
العظمى يتمتعون بمهارة متوسطة في استخدام الحاسب الآلي والإنترنت، كما يتضح أن نسبة النبة

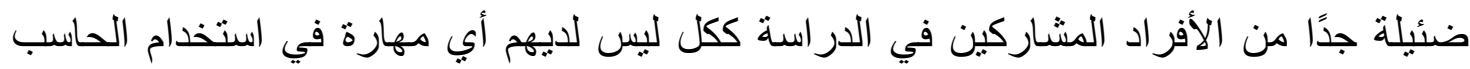

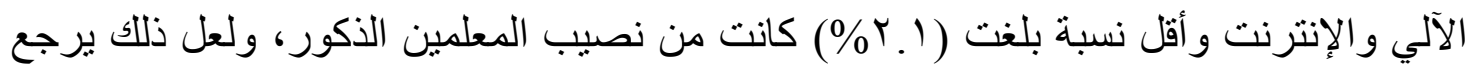
إلي عدم تفضيل استخدام التكنولوجيا والاعتماد على المصادر التقلبدية للمعلومات لهذه الفئة العمرية الغالبة التي تنحصر في ( • ن سنة فأكثر).

\section{جدول (r I ) مهارات استخدام الحاسب الآلي والانترنت}

\begin{tabular}{|c|c|c|c|c|c|c|c|c|c|c|c|c|c|}
\hline \multicolumn{2}{|c|}{ الإجمالي } & \multicolumn{2}{|c|}{ المتوسط } & \multicolumn{2}{|c|}{ متوسط } & \multicolumn{2}{|c|}{ جيا } & \multicolumn{2}{|c|}{ جيد جداً } & \multicolumn{2}{|c|}{ ممتاز } & \multirow{2}{*}{ 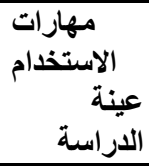 } & \multirow[t]{2}{*}{ R } \\
\hline$\%$ & $\varepsilon$ & $\%$ & $\varepsilon$ & $\%$ & $\varepsilon$ & $\%$ & $\varepsilon$ & $\%$ & $\varepsilon$ & $\%$ & $\varepsilon$ & & \\
\hline $1 \ldots$ & $07 \varepsilon$ & 0.1 & r & 11 & $1 \cdot r$ & TV.r & 105 & $r \leqslant . r$ & $1 T V$ & $T \leqslant . \varepsilon$ & $1 \pi \wedge$ & طلبة ذكور & 1 \\
\hline $1 \ldots$ & $07 \varepsilon$ & $\varepsilon .7$ & $r 7$ & $r \cdot r$ & 110 & $7 . V$ & 101 & Y..V & 101 & YI. & $T M$ & طلبة إناث & $r$ \\
\hline $1 \cdots$ & 94 & Y. & $\varepsilon$ & 19 & ro & $10 . \mathrm{V}$ & rq & $\Lambda .1$ & 10 & $\varepsilon . \wedge$ & 9 & معلمين & $r$ \\
\hline $1 \ldots$ & 94 & 0.9 & 11 & $r \cdot .1$ & rV & 11.9 & $\overline{r Y}$ & 9.5 & IV & Y.V & 0 & معلمات & $\varepsilon$ \\
\hline $1 \ldots$ & $\begin{array}{c}1 \pi T \\
r\end{array}$ & $1 \ldots$ & $V \varepsilon$ & $1 \cdots$ & $r \wedge 9$ & $1 \ldots$ & rot & $1 \ldots$ & r. & $1 \ldots$ & TVT & الإجمالي & 0 \\
\hline
\end{tabular}

\section{r/ / / واقع الاستخدام والتسجيل لبنك المعرفة المصري:}

يتبين من إجابات عينة الدراسة ـ كما بلخصها الجدول رقم (T I) - أن السواد الأعظم من الطلبة (الذكور و الإناث) لم يقو موا بالتسجيل، ومن ثم الاستخدام و الإفادة من بنك المعرفة بنسبة

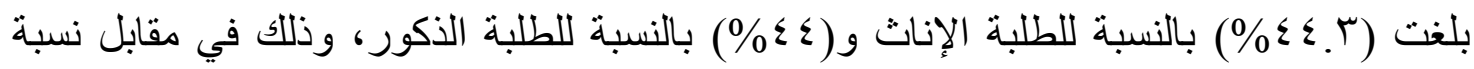

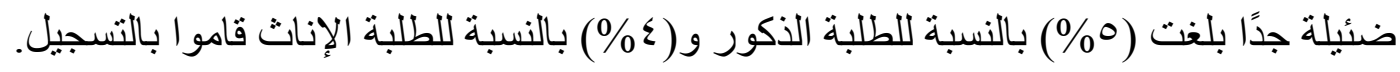




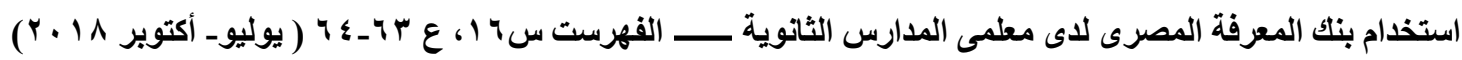

جدول (ب ا ) واقع الاستخدام والإفادة من بنك المعرفة المصري

\begin{tabular}{|c|c|c|c|c|c|c|c|c|c|}
\hline \multicolumn{2}{|c|}{ المعلمات } & \multicolumn{2}{|c|}{ المطلمون } & \multicolumn{2}{|c|}{ طلبة إناث } & \multicolumn{2}{|c|}{ طلبة ذكور } & \multirow{2}{*}{ التسجيل عينة الراسة } & \multirow[b]{2}{*}{ p } \\
\hline$\%$ & $\varepsilon$ & $\%$ & $\varepsilon$ & $\%$ & $\varepsilon$ & $\%$ & $\varepsilon$ & & \\
\hline ro. & $\leqslant V$ & rT.l & $\varepsilon r$ & $\varepsilon$. & $\leqslant 0$ & 0. & 07 & سجلت & 1 \\
\hline - & - & - & - & 1.7 & 19 & 1.1 & $\pi$ & سجلت ولم استخذم & $r$ \\
\hline $\begin{array}{c}T \leqslant . \\
0\end{array}$ & $\leqslant 0$ & Y५. V & $\varepsilon 9$ & $\begin{array}{c}\varepsilon \varepsilon . \\
r\end{array}$ & $0 \ldots$ & $\varepsilon \varepsilon$ & $\leqslant 90$ & لم اسجل & $r$ \\
\hline $1 \ldots$ & 94 & $1 \cdots$ & 94 & $1 \ldots$ & $07 \varepsilon$ & $1 \ldots$ & $07 \varepsilon$ & الإجمالى & \\
\hline
\end{tabular}

ويتضح من هذا الجدول رقم (T I) أيضاً تفوق المعلمات في تسجيلهن ومن ثم إفادتهن من بنك المعرفة بنسبة بلغت (0\%\%\%) من العينة الكلية في مقابل عدد أكبر لم يسجلوا بعد بلغت

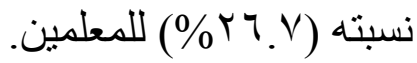

وبذلك نجد أن الغالبية العظمى من الطلبة بنسبة كلية بلغت (19\%) لم يقوموا بالتسجيل ومن ثم الاستخدام والإفادة المرجوة من بنك المعرفة المصري في مقابل أكثر من نصف العبندة العينة

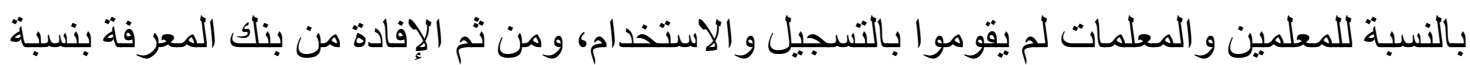
بلغت (1\%) ، و ولعل تفسير ذلك يرجع إلي عدة أسباب سوف نوضحها في النقطة التالية : ץ / / ع أسباب عدم التسجيل وعدم استخدام بنك المعرفة المصري: يشير الجدول رقم (ع ا) أن السبب الرئيسي في عدم التسجيل والاستخدام، ومن ثم الإفادة

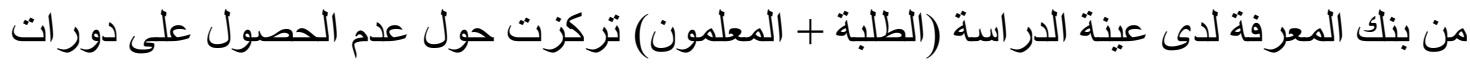
تدريبية حول استخدام بنك المعرفة المصري بنسب بلغت (^ش\%) بالنسبة للطلبة الإناث

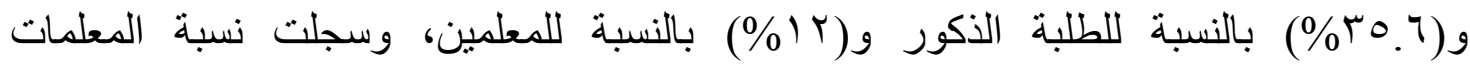

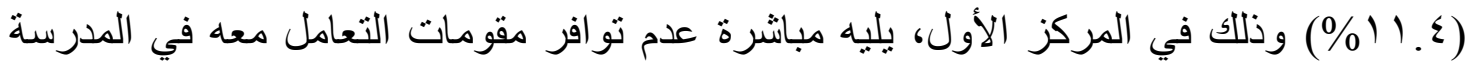

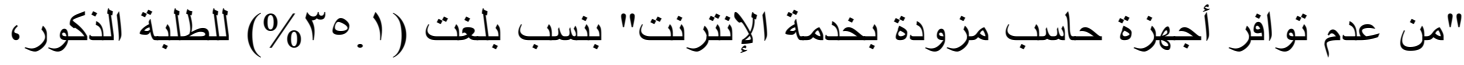

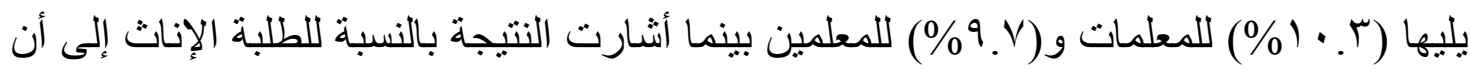

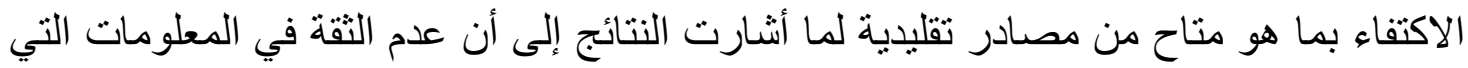

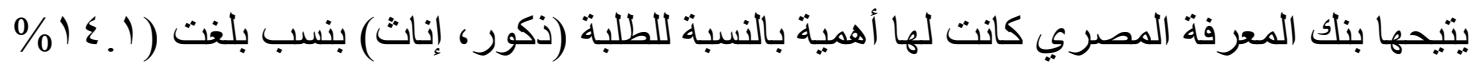

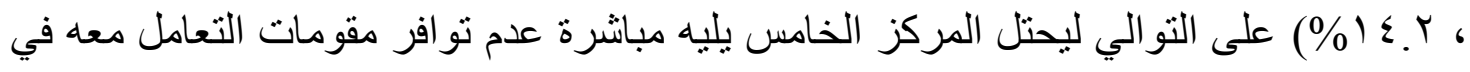

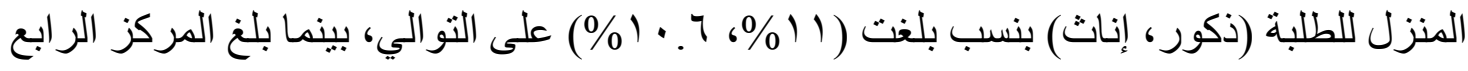

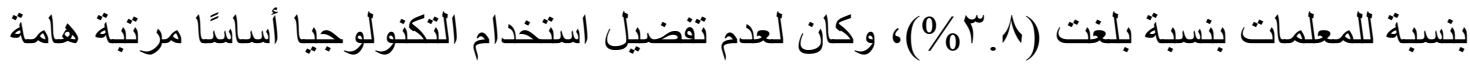

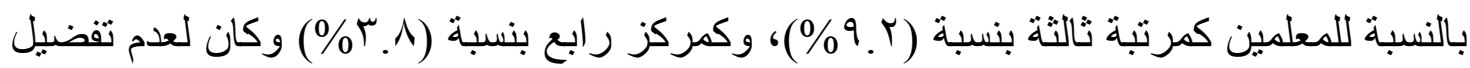

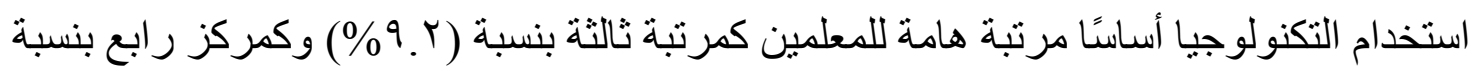




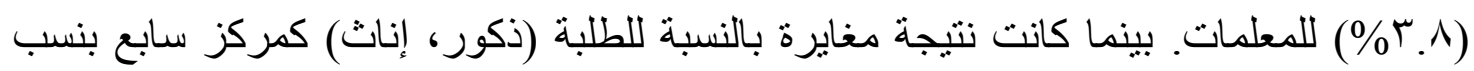

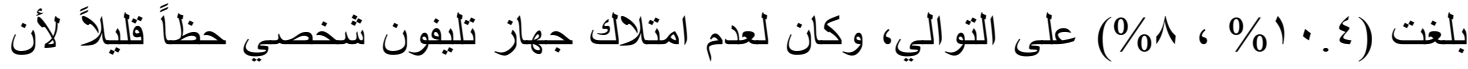
الغالبية العظمى تمتلك تليفون شخصي بحيث احتل مركز أخير بالنسبة للطلبة الإناث بنسبة بلغت

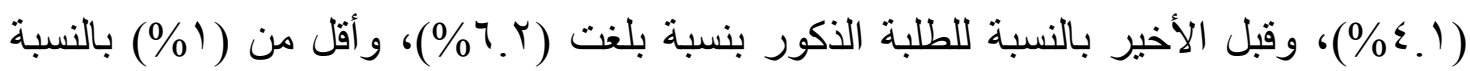
للمعلمات، وجاء عدم معرفة استخدام الحاسب الآلي أو ضعف مهار اتي كمركز أخير بالنسبة

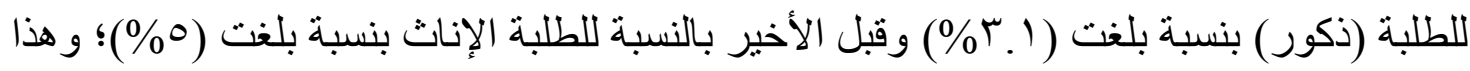
يؤكد ويدعم نتائج الجدول رقم (Y T) في أن الغالبية العظمى من الطلبة (ذكور و إناث) مهار اتهم جيدة في استخدام الحاسب، وكانت النتيجة أيضًا في هذا الجدول تدل على أن المعلمين و المعلمات مستو اهم متوسط في الحاسب ويدعم هذه النتيجة ما أثنارت إليه النسب بالنسبة للمعلمين حيث احتل

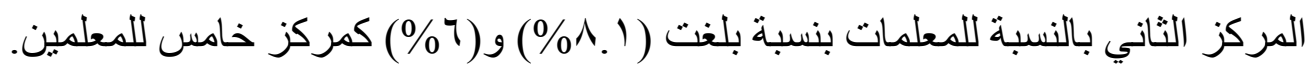
جدول (\& 1) أسباب عدم التسجيل وعدم استخدام بنك المعرفة المصري

\begin{tabular}{|c|c|c|c|c|c|c|c|c|c|}
\hline \multicolumn{2}{|c|}{ معلمات } & \multicolumn{2}{|c|}{ معلمين } & \multicolumn{2}{|c|}{ عينة إناث } & \multicolumn{2}{|c|}{ عينة ذكور } & \multirow{2}{*}{ أسباب عدم التسجيل عينة الدراسة } & \multirow[b]{2}{*}{ s } \\
\hline$\%$ & $\varepsilon$ & $\%$ & $\varepsilon$ & $\%$ & $\varepsilon$ & $\%$ & $\varepsilon$ & & \\
\hline ^.1 & 10 & 7 & 11 & 0 & or & r. & ro & الحاسب معرفتي باستخدام كهيفة اتي ضعيفة & 1 \\
\hline r. & $\varepsilon$ & $.0 \leqslant$ & 1 & $r \wedge . r$ & rr. & r.. & $\begin{array}{c}r q \\
q\end{array}$ & المعرفة المصني وسماعي بينكأك & $r$ \\
\hline $11 . \varepsilon$ & Y) & IT & YY & ऍ^ & $\varepsilon \curlyvee \wedge$ & ro. & $\begin{array}{l}r q \\
7\end{array}$ & 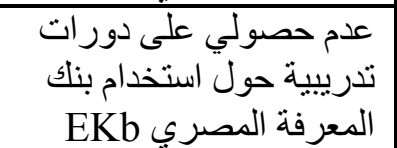 & $\Gamma$ \\
\hline $1 \cdot . r$ & 19 & $9 . \vee$ & 11 & r. & «1 & ro.17 & $\varepsilon$ & معهد في العمل "المدرسة مقات التعامل & $\varepsilon$ \\
\hline$r . \wedge 1$ & V & - & - & $1 \cdot .7$ & Ir. & 11 & $\sum^{1 T}$ & 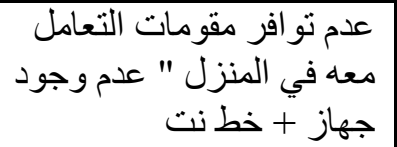 & 0 \\
\hline $.0 \leqslant$ & 1 & - & - & $\varepsilon .1$ & $\leqslant V$ & $7 . r$ & $v \cdot$ & شانمتلكي" جهاز " تليفون نسلاله & 7 \\
\hline ^.1 & 10 & V & $\pi$ & $r v . r$ & $\{r \mid$ & TV & r. & 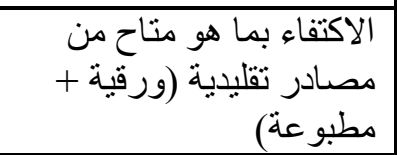 & $\mathrm{V}$ \\
\hline & - & 1 & $r$ & $1 \leqslant . T$ & 171 & $1 \leq .1$ & 17 & 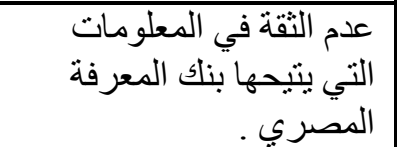 & $\Lambda$ \\
\hline r.A & $V$ & 9.1 & IV & 1.10 & 91 & $1 \cdot . \varepsilon$ & $\begin{array}{l}11 \\
1\end{array}$ & التكنو توضياً أسباساً لاستخدام & 9 \\
\hline $1 \leqslant .7$ & TV & 14.0 & ro & $V .9$ & 9. & T.V & ro & أسباب أخرى & 1. \\
\hline
\end{tabular}




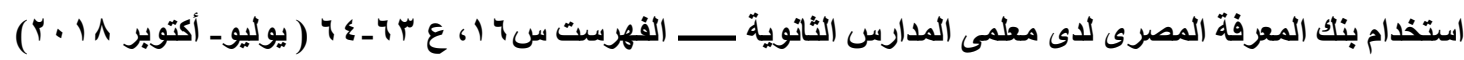

هذا بالإضافة إلى العديد من الأسباب الأخرى التي ذكرها أفر اد عينة الدراسة (المعلمين و الطلبة) تفيد بعدم تسجيلهم في بنك المعرفة ومن ثم عدم الاستخدام و الإفادة، من الطلبة الذكور

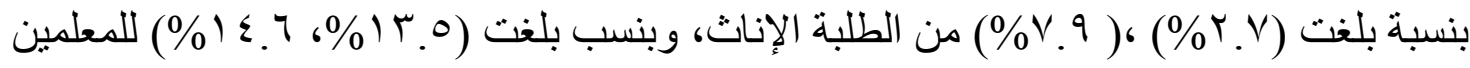
و المعلمات على التوالي، وكان من أهم هذه الأسباب بالنسبة (للطلبة) عدم تو افر الوقت، وعنة وعدم

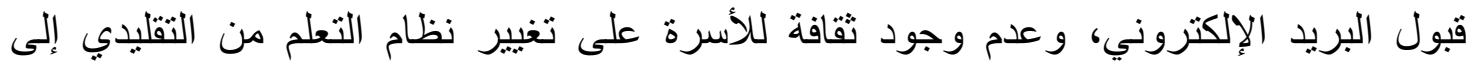
التكنولوجي، ووجهة النظر التي تعكس أن الحاسب الآلي مصدر إثاعات خطيرة على الإنسان

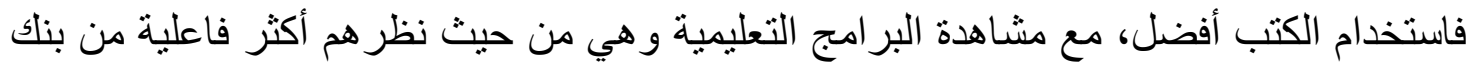

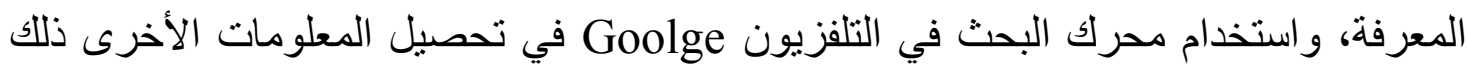

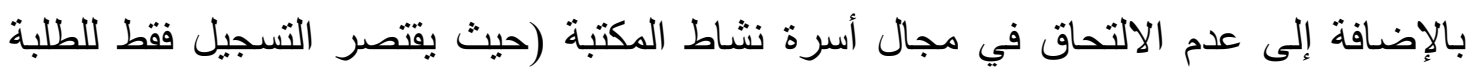
المسجلين في الأسرة)، كذلك غلق الإنترنت في المنزل أثناء الدراسة وعدم التشجيع من قبل التبل

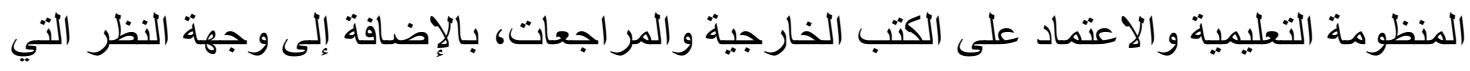
تعتقد أن المنهج التعليمي يشتمل على معلومات تعتمد على الإبداع و التمبز التي لا تتو افر في بنك المعرفة.

و انحصرت الأسباب الأخرى بالنسبة للمعلمين و المعلمات في عدم جدية الدورات و اعتمادها على السرد في التدريب، والتدريب كان نظريًا وليس عمليًا، و الدورات التي تم أخذها كانت غير التير فعالة للاستخدام و الإفادة.

س/ / /ه سبل اكتساب مهارات التعامل مع بنك المعرفة المصري: جدول (0 1 ) سبل اكتساب مهارات التعامل مع بنك المعرفة المعلئ المصري

\begin{tabular}{|c|c|c|c|c|c|c|c|c|c|}
\hline \multicolumn{2}{|c|}{ معلمات } & \multicolumn{2}{|c|}{ معلمين } & \multicolumn{2}{|c|}{ إناث } & \multicolumn{2}{|c|}{ ذكور } & \multirow{2}{*}{ مهار ات التعامل عينة الدر اسة } & \multirow[b]{2}{*}{ r } \\
\hline$\%$ & $\varepsilon$ & $\%$ & $\varepsilon$ & $\%$ & $\varepsilon$ & $\%$ & $\varepsilon$ & & \\
\hline$r V . V$ & r & $r \leqslant .9$ & 10 & ro.07 & 17 & $\{\Lambda, Y)$ & TV & | بنفسك عن طريق الذاتي & 1. \\
\hline 71.1 & $\overline{r T}$ & VY.I & 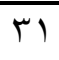 & 10.07 & $\mathrm{~V}$ & $1 \cdot . v 1$ & 7 & |الدورات التدريبية & 11 \\
\hline Ir.A & 7 & 11.7 & 0 & $\wedge . \wedge 9$ & $\varepsilon$ & V.ls & $\varepsilon$ & |الاستعانة بالزملاء & TY \\
\hline 1.0 & $\varepsilon$ & $r \pi . r$ & 1. & ro.07 & 17 & ro.vi & $r \cdot$ & |الموالتع التعليمية & $\pi$ \\
\hline $7 . \varepsilon$ & $r$ & Tr.T & 1. & OV.VA & YT & Tr.0. & ro & |أخصائي المكتبة & $1 \varepsilon$ \\
\hline 7.2 & $r$ & $V_{.}$. & $r$ & 11.11 & 0 & IV.AT & 1. & |أحد أفر اد الأسرة & 10 \\
\hline
\end{tabular}

هناك عدة سبل لاكتساب مهار ات التعامل مع بنك المعرفة المصري؛ حيث تفاوتت معدلات اعتماد الطلبة على كل منها؛ حيث يعد الاستعانة بأخصائي المكتبة هو الخيار الأول الذي يلجأ إليه

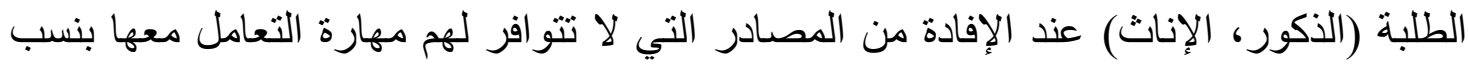




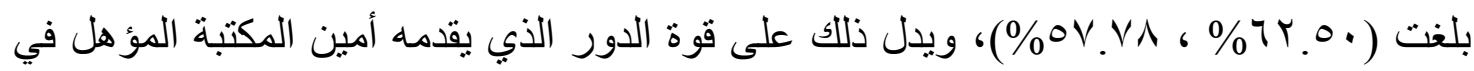
الإفادة عن بنك المعرفة، أما بالنسبة للمعلمين والمعلمات وهات فكانت الدورات التذريبية هي الخيار

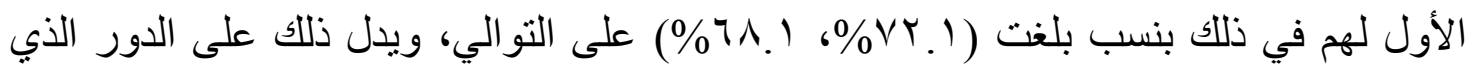

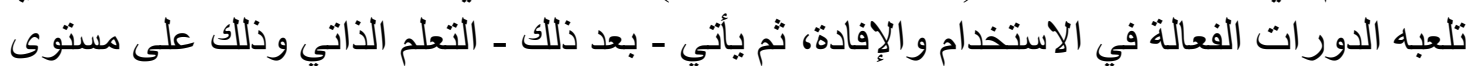

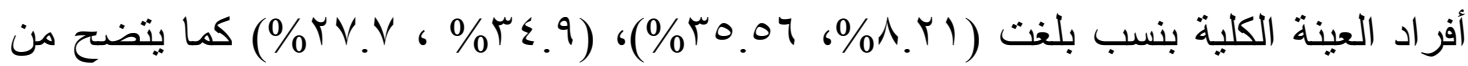

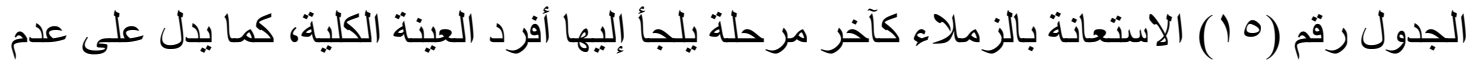

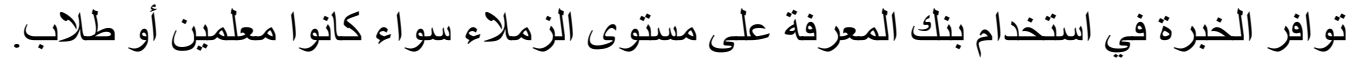

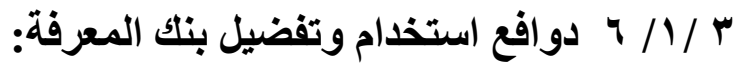

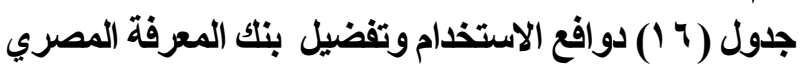

\begin{tabular}{|c|c|c|c|c|c|c|c|c|c|c|c|c|c|}
\hline \multicolumn{3}{|c|}{ مطلتت } & \multicolumn{3}{|c|}{ معمين } & \multicolumn{3}{|c|}{ طبة إنث } & \multicolumn{3}{|c|}{ طلبة نكور } & \multirow{2}{*}{\multicolumn{2}{|c|}{ دوافع الاستخدام }} \\
\hline الأهثيبة & أنحراف & متوسط & الأهميبة & مجري & متوسط & تالهيثية & معريري & متوسط & الأهميبة & اتعرافي & متوسط & & \\
\hline 1 & 1.79 & $\varepsilon . \mu$ & 1 & $\quad .94$ & E.Tr & 1 & 1.71 & $r . \wedge 1$ & 1 &. .10 & $\{. \xi 1$ & البو الديث لاغراض & 1 \\
\hline$r$ & $1 . \cdot v$ & r.A & $r$ & $1 . \cdot v$ & $\varepsilon \cdot v$ & $\wedge$ & $1 . \leqslant 0$ & r.71 & v & I.YV & $\Gamma . \Gamma \varepsilon$ & |لمبلاحق في & r \\
\hline$r$ & 1.81 & 5.70 & $r$ & $\overline{1}$ & $\varepsilon \cdot v$ & $r$ & $1.0 r$ & T.YV & $r$ & $1.1 \varepsilon$ & r. & | الدحلومات & $r$ \\
\hline v & $1.0 \varepsilon$ & $T . \varepsilon \varepsilon$ & $\varepsilon$ & 1.14 & $r . \Delta 1$ & 。 & $1 . \mathrm{Vr}$ & r.1A & 1 & 1.19 & r. & سعن المعلومات البحت & $\varepsilon$ \\
\hline$\wedge$ & 1.00 & T & 9 & 1.00 & r.Al & 9 & 1.01 & $r .70$ & 0 & $1 . r r$ & r.tr & 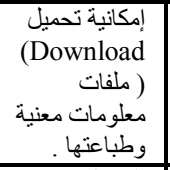 & 0 \\
\hline 9 & 1.57 & r.rq & $\wedge$ & 1.17 & r.91 & $r$ & $1 .{ }^{\prime} 1$ & $r . T \varepsilon$ & $r$ & $1 . r r$ & $r .71$ & 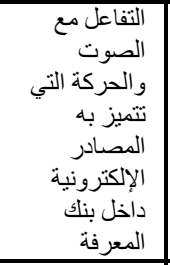 & 1 \\
\hline 1 & $1.2 \pi$ & r.o. & 1 & $1 \ldots$ & r.r. & 7 & 1.00 & T.IV & 9 & 1.70 & r.IV & 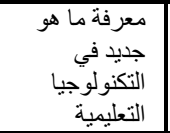 & v \\
\hline$\varepsilon$ & 1.17 & $r .00$ & V & $1 . r$ & r.A. & v & T. & $r . \leqslant 9$ & $\wedge$ & $1 . Y A$ & $r .19$ & 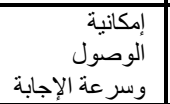 & $\wedge$ \\
\hline 1. & 1.01 & r.r. & 1. & $1, r$. & $r .1 \varepsilon$ & 1. & 1.71 & r.11 & 1. & $1 . r 4$ & ror & 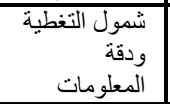 & 9 \\
\hline 0 & 1.19 & r.or & 。 & $\cdot . \wedge 9$ & $r . \Sigma A$ & $\varepsilon$ & 1.71 & r.1A & $\varepsilon$ & I.rT & $r .01$ & 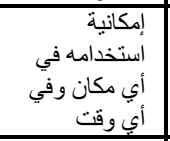 & 1. \\
\hline 11 & $1 . \leqslant 9$ & r.q६ & 11 & $1, \mathrm{rA}$ & $r . \leqslant T$ & 11 & $1 . \leqslant 9$ & $r . r$. & 11 & $1 . \varepsilon \varepsilon$ & $r . \Lambda 1$ & 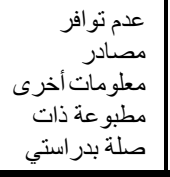 & 11 \\
\hline
\end{tabular}




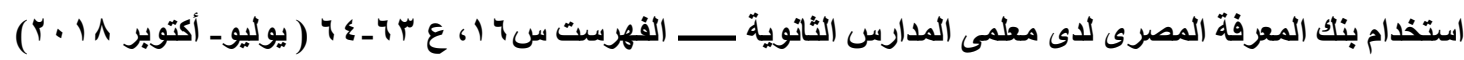

يثير الجدول رقم (7 (1) إلى تنوع دوافع الاستخدام والتفضيل لبنك المعرفة المصري،

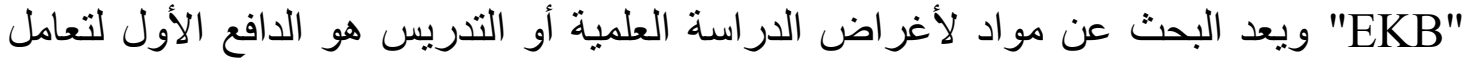

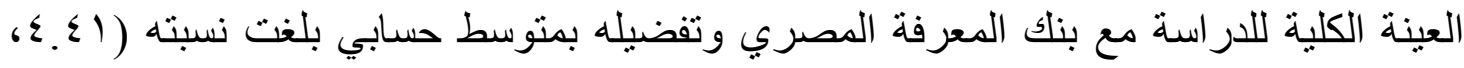

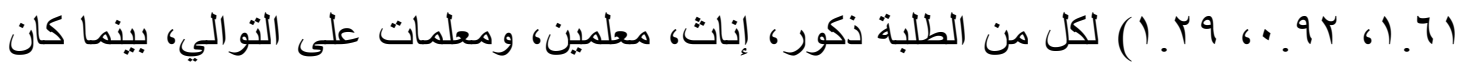
الدافع الثاني للاستخدام و التفضيل ملاحقة التطورات في مجال التخصص وذللك بالنسبة للمعلمين

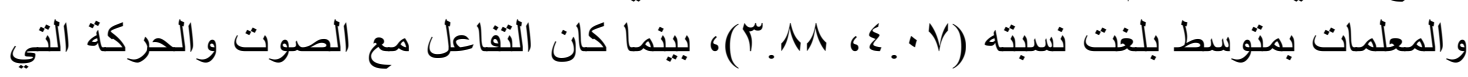
تتميز بها المصادر الإلكترونية داخل بنك المعرفة الدافع الثاني بالنسبة للطلبة الذكور والإناث

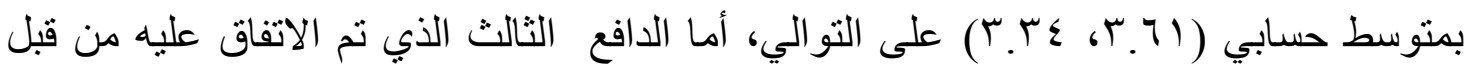
العينة الكلية للاراسة هو حداثة المعلومات التي يتميز بها بنك المعرفة المصري بنسب تبلغ

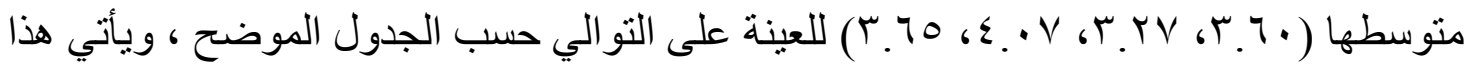
كنتيجة منطقية تتوافق مع ملاحظة العينة وخاصة المعلمين والمعلمات للتطورات في مجال

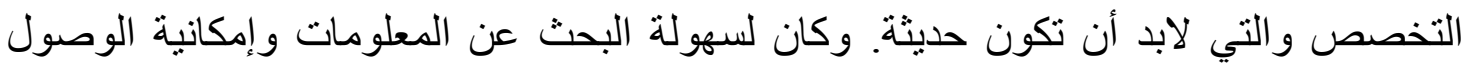

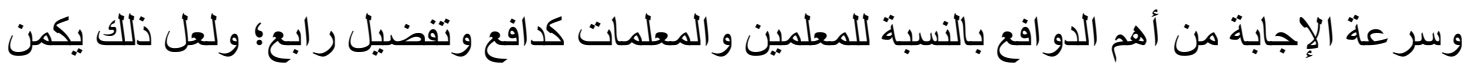

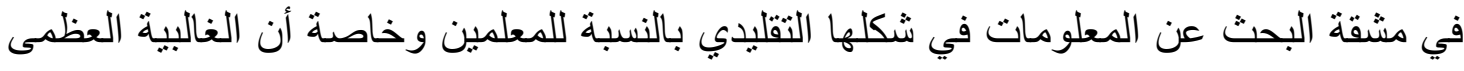
منهم تتر اوح أعمار هم بين ( •0 فأكثر) عامًا بينما اختلف الدافع والتفضيل الر ابع للطلبة كذكور

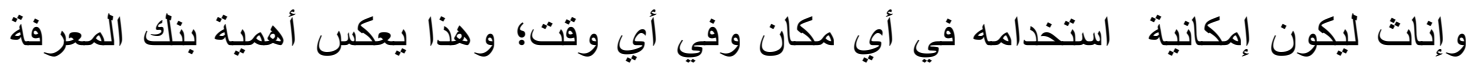
المصري للحصول على المعلومات التي يحتاجونها دون التقبد بمكان أو زمان بالنسبة لهم، وأيضًا

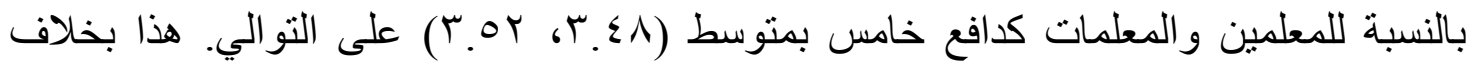

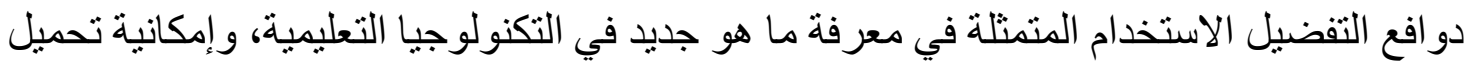

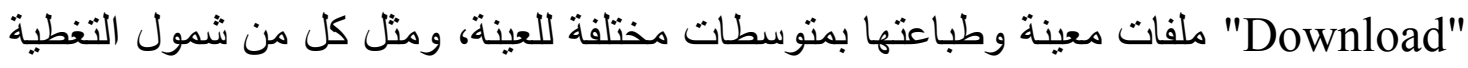
ودقة المعلومات ، كذلك عدم تو افر مصادر معلومات مطبوعة، دو افع استخدام وتفضيل أخيرة

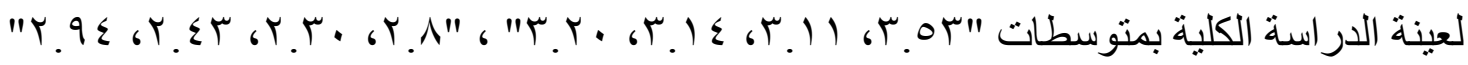

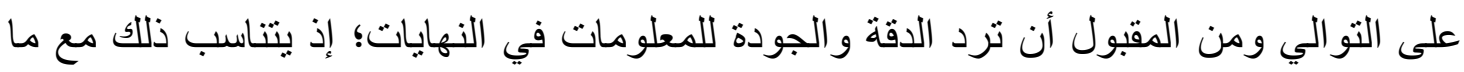

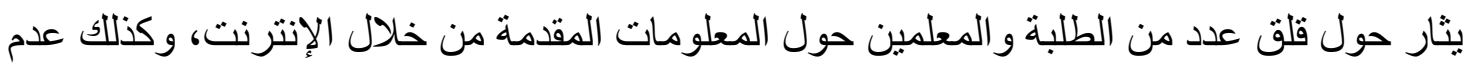

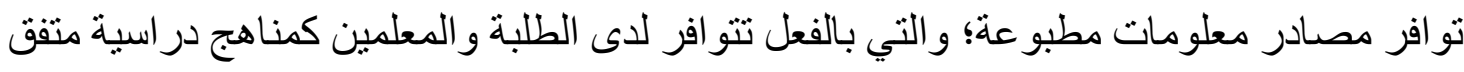
ومتعارف عليها من قبل المنظومة التعليمية.

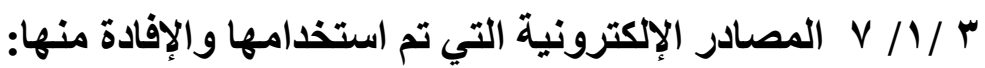

تعد الكتب و المناهج الدر اسية من أهم و أكثر مصادر المعلومات التي تم استخدامها والإفادة

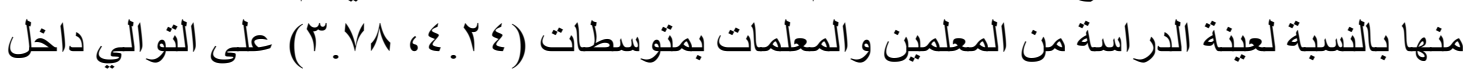
بنك المعرفة المصري "EKB". بينما تعد في المركز الثاني بالنسبة لعينة الدراسة من الطلبة

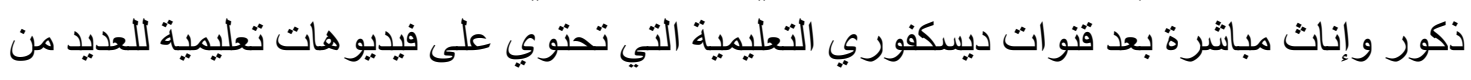


المقررات التعليمية وخاصة في العلوم و الرياضيات باللغات المختلفة بمتوسط (ج و. ب) للطلبة الذكور، ثم (Yr. () للإناث. بينما احتلت قنوات ناشيونال جيوجر افيك المستوى الثالث بالنسبة

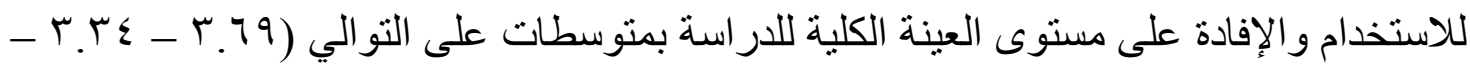

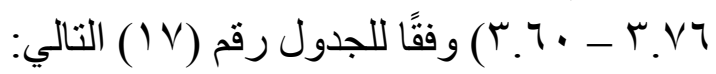

جدول (IV) المصادر الإكترونية التي تم استخدمها والإفادة منها

\begin{tabular}{|c|c|c|c|c|c|c|c|c|c|c|c|c|c|}
\hline \multicolumn{3}{|c|}{ مطمات } & \multicolumn{3}{|c|}{ معلمين } & \multicolumn{3}{|c|}{ طبة إنث } & \multicolumn{3}{|c|}{ طبة نكور } & \multirow{2}{*}{\multicolumn{2}{|c|}{ المصلدر المستخلمة الثراسة }} \\
\hline الأرميية & معيري & متوسط & الأهميبة & معيلري & متوسط & الأهمية & معحراف & متوسط & الأهميبة & معجري & متوبط & & \\
\hline 1 & $1 . \pi 1$ & r.v^ & 1 & 1.99 & $\varepsilon . Y \varepsilon$ & $r$ & $1 . r$. & 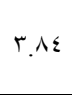 & $r$ & $1 . r r$ & $r .9 \varepsilon$ & 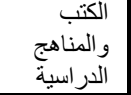 & 1 \\
\hline$\circ$ & $1 . r$ & $r .00$ & $r$ & $\cdot .9 \varepsilon$ & $\varepsilon .11$ & 7 & $1 . \Sigma V$ & r.AT & $\wedge$ & $1 . \varepsilon \varepsilon$ & $r . r u$ & الكتب & $r$ \\
\hline 9 & $1.0 \varepsilon$ & r.Ar & $\wedge$ & $1 . r 1$ & $r . \wedge$ & 9 & T.YT & $r_{.} \cdot \cdot$ & v & 1.87 & T.rv & العربية & $r$ \\
\hline$\wedge$ & $1 . \Gamma \Lambda$ & r.AT & 1 & $1 . r 1$ & $r . r T$ & 1. & $1 . \varepsilon \varepsilon$ & 1.94 & 1. & $1 . r \Lambda$ & r.79 & الأجنبية & $\varepsilon$ \\
\hline$\varepsilon$ & $1 . \varepsilon r$ & r.. & $\varepsilon$ & ع & T.TV & $\varepsilon$ & $1 . r \wedge$ & $r .71$ & $\varepsilon$ & $1 . r^{\prime}$ & rT. & 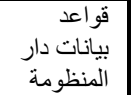 & 。 \\
\hline 1. & I.v. & r.v. & 1. & 1.00 & $r .$. & V & 1.04 & r.Tr & 9 & $1 . \leqslant 7$ & r.10 & |الدوريات & 7 \\
\hline 1 & $1.7 \pi$ & r.or & 9 & 1.09 & $r . \cdot \varepsilon$ & 0 & 1.87 & $\Gamma . \Gamma \varepsilon$ & 0 & 1.50 & $r . \varepsilon r$ & 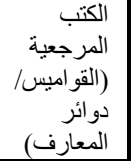 & V \\
\hline v & $1.0 \varepsilon$ & $r .11$ & 0 & א & $r .77$ & $\wedge$ & $1.0 \mathrm{~V}$ & r.ov & 1 & 1.89 & r. ¿. & |بريتانكا & $\wedge$ \\
\hline r & 1.71 & $r .7 \pi$ & v & 1.00 & 5.11 & 1 & $1 . r 1$ & $\varepsilon . r q$ & 1 & I.rT & $r .97$ & قاتنوات & 9 \\
\hline$r$ & $1 . \leqslant 0$ & r.7. & $r$ & 1.r. & $r . v 4$ & $r$ & 1.174 & $\Gamma . \Gamma \varepsilon$ & $r$ & $1.0 r$ & $r .79$ & ناتشيونال & 1. \\
\hline
\end{tabular}

و هذا يتفق مع دافع التفاعل مع الصوت و الحركة التي تتميز بها المصادر الإلكترونية داخل بنك المعرفة في كونه يشكل الدافع الثاني مباشرة المفضل لدى الطلبة "الذكور و الإناث" ويبرز

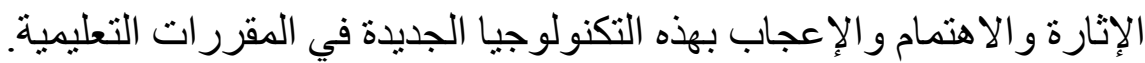

وتتربع قو اعد بيانات دار المنظومة كمصدر رابع في الاستخدام و الإفادة بالنسبة أيضًا للعينة الكلية؛ وذلك نظرًا لثراء هذه القواعد بالعديد من المجالات المتخصصة المختلف التي يلجأ إليها المعلمون، و الطلبة للحصول على غايتهم العلمية مما بدل على ثر ائها العلمي وأهميتها البحثية لهم. ثم توالت عدد من المصادر الإلكترونية التي تم استخدامها والإفادة منها بالنسبة لعينة الدراسة من: الكتب المتخصصة، والدوريات العربية، والكتب المرجعية، وموسوعة بريتانكا الأكاديمية بمتوسطات مختلفة كما يتضح من الجدول. رقم (IV) 


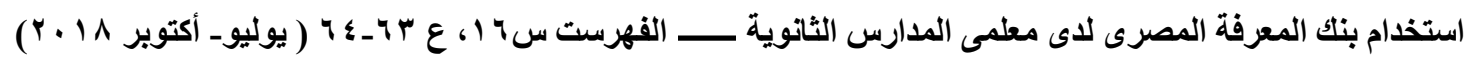

و أخيرًا شكلت الدوريات الأجنبية بالنسبة للطلبة "الذكور، والإناث" المصدر الأخير في الاستخدام والإفادة ، ويشير ذلك إلى أن هناك صعوبات في اللغة عند الغالبية العظمى من الطلبة

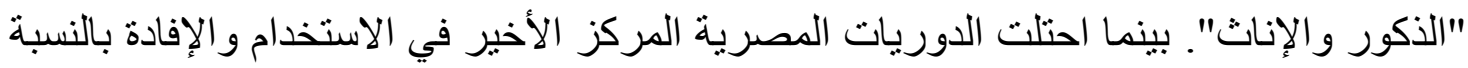
للمعلمين ، ويكمن ذللك في عدم توافر العديد من الدوريات المصرية المتخصصة في مجالات مختلفة في بنك المعرفة المصرين ويكري.

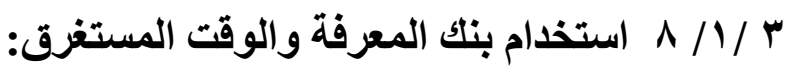
يبين الجدول رقم (1 ( ) إجابات المشاركين على معدل الاستخدام وبناءً على البيانات الواردة فيه يمكن التوصل إلى ما يلي: جدول (1 1 ) معدل الاستخدام والوقت المستغق

\begin{tabular}{|c|c|c|c|c|c|c|c|c|c|}
\hline \multicolumn{2}{|c|}{ معلمات } & \multicolumn{2}{|c|}{ معلمين } & \multicolumn{2}{|c|}{ طلبة إناث } & \multicolumn{2}{|c|}{ طلبة ذكوف } & \multirow{2}{*}{ معدل الاستخدام } & \multirow[t]{2}{*}{5} \\
\hline$\%$ & $\varepsilon$ & $\%$ & $\varepsilon$ & $\%$ & $\varepsilon$ & $\%$ & $\varepsilon$ & & \\
\hline r. & 1 & $9 . r$ & $\varepsilon$ & 1.9 & $\varepsilon$ & $0 . \varepsilon$ & $r$ & يو ميا & 1 \\
\hline $1 I_{.1}$ & 7 & $r \cdot . r$ & $\pi$ & $r \cdot$. & 9 & T.9 & 19 & أسبو عيا & $r$ \\
\hline $\mid r . \wedge$ & 7 & $9 . r$ & $\varepsilon$ & 11.1 & 0 & v. 1 & $\varepsilon$ & كل أسبو عين & $r$ \\
\hline VY.r & $r \varepsilon$ & $01 . r$ & KT & $7 .$. & TV & or. 1 & $\Gamma$. & شهريا & $\varepsilon$ \\
\hline $1 \ldots$ & $\varepsilon V$ & $1 \ldots$ & $\varepsilon r$ & $1 \cdots$ & $T \varepsilon$ & $1 \ldots$ & 07 & الإجمالي & \\
\hline
\end{tabular}

أصبحت الإفادة من بنك المعرفة المصري نشكل جزءًا من النشاط الثهري لعينة الدراسة

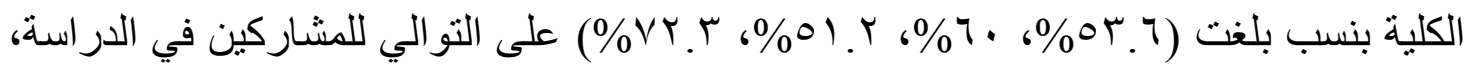

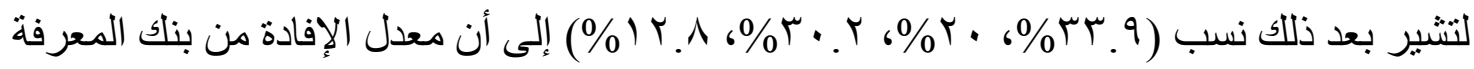

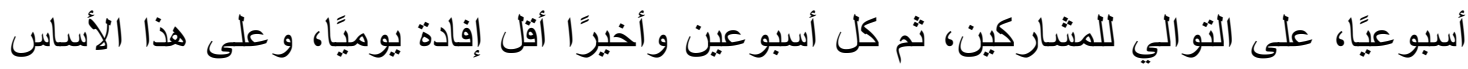

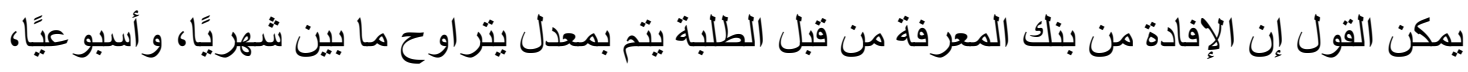
وكل أسبو عين، ويوميًا.

أما الوقت الذي تستغرقه العينة في الإفادة من بنك المعرفة المصري فيمكن القول إنه لا

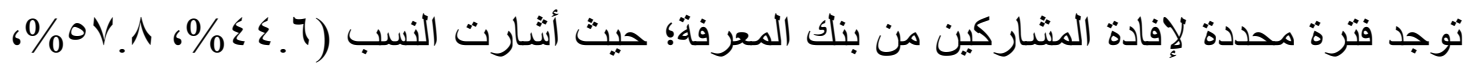

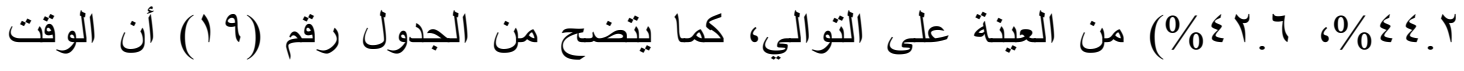
المستغرق في الإفادة غير محدد بفترة زمنية، أما عند تحديد باقي العينة لفترة زمنية محددة، فقد مناف

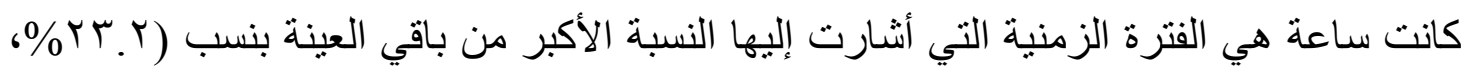

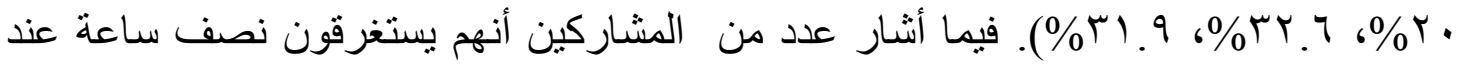

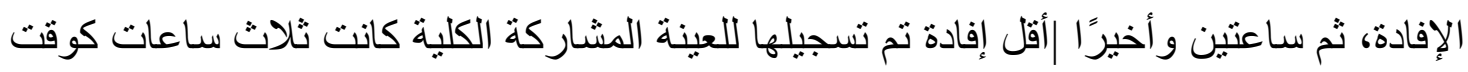
مستغرق عند التعامل مع بنك المعرفة، 
جدول (9 (1) الوقت المستغرق في الاستخدام والإفادة

\begin{tabular}{|c|c|c|c|c|c|c|c|c|c|}
\hline \multicolumn{2}{|c|}{ مطلمات } & \multicolumn{2}{|c|}{ مطمين } & \multicolumn{2}{|c|}{ طلة إناث } & \multicolumn{2}{|c|}{ طلبة نكور } & \multirow{2}{*}{ الوقت المستغرق عينة الدراسة } & \multirow[t]{2}{*}{$\overline{5}$} \\
\hline$\%$ & $\varepsilon$ & $\%$ & $\varepsilon$ & $\%$ & $\varepsilon$ & $\%$ & $\varepsilon$ & & \\
\hline $1 \leq .9$ & V & 11.7 & 0 & 10.7 & v & 17.1 & 9 & نصف ساعة & 1 \\
\hline 51.9 & 10 & r.T & $1 \leq$ & $r \cdot . \cdot$ & 9 & rT.Y & $1 \pi$ & ساعة & $r$ \\
\hline $1 . .7$ & 0 & $9 . r$ & $\varepsilon$ & T.. & $r$ & $1 T_{0}$ & $\mathrm{v}$ & ساعتان & $r$ \\
\hline- & - & r.r & 1 & - & - & $r .7$ & $r$ & ثلاث ساعات & $\varepsilon$ \\
\hline$\varepsilon Y . T$ & $r$. & $\overline{\varepsilon \varepsilon . Y}$ & 19 & or.A & $r 4$ & $\varepsilon \Sigma .7$ & ro & فترة غير محددة & 0 \\
\hline $1 \ldots$ & $\varepsilon V$ & $1 \ldots$ & $\varepsilon r$ & $1 \ldots$ & $\leqslant 0$ & $1 \ldots$ & 07 & الإجمالي & \\
\hline
\end{tabular}

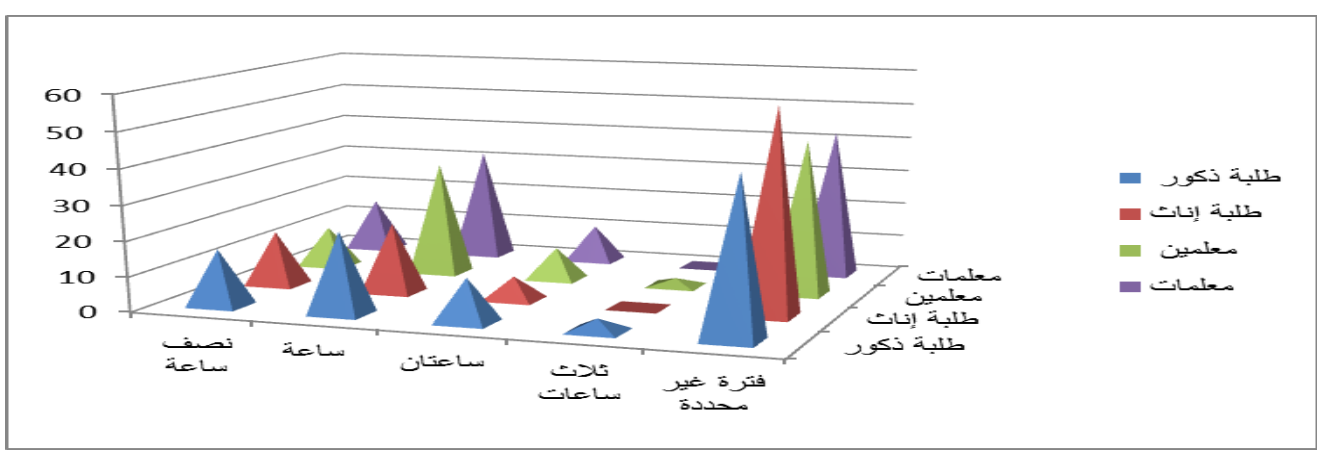

شكل ( ) الوقت المستغرق في الاستخدام والإفادة

r / / 9 لغة المصادر التي تفيد منها:

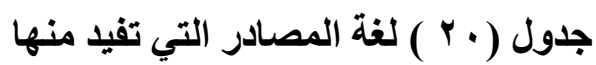

\begin{tabular}{|c|c|c|c|c|c|c|c|c|c|}
\hline \multicolumn{2}{|c|}{ مطمات } & \multicolumn{2}{|c|}{ مطلمين } & \multicolumn{2}{|c|}{ طلبة إناث } & \multicolumn{2}{|c|}{ طلبة نكور } & \multirow{2}{*}{ لغة المصادر عينة الدراسة } & \multirow[t]{2}{*}{ م } \\
\hline$\%$ & $\varepsilon$ & $\%$ & $\varepsilon$ & $\%$ & $\varepsilon$ & $\%$ & $\varepsilon$ & & \\
\hline$\vee \wedge . \vee$ & $r v$ & $\Lambda \wedge . \varepsilon$ & $\mu \wedge$ & 90.7 & $\varepsilon r$ & $1 \ldots$ & 07 & العربية & 1 \\
\hline Yo.0 & Ir & rV.r & 17 & $r \cdot$. & 9 & ro. & $1 \varepsilon$ & الانجليزية & r \\
\hline$\varepsilon . r$ & $r$ & - & - & - & - & - & - & الفرنسية & $\Gamma$ \\
\hline
\end{tabular}

يشير الجدول رقم (·r ) إلى لغات المصادر الإلكترونية التي أشار المشاركون إلى إفادتهم

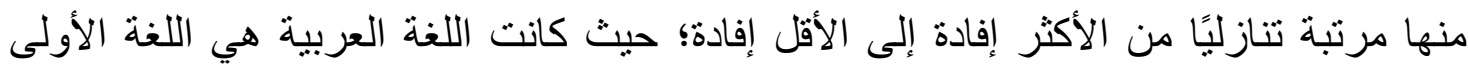
للمصادر الإلكترونية التي يفيد منها المشاركون في الدراسة ككل. ويتأكد ذلك من النسب الإنب المرتفعة

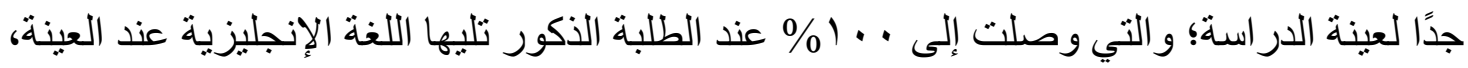
ويأتي هذا كنتيجة منطقية تتوافق مع الدوريات الأجنبية التي احتلت المركز الأخير في المصادر

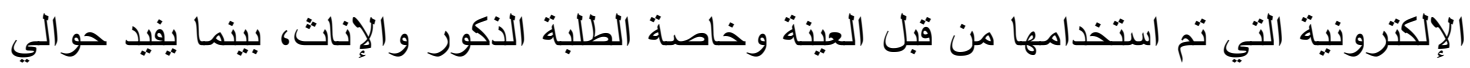

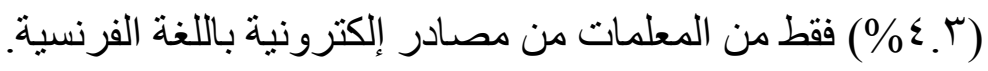




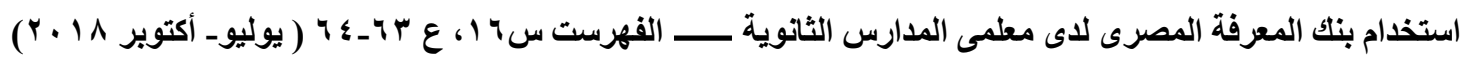

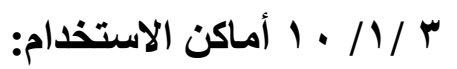

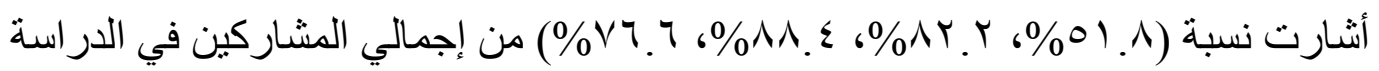

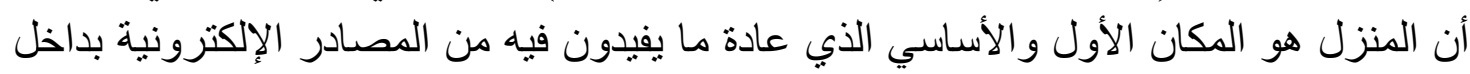

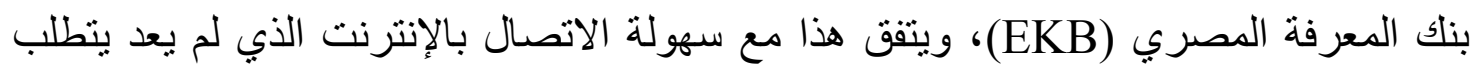

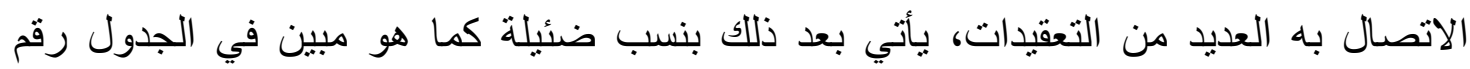

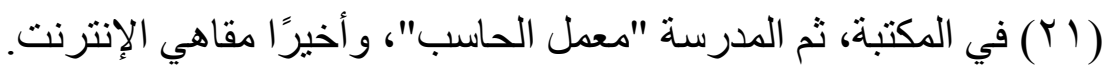

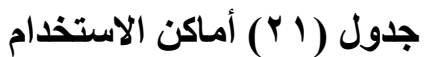

\begin{tabular}{|c|c|c|c|c|c|c|c|c|c|}
\hline \multicolumn{2}{|c|}{ مطمات } & \multicolumn{2}{|c|}{ مطمين } & \multicolumn{2}{|c|}{ طلبة إناث } & \multicolumn{2}{|c|}{ طلبة ذكور } & \multirow{2}{*}{ أماكم الاستخدام } & \multirow[t]{2}{*}{ 5 } \\
\hline$\%$ & $\varepsilon$ & $\%$ & $\varepsilon$ & $\%$ & $\varepsilon$ & $\%$ & $\varepsilon$ & & \\
\hline 1.7 & 0 & V.. & r & $1 V .1$ & $\Lambda$ & 1.9 & 0 & المدرسة & 1 \\
\hline $14 . \wedge$ & 7 & r.rץ & 1. & Tr. & 1. & I & $\Lambda$ & المكتبة & $r$ \\
\hline VI. 7 & דו & $\Lambda \wedge . \Sigma$ & rᄉ & Ar. & rv & r.t & $\varepsilon 1$ & البيت & $r$ \\
\hline- & - & $\varepsilon . V$ & $r$ & - & - & r.7 & $r$ & مقاهي الانترنت & $\varepsilon$ \\
\hline
\end{tabular}

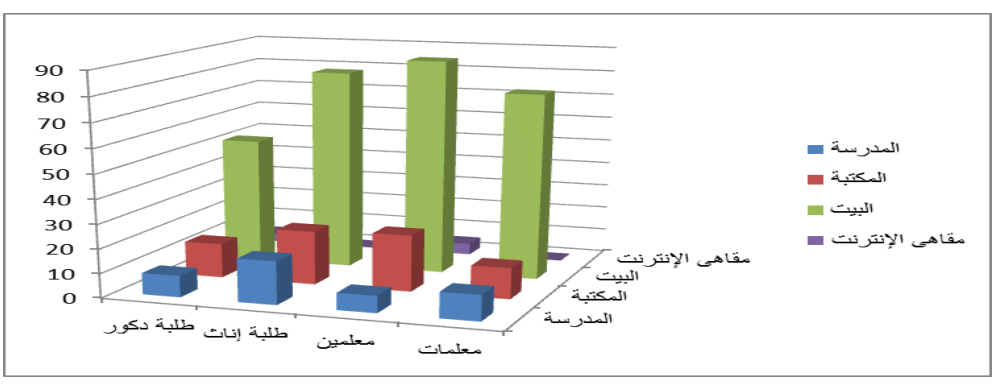

شكل (•) أماكن الاستخدام

\section{ب/ / / 1 مدى تلبية الاحتياجات المعلوماتية:}

و عن مدى تلبية الاحتياجات المعلوماتية يشير الجدول رقم (Yr) إلى أن الغالبية العظمى من

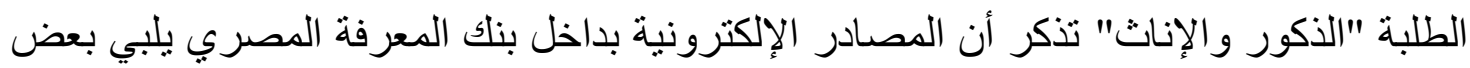

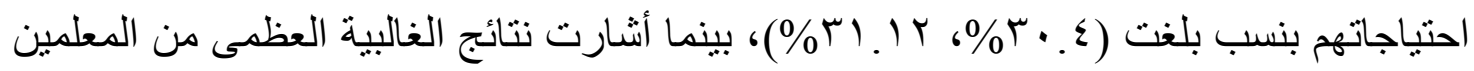

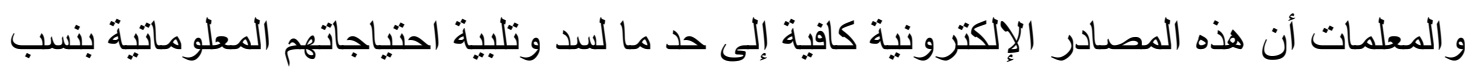

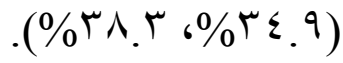


جدول (Yr ) مدى تلبية الاحتياجات المعلوماتية

\begin{tabular}{|c|c|c|c|c|c|c|c|c|c|}
\hline \multicolumn{2}{|c|}{ معلمات } & \multicolumn{2}{|c|}{ معثمين } & \multicolumn{2}{|c|}{ طلبة إناث } & \multicolumn{2}{|c|}{ طلبة ذكور } & \multirow{2}{*}{ تلبية الاحتياجات المعلوماتية الراسة } & \multirow[t]{2}{*}{5} \\
\hline$\%$ & $\varepsilon$ & $\%$ & $\varepsilon$ & $\%$ & $\varepsilon$ & $\%$ & $\varepsilon$ & & \\
\hline r. & 1 & $1 \leqslant$. & 7 & $r \leqslant . \varepsilon$ & 11 & $1 \pi .0$ & V & كافي لجميع احتياجات & 1 \\
\hline 19.1 & 9 & $17 . r$ & V & $r \leqslant . \varepsilon$ & 11 & rA. ${ }^{\top}$ & 17 & كافي لمعظم & $r$ \\
\hline rᄉ.r & 11 & $r \leqslant . q$ & 10 & Ir.r & 7 & YI. & Ir & كافي إلى حد ما & $r$ \\
\hline ro. 0 & ir & $r \cdot r$ & 14 & ए.. & $1 \leq$ & $r \cdot . \Sigma$ & IV & كافي لبعض & $\varepsilon$ \\
\hline $1 \leq .9$ & v & $\varepsilon . V$ & $r$ & 7.. & $r$ & $v .1$ & $\varepsilon$ & غير كافي & 0 \\
\hline $1 \ldots$ & $\varepsilon V$ & $1 \ldots$ & $\varepsilon r$ & $1 \ldots$ & $\leqslant 0$ & $1 \ldots$ & 07 & & \\
\hline
\end{tabular}

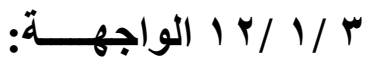

جدول ( Yrr) مدى تميز الواجهة التعامل والتشغيل بسهولة الاستخدام

\begin{tabular}{|c|c|c|c|c|c|c|c|c|c|}
\hline \multicolumn{2}{|c|}{ معلمات } & \multicolumn{2}{|c|}{ مطمين } & \multicolumn{2}{|c|}{ طلبة إناث } & \multicolumn{2}{|c|}{ طلبة ذكور } & \multirow{2}{*}{ واجهة التعامل عينة الدر اسة } & \multirow[t]{2}{*}{ r } \\
\hline$\%$ & $\varepsilon$ & $\%$ & $\varepsilon$ & $\%$ & $\varepsilon$ & $\%$ & $\varepsilon$ & & \\
\hline $1 V_{.}$. & $\Lambda$ & $9 . r$ & $\varepsilon$ & $1 \pi . r$ & 7 & $1 \varepsilon . r$ & $\wedge$ & سهلة جدا & 1 \\
\hline r.r & IV & $\varepsilon \varepsilon . Y$ & 19 & $\varepsilon \varepsilon . \varepsilon$ & $r$. & $\varepsilon \wedge . r$ & $r V$ & سهلة & r \\
\hline$r \varepsilon$. & 17 & r9.0 & IV & $r 0.7$ & 17 & r.. & 11 & الى حد ما & $\mu$ \\
\hline $1 . .7$ & 0 & $\varepsilon . V$ & r & 7. V & $\mu$ & $0 . \varepsilon$ & r & صعبة & $\varepsilon$ \\
\hline$r .1$ & 1 & r.r & 1 & - & - & & - & صعبة جدا & 0 \\
\hline $1 \ldots$ & $\leqslant V$ & $1 \ldots$ & $\varepsilon r$ & $1 \ldots$ & $\leqslant 0$ & $1 \ldots$ & 07 & الي & \\
\hline
\end{tabular}

يوضح الجدول رقم (YT) مدى تميز واجهة التعامل والتشغيل الخاصة ببنك المعرفة

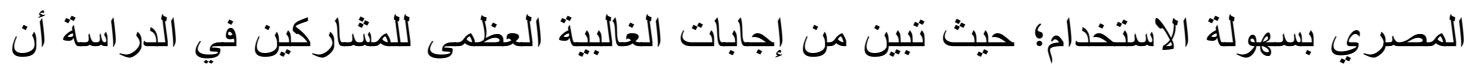

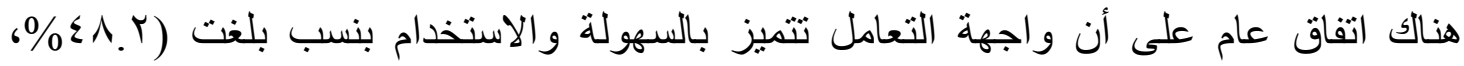

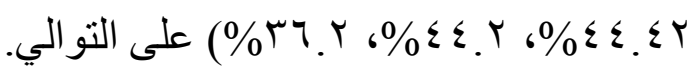

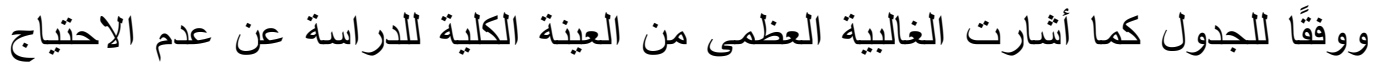

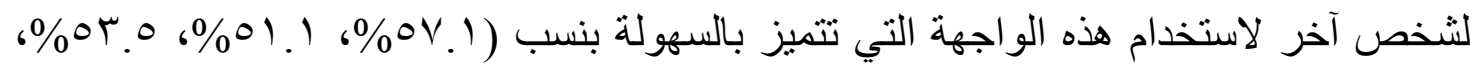

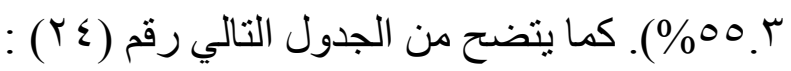

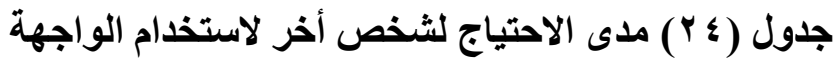

\begin{tabular}{|c|c|c|c|c|c|c|c|c|c|}
\hline \multicolumn{2}{|c|}{ مطمات } & \multicolumn{2}{|c|}{ مغلمين } & \multicolumn{2}{|c|}{ طلبة إناث } & \multicolumn{2}{|c|}{ طلبة نكور } & \multirow{2}{*}{ استخدام الو اجهة عينة اللراسة } & \multirow[t]{2}{*}{ م } \\
\hline$\%$ & $\varepsilon$ & $\%$ & $\varepsilon$ & $\%$ & $\varepsilon$ & $\%$ & $\varepsilon$ & & \\
\hline$\varepsilon \varepsilon . V$ & YI & $\leqslant 7.0$ & $r$. & $\varepsilon \wedge .9$ & $r Y$ & $\varepsilon r .9$ & $r \xi$ & نعم & 1 \\
\hline $00 . r$ & $r 4$ & or.o & rT & 01.1 & $r \mu$ & ov.1 & Tr & $\bar{\gamma}$ & $r$ \\
\hline $1 \ldots$ & $\varepsilon V$ & $1 \ldots$ & $\varepsilon r$ & $1 \ldots$ & $\leqslant 0$ & $1 \ldots$ & 07 & & \\
\hline
\end{tabular}




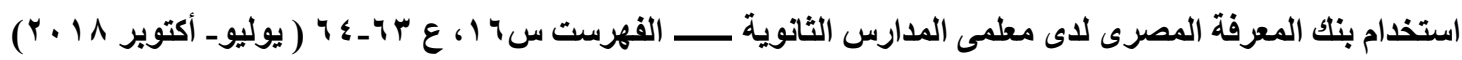

و هنالك اتفاق عام من المشاركين في الدر اسة حول شعور هم بالرضا إلى حد ما، و انطباعهم

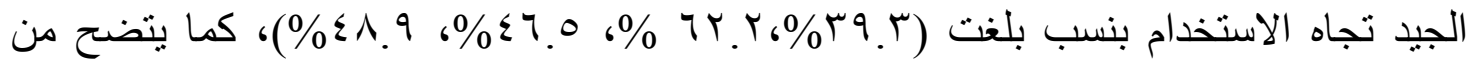

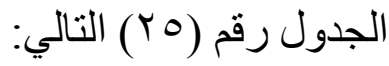

جدول (0) مدى الثعور بالرضا والانطباع الجيد تجاه الحاسب

\begin{tabular}{|c|c|c|c|c|c|c|c|c|c|}
\hline \multicolumn{2}{|c|}{ معمات } & \multicolumn{2}{|c|}{ مطلمين } & \multicolumn{2}{|c|}{ طلبة إناث } & \multicolumn{2}{|c|}{ طلبة ذكور } & \multirow{2}{*}{ الثشعور بالرضا عبنة الدراسة } & \multirow[t]{2}{*}{ م } \\
\hline$\%$ & $\varepsilon$ & $\%$ & $\varepsilon$ & $\%$ & $\varepsilon$ & $\%$ & $\varepsilon$ & & \\
\hline r. & 1 & $9 . r$ & $\varepsilon$ & TY.Y & 1. & $1 T_{0}$ & v & كثيرًا جدًا & 1 \\
\hline$\varepsilon Y . T$ & $r$. & ד.r. & $1 \varepsilon$ & r.r & 7 & ro.V & $r$. & كثيرًا & r \\
\hline$\leqslant 1.9$ & $r$ & $\leqslant 7.0$ & $r$. & $T r . r$ & rA & rq.r & rr & إلى حدا ما & $r$ \\
\hline$\varepsilon . \mu$ & $r$ & $9 . r$ & $\varepsilon$ & $r . r$ & 1 & $\wedge .9$ & 0 & نادرًا & $\varepsilon$ \\
\hline Y. 1 & 1 & $r . r$ & 1 & - & $\cdot$ & r.o & r & أبدًا & 0 \\
\hline $1 \ldots$ & $\leqslant V$ & $1 \ldots$ & $\varepsilon$ & $1 \ldots$ & $\leqslant 0$ & $1 \ldots$ & 07 & الإجمالي & \\
\hline
\end{tabular}

r / / / ا التدريب حول التفعيل والاستخدام:

تظهر إجابات المشاركين حول الحصول على التدريب وتفعيل استخدام بنك المعرفة المصري (EKB) كما يوضحها الجدول رقم (Yo) أن القاعدة العريضة من المشاركين تم

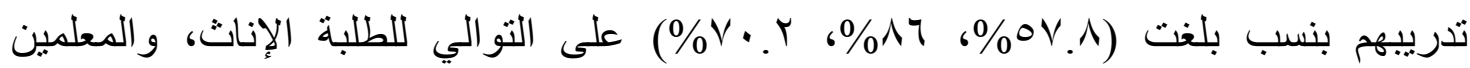

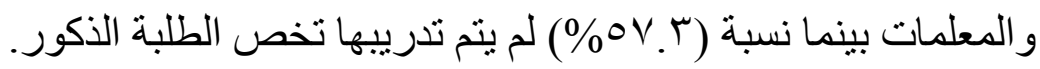

\begin{tabular}{|c|c|c|c|c|c|c|c|c|c|}
\hline \multicolumn{2}{|c|}{ معلمات } & \multicolumn{2}{|c|}{ مطفين } & \multicolumn{2}{|c|}{ طلبة إناث } & \multicolumn{2}{|c|}{ طلبة ذكور } & \multirow{2}{*}{ التدريب و التقعيل عبنة الدر اسة } & \multirow[t]{2}{*}{ م } \\
\hline$\%$ & $\varepsilon$ & $\%$ & $\varepsilon$ & $\%$ & $\varepsilon$ & $\%$ & $\varepsilon$ & & \\
\hline$V \cdot . r$ & rr & ᄉт. & $r v$ & $0 V .1$ & $r T$ & $\varepsilon r . q$ & rs & نعم & 1 \\
\hline r9.1 & $1 \leq$ & $1 \varepsilon$. & 7 & $\varepsilon Y, Y$ & 19 & ov.1 & Tr & $\bar{y}$ & $T$ \\
\hline $1 \ldots$ & $\Sigma V$ & $1 \ldots$ & $\varepsilon r$ & $1 \ldots$ & $\leqslant 0$ & $1 \ldots$ & 07 & الإجمالي & \\
\hline
\end{tabular}

جدول ( צ ץ) التدريب حول التفعيل والاستخدام 
ץ / / \& 1 أسباب عدم الحصول على دورات تدريبية حول التفعيل والاستخدام: جذول (YV أسباب عدم الحصول على دورات تدريبية حول التفعيل والاستخدام

\begin{tabular}{|c|c|c|c|c|c|c|c|c|c|}
\hline \multicolumn{2}{|c|}{ معلمات } & \multicolumn{2}{|c|}{ مغلمين } & \multicolumn{2}{|c|}{ طلبة إناث } & \multicolumn{2}{|c|}{ طلبة ذكور } & \multirow{2}{*}{ 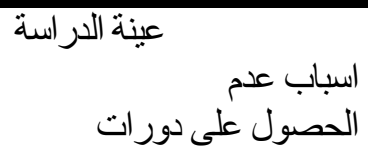 } & \multirow[t]{2}{*}{ م } \\
\hline$\%$ & $\varepsilon$ & $\%$ & $\varepsilon$ & $\%$ & $\varepsilon$ & $\%$ & $\varepsilon$ & & \\
\hline$\varepsilon . \mu$ & $r$ & - & - & $r . r$ & 1 & r.o & r & لا أحتاجها & 1 \\
\hline$\varepsilon . r$ & r & $\varepsilon . \vee$ & r & IV.V & $\wedge$ & 19.7 & 11 & قلة الوقت & $T$ \\
\hline- & - & - & - & - & - & - & - & عو ائق بسبب اللغة & $r$ \\
\hline $1 . r$ & 1. & $9 . \mu$ & $\varepsilon$ & YY.Y & 1. & $r \varepsilon$ & 19 & لا أعلم بمو اعيد إجر ائها & $\varepsilon$ \\
\hline
\end{tabular}

$$
\text { يتبين من الجدول رقم (YV) ماء يلي: }
$$

- جاء عدم العلم بمو اعيد إجراء الدور ات التدريبية في مقدمة أسباب عدم الحصول عليها باتبات بالنسبة

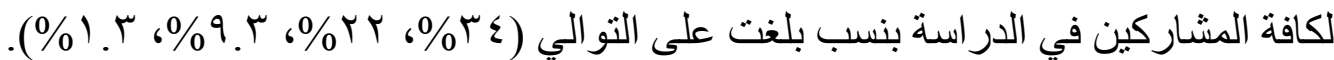
- يليها مباشرة قلة الوقت بالنسبة لكافة المشاركين، ويتبعها عدم الاحتياج الذي شكل نسبة ضئيلة

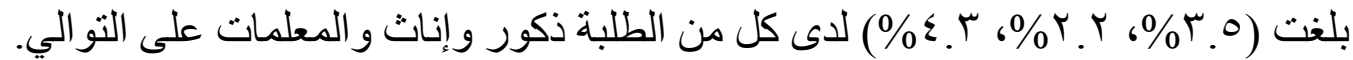
ـ لا تشكل العوائق بسبب اللغة أي دور في عدم الحصول على عذى هذه الدور ات التدريبية التفاعلية. ץ / / / 1 / الجهات التي قامت بعملية التدريب: هنالك العديد من الجهات التي قامت بتدريب المشاركين في الدراسة حيث يتبين من الجدول

جول (Y^) الجهات التي قامت بعملية التدريب للطلاب

\begin{tabular}{|c|c|c|c|c|c|}
\hline \multicolumn{2}{|c|}{ طبة إناث } & \multicolumn{2}{|c|}{ طلبة ذكور } & \multirow[t]{2}{*}{ عينة الاسر اسة } & \multirow[t]{2}{*}{5} \\
\hline$\%$ & $\varepsilon$ & $\%$ & $\varepsilon$ & & \\
\hline- & - & r). & IT & أخصائي المكتبة في مدرسة الإبر اهيمية للبنين & 1 \\
\hline- & - & $1 . . v$ & 7 & معمل علم الأحباء في مدرسة الإبر اهيمية للبنين & $\bar{r}$ \\
\hline- & - & $1 . . v$ & 7 & أخصائي المكتبة في مدرسة شبرا الثانوية للبنين & $\bar{r}$ \\
\hline 10.7 & $\mathrm{~V}$ & - & - & أخصائية المكتبة في مدرسة حلمية الزيتون - بنات & $\varepsilon$ \\
\hline 11.1 & 0 & - & - & أخصائية المكتبة في مدرسة المعصرة - بنات & 0 \\
\hline$r \cdot . \cdot$ & 9 & - & - & أخصائية المكتبة في مدرسة الزمالك ع. ث - بنات & 7 \\
\hline 11.1 & 0 & - & - & أخصائية المكتبة في مدرسة الثهيد أحمد عبد الباسط - بنات & $\mathrm{V}$ \\
\hline ov. . & $r \tau$ & $\varepsilon r . \wedge$ & $r \xi$ & 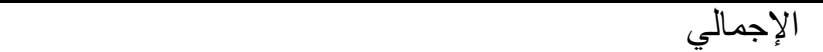 & \\
\hline
\end{tabular}




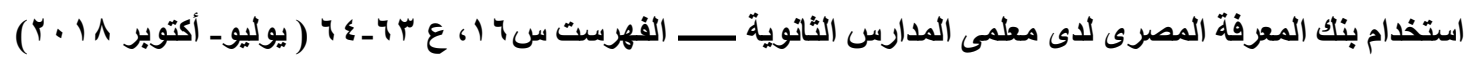

إن الغالبية العظمى من الطلبة "الذكور والإناث" تم تدريبهم من خلال أخصائي المكتبات؛ و هذا يشير إلى أن المكتبة المدرسية لها دور هام في هذا التفعيل والاستخدام بالنسبة للطلبة

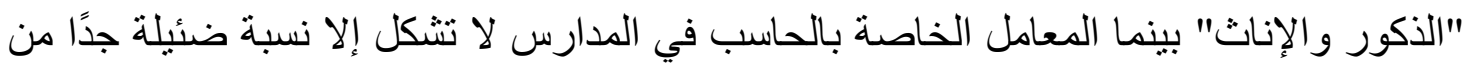
هذا التدريب بلغت (V. • (

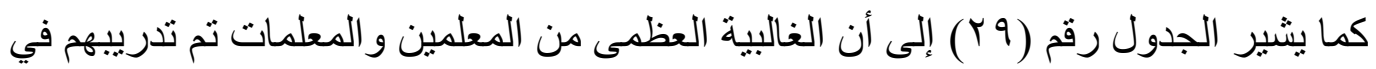

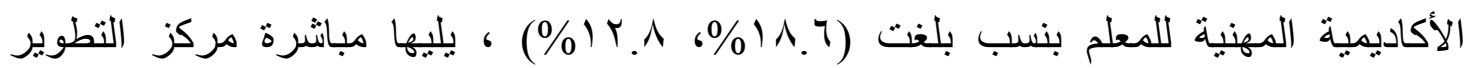

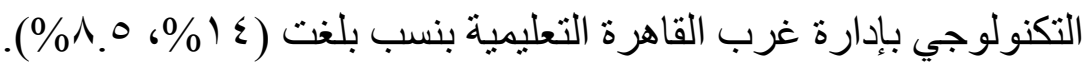
جدول (9 ץ) الجهات التي قامت بعملية التدريب للمعلمين

\begin{tabular}{|c|c|c|c|c|c|}
\hline \multicolumn{2}{|c|}{ مطمات } & \multicolumn{2}{|c|}{ مطلمين } & \multirow{2}{*}{ 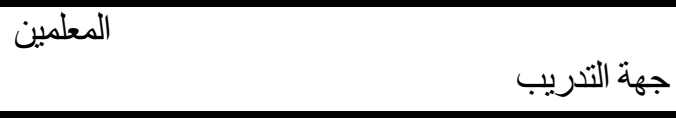 } & \multirow[t]{2}{*}{ 5 } \\
\hline$\%$ & $\varepsilon$ & $\%$ & $\varepsilon$ & & \\
\hline 1.0 & $\varepsilon$ & $9 . \%$ & $\varepsilon$ & إدارة روض الفرج وحدة التدريب & 1 \\
\hline $7 . \varepsilon$ & $r$ & 11.7 & $\wedge$ & الأكاديمية المهنية للمعلم & r \\
\hline $1 . .7$ & 0 & $r \cdot .9$ & 9 & وزارة التربية و التعليم & $r$ \\
\hline 1.0 & $\varepsilon$ & $1 \leqslant$. & 7 & التعليمية التطوير التكنولوجي بإدارة غرب القاهرة & $\varepsilon$ \\
\hline 1.0 & $\varepsilon$ & 11.7 & 0 & مركز المعلومات لاظو غلي & 0 \\
\hline $1{ }^{\prime} . \wedge$ & 7 & 11.7 & 0 & مدرسة الزمالك ع. ث - بنات & 7 \\
\hline$\varepsilon . r$ & r & & & مدرسة حلمية الزيتون ثُب & V \\
\hline $7 . \varepsilon$ & $r$ & & & مدرسة ز هر اء حلو ان الإعدادية بنين & $\wedge$ \\
\hline$\varepsilon . \mu$ & r & & & مدرسة السباحين التجريبية الثانوية & 9 \\
\hline$V \mu . V$ & ru & 77 & $r v$ & الإجمالي & \\
\hline
\end{tabular}

ب/ / 1 / تقييم مستوى الدورات التدريبية:

تشير نتائج الدر اسة في الجدول رقم (·r) إلى أن هنالك تباين واضح بالنسبة لتقييم مستوى

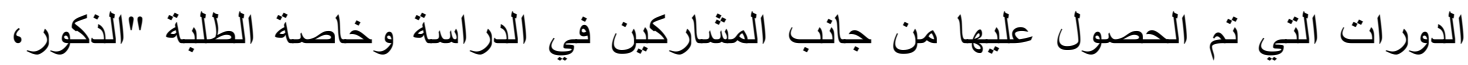
الإناث" و المعلمين ، وبناءً على ذلك نجد أن الغالبية العظمى من الطلبة "الذكور و الإناث" أشاروا

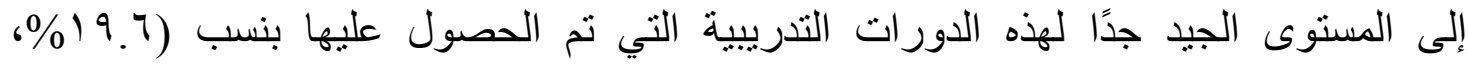
r.r\%\%)، ويكمن ذلك في أخصائي المكتبة المؤهل فنيًا القائم بعملية التدريب و التفعيل. 
جلول ( • (ץ) تقييم مستوى الدورات التدريبية

\begin{tabular}{|c|c|c|c|c|c|c|c|c|c|}
\hline \multicolumn{2}{|c|}{ معلمات } & \multicolumn{2}{|c|}{ معلمين } & \multicolumn{2}{|c|}{ طلبة إناث } & \multicolumn{2}{|c|}{ طلبة ذكور } & \multirow{2}{*}{ مستوى الدورات عينة الدراسة } & \multirow[t]{2}{*}{5} \\
\hline$\%$ & $\varepsilon$ & $\%$ & $\varepsilon$ & $\%$ & $\varepsilon$ & $\%$ & $\varepsilon$ & & \\
\hline- & - & - & - & r & 7 & $1 Y .0$ & v & ممتاز & 1 \\
\hline - & - & $17 . r$ & v & Tr. & 1. & 19.7 & 11 & جيد جذا & $r$ \\
\hline Ir.A & 7 & $1 \leqslant$. & 7 & IV.A & $\wedge$ & $1 . .1 \mathrm{~V}$ & 7 & جيد & $r$ \\
\hline 19.1 & 9 & r.r & 1. & $r . r$ & 1 & - & - & مقبول & $\varepsilon$ \\
\hline rА. & 11 & T.T & $1 \varepsilon$ & Y. & 1 & - & - & لا فائدة منها & 0 \\
\hline $1 \ldots$ & rr & $1 \ldots$ & rV & $1 \ldots$ & $r q$ & $1 \ldots$ & $r \varepsilon$ & الاجمالي & \\
\hline
\end{tabular}

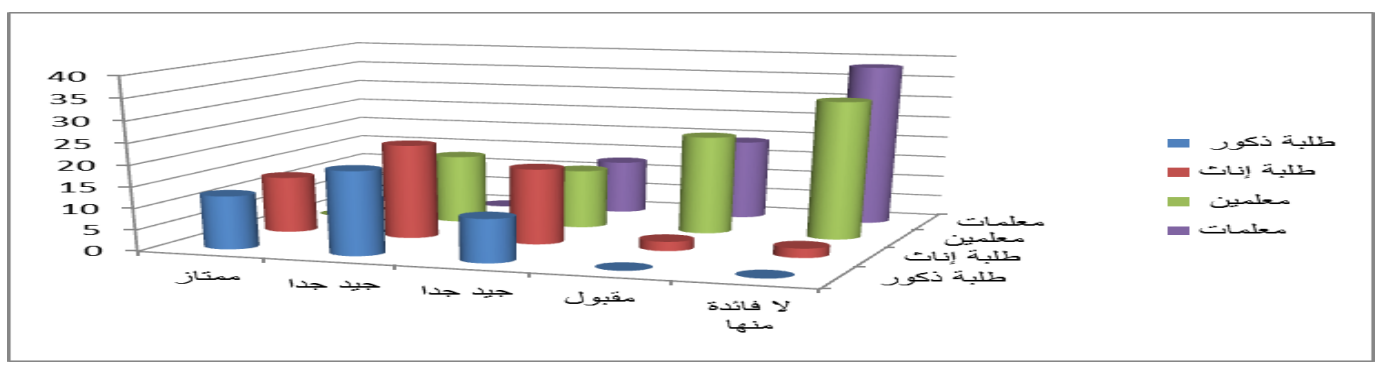

شكل (ד) تقييم مستوى الدورات التدريبية

بينما أثشارت الغالبية العظمى من المعلمين و المعلمات إلى عدم الفائدة من هذه الدور ات بنسبة

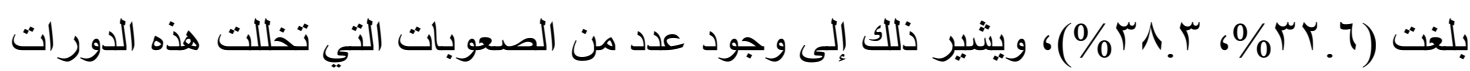
و التي سوف نتعرف عليها من خلال الجدول التالي:

ا / / / معوبات التلريب

جدول ( آم) مدى صعوبات برامج التدريب

\begin{tabular}{|c|c|c|c|c|c|c|c|c|c|}
\hline \multicolumn{2}{|c|}{ معلمات } & \multicolumn{2}{|c|}{ معثين } & \multicolumn{2}{|c|}{ طلبة إناث } & \multicolumn{2}{|c|}{ طلبة ذكور } & عينة الدر اسة & \\
\hline$\%$ & $\varepsilon$ & $\%$ & $\varepsilon$ & $\%$ & $\varepsilon$ & $\%$ & $\varepsilon$ & صعوبات بر امج التدريب & \\
\hline$O V . \varepsilon$ & $r v$ & $\varepsilon \wedge . \wedge$ & YI & TV.A & IV & Y). & Ir & نعم & 1 \\
\hline Ir.A & 7 & r. & 17 & $r \cdot$. & 9 & Y). & ir & y & r \\
\hline $1 \ldots$ & rr & $1 \ldots$ & rv & $1 \ldots$ & YT & $1 \ldots$ & TI & الإجمالي & \\
\hline
\end{tabular}

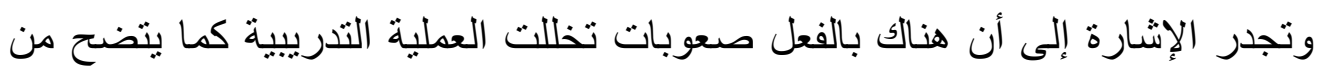

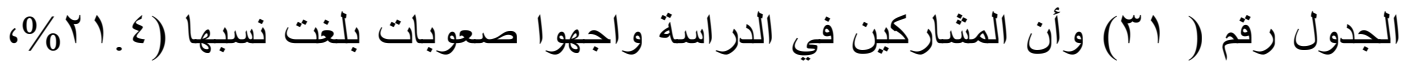

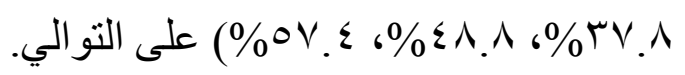




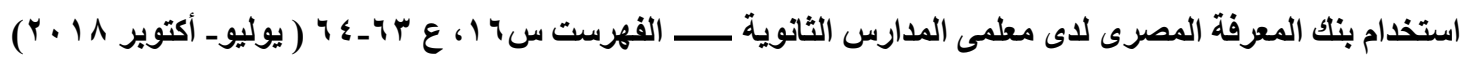

جلول ( T r ) صعوبات التدريب

\begin{tabular}{|c|c|c|c|c|c|c|c|c|c|}
\hline \multicolumn{2}{|c|}{ معلمات } & \multicolumn{2}{|c|}{ معلمين } & \multicolumn{2}{|c|}{ طلبة إناث } & \multicolumn{2}{|c|}{ طلبة ذكور } & \multirow{2}{*}{ صعوبات التدريب عينة الدراسة } & \multirow[t]{2}{*}{ r } \\
\hline$\%$ & $\varepsilon$ & $\%$ & $\varepsilon$ & $\%$ & $\varepsilon$ & $\%$ & $\varepsilon$ & & \\
\hline rI.r & 1. & $q . r$ & $\varepsilon$ & 11.1 & 0 & 1.9 & 0 & كافية الفترة الزمنية للتدريب غير & 1 \\
\hline r৭.^ & $1 \leq$ & $\leqslant 7.0$ & $r$. & Yr. & 1. & 17 & 9 & العقلي غير كاف المخص للنطبيق & $T$ \\
\hline $7 . \varepsilon$ & r & $r \cdot . q$ & 9 & $\wedge .9$ & $\varepsilon$ & 1.1 & 1 & عدم كفاءة المدرب & $r$ \\
\hline $00 . r$ & $r T$ & $\varepsilon \wedge . \wedge$ & YI & ro. 7 & 17 & 18.9 & 1. & 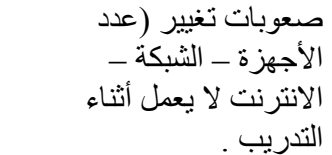 & $\varepsilon$ \\
\hline
\end{tabular}

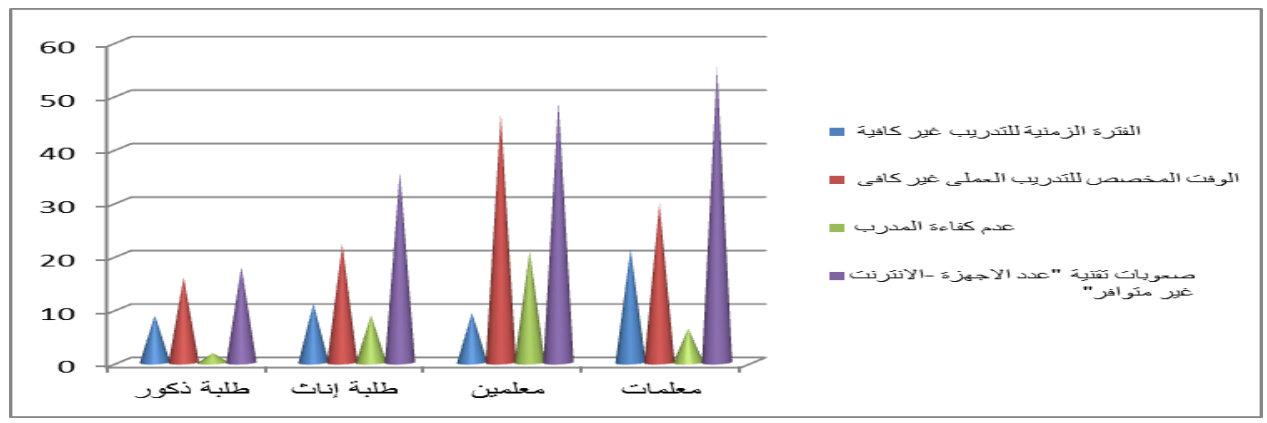

شكل ( 7 ) صعوبات التدريب

كما يشير الجدول رقم (Yr) إلى تنوع هذه الصعوبات وكان لصعوبات التقنية "عدد الأجهزة

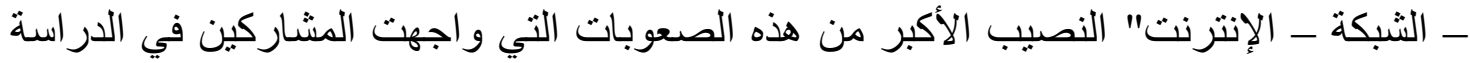

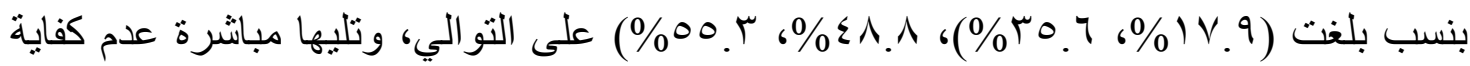
الوقت المخصص للتطبيق العملي بالنسبة للمشاركين، بالإضافة إلى عدم كفاية الفترة الزمنية للتجريب. وبشكل عام عدم كفاءة المدرب القائم على التدريب و التفعيل و الاستخدام.

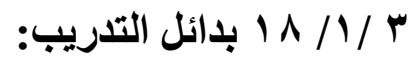

وبناء على ذلك كان هنالك بدائل للتذريب لمواجهة تلك الصعوبات؛ حيث يبين الجدول رقم

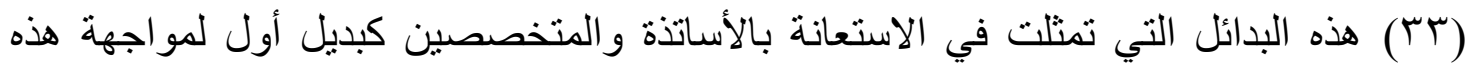

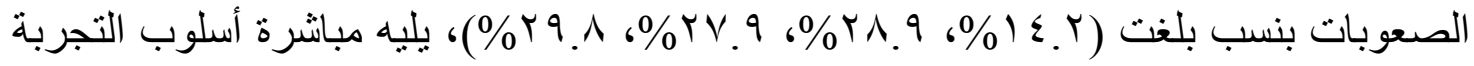
و الخطأ الذي كان ملاذا للمشاركين في الدراسة لمواجهة هذه الصعوبات من أجل التفعيل

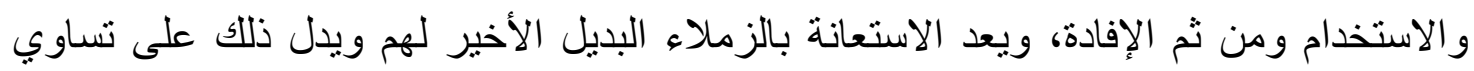
الخبرات، و عدم شيوع تفعيل واستخدام بنك المعرفة المصري في المنظومة التعليمية التي تضم

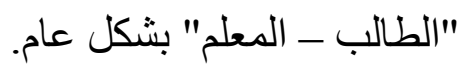


جلول رقم (rr) بدائل التدريب

\begin{tabular}{|c|c|c|c|c|c|c|c|c|c|}
\hline \multicolumn{2}{|c|}{ معلمات } & \multicolumn{2}{|c|}{ مطمين } & \multicolumn{2}{|c|}{ طلبة إناث } & \multicolumn{2}{|c|}{ طلبة ذكور } & \multirow{2}{*}{ البدائل عينة الدر اسة } & \multirow[t]{2}{*}{ 5 } \\
\hline$\%$ & $\varepsilon$ & $\%$ & $\varepsilon$ & $\%$ & $\varepsilon$ & $\%$ & $\varepsilon$ & & \\
\hline$r 9 . \wedge$ & $1 \varepsilon$ & $r V . q$ & ir & r^.q & r & $1 \varepsilon . r$ & $\Lambda$ & الاستعانة بالأساتذة & 1 \\
\hline 19.1 & 9 & $r \cdot .9$ & 9 & r.r & 7 & $1 \cdot . v$ & 7 & الاستعانة بالزملاء & $T$ \\
\hline rT. & 11 & Y0.7 & 11 & 1.1 & $1 \leq$ & 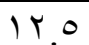 & V & التجربة و الخطاً & $\mu$ \\
\hline
\end{tabular}

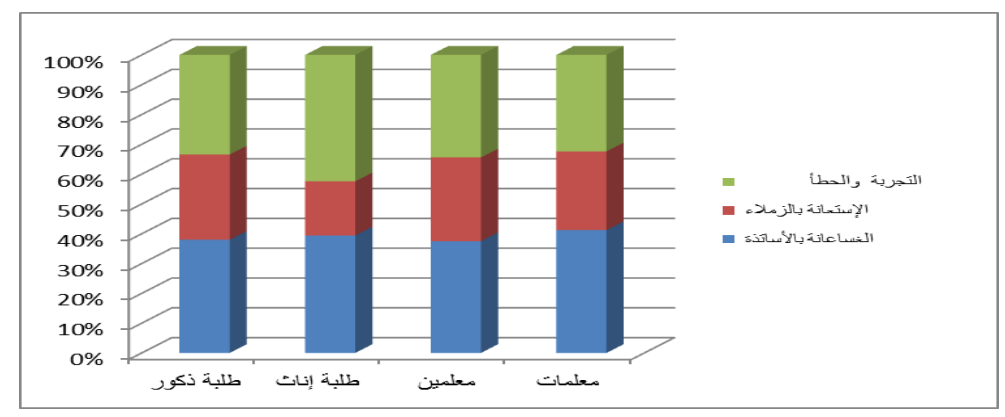

$$
\text { شكل (V) بدائل التدريب }
$$

ץ/ / /9 19 مدى توافر مقومات التعامل مع بنك المعرفة المصري داخل المدارس:

وفيما يتعلق بمدى نوافر مقومات التعامل مع بنك المعرفة المصري داخل المدارس من حيث أجهزة حاسب آلي مزودة بالإنترنت ومختصين مدربين قائمين بعملية التدريس أثنارت نتائج

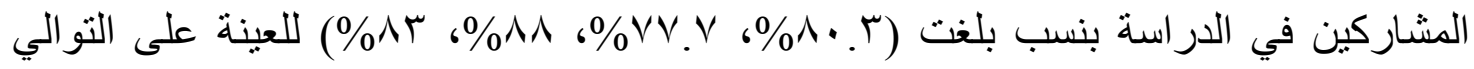

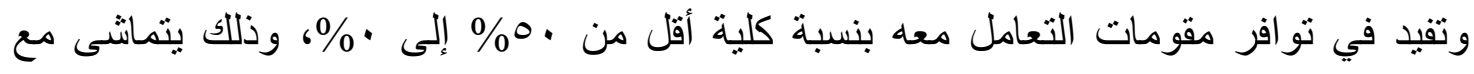
صعوبات التقنية التي واجهت المشاركين في الدراسة، وتم تصنيفها في المرتبة الأولى كما تم

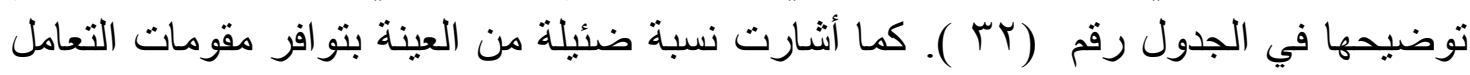

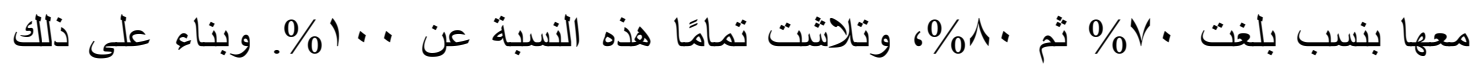

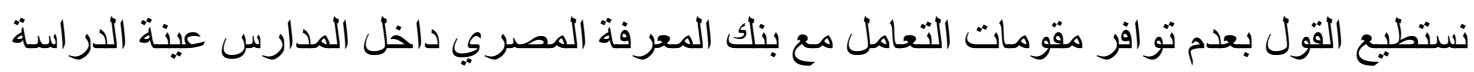
من وجهة نظر كل من الطلبة و المعلمين. 


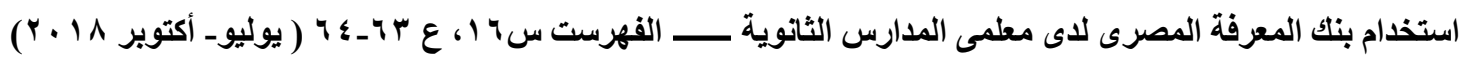

جلول (ع ") مدى توافر مقومات التعامل مع بنك المعرفة المصري

\begin{tabular}{|c|c|c|c|c|c|c|c|c|c|}
\hline \multicolumn{2}{|c|}{ مطمات } & \multicolumn{2}{|c|}{ مطعين } & \multicolumn{2}{|c|}{ طلبة إناث } & \multicolumn{2}{|c|}{ طلبة ذكور } & \multirow{2}{*}{ 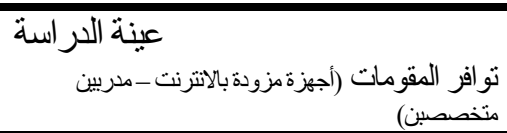 } & \multirow[t]{2}{*}{ r } \\
\hline$\%$ & $\varepsilon$ & $\%$ & $\varepsilon$ & $\%$ & $\varepsilon$ & $\%$ & $\varepsilon$ & & \\
\hline - & - & - & - & - & - & - & - & $\% 1 \ldots$ & 1 \\
\hline 7.1 & $r$ & 9.4 & $\varepsilon$ & 7.7 & $r$ & 1.9 & 0 & $\%$ & $T$ \\
\hline $1 . .7$ & 0 & 11.7 & 0 & 10.0 & $\mathrm{~V}$ & $1 \cdot . V$ & 7 & $\%{ }^{\vee} \cdot$ & $r$ \\
\hline OV.乏 & $r V$ & 00.1 & $r \varepsilon$ & 01.1 & Tr & 00.r & T & اقل من •0\%\% & $\varepsilon$ \\
\hline YO. & IT & Tr.Y & 1. & Y7.T & IT & ro & $1 \varepsilon$ & $\%$ & 0 \\
\hline $1 \ldots$ & TV & $1 \ldots$ & $\varepsilon r$ & $1 \ldots$ & $\leqslant 0$ & $1 \ldots$ & 07 & & الإ. \\
\hline
\end{tabular}

r/ / / • دور المكتبة الرئيسي لتعزيز ورفع الإفادة من بنك المعرفة المصري:

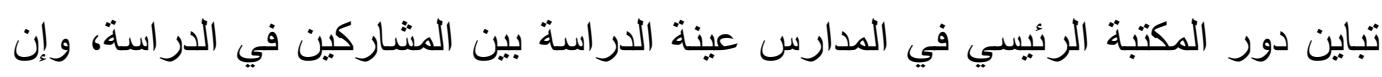

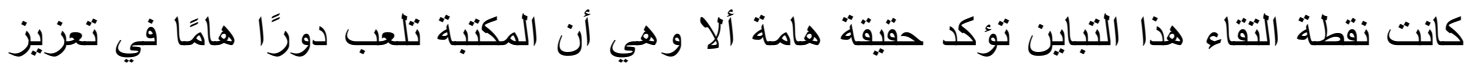

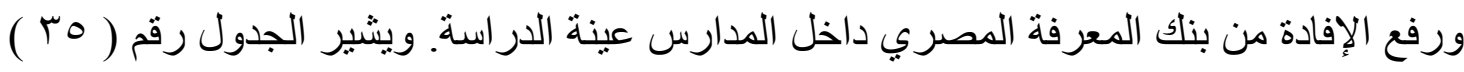

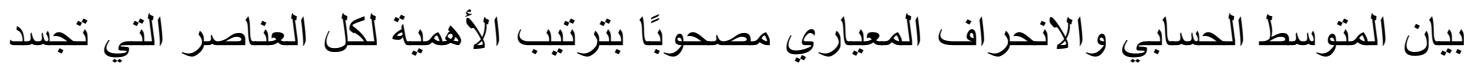
هذا الدور الهام وتعزيز الإفادة من بنك المعرفة، وتصدر هذه العناصر بالنسبة لجميع المشاركين

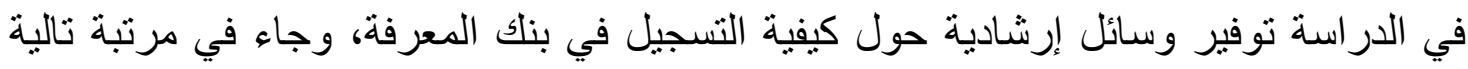

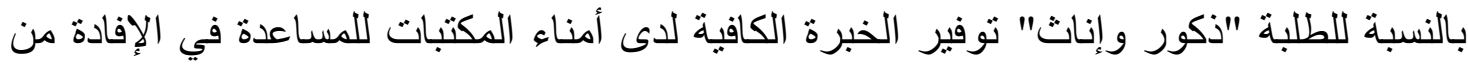

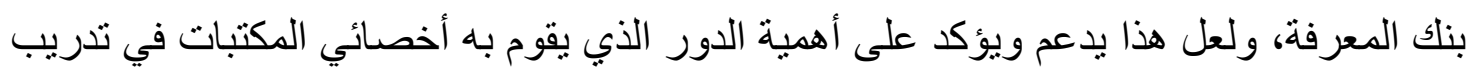

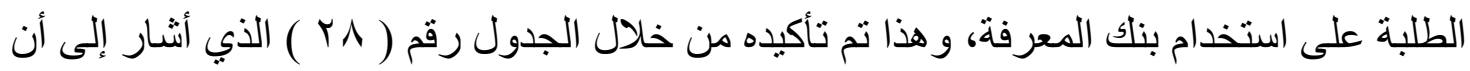
الغالبية العظمى من الطلبة (ذكور، إناث)؛ حيث تم تدريبهح من فبل أخصائي المكتبة ونظرًا لتباين هذه العناصر بين المشاركين فقد كان لأخصائي المكتبة المرتبة الأخيرة بالنسبة للمعلمين و الر ابعة الماته بالنسبة للمعمات، أما بالنسبة لعنصر الإعلام بكل ما هو جديد حول بنك المعرفة قد اتفق الفق عليه

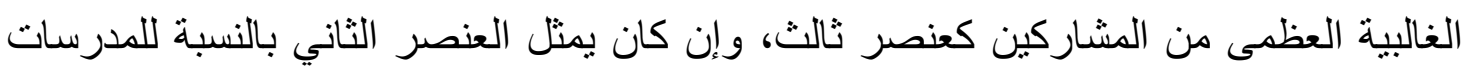
كما هو مبين في الجدول التالي. 


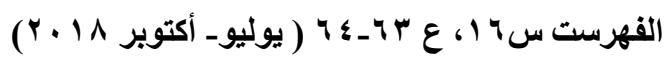

د. نجوى شكرى يمنى أحمد

جلول (ه) دور المكتبة في الإفادة من بنك المعرفة المصري

\begin{tabular}{|c|c|c|c|c|c|c|c|c|c|c|c|c|c|}
\hline \multicolumn{3}{|c|}{ معلمات } & \multicolumn{3}{|c|}{ مطمين } & \multicolumn{3}{|c|}{ طلبة إنث } & \multicolumn{3}{|c|}{ طلبة ذكور } & \multirow{2}{*}{ دور الدراسة } & ? \\
\hline الآهنيبة & معبرافي & متوسط & الأرثية & معباري & متوسط & الآهنيّة & معياري & متوسط & الالاهينية & معباري & متوسط & & \\
\hline r & 1.74 & $r . \leqslant 7$ & $r$ & $1.0 r$ & r.00 & $r$ & $1 . \leqslant V$ & $r . r^{q}$ & $r$ & 1.04 & r. $\varepsilon$. & 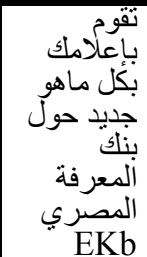 & \\
\hline$r$ & $1 . \leqslant V$ & r. rq & $r$ & 1.71 & $T .7 \varepsilon$ & 7 & $1 . \leqslant 9$ & r.vq & $\varepsilon$ & 1.20 & $r . v$ & 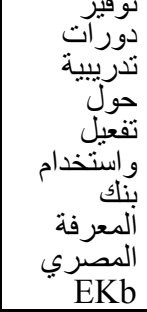 & \\
\hline 0 & $1 . \leqslant 7$ & T.IV & 0 & $1 . \varepsilon r$ & r. $\varepsilon$. & 0 & $1 . r 1$ & r.9v & 7 & 1.47 & r.V4 & 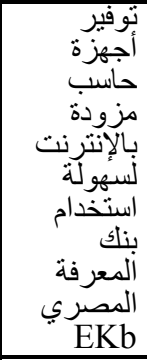 & \\
\hline 1 & $1.0 r$ & r.v & $\varepsilon$ & 1.01 & r.Or & 1 & $1, r)$ & $r .0 \varepsilon$ & $r$ & $1 . \varepsilon \cdot$ & $r . \leqslant \wedge$ & 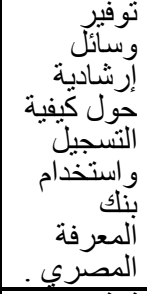 & \\
\hline 1 & $1 . \leqslant 9$ & $r . \wedge$ & 1 & $1 . \varepsilon 9$ & r. . & $\varepsilon$ & $1 . \varepsilon$. & r.91 & 。 & $1 . \varepsilon 9$ & r. .19 & 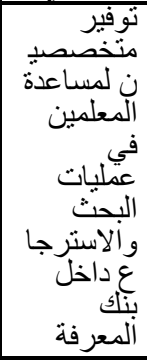 & \\
\hline$\varepsilon$ & $1 . \leqslant 9$ & $r . r T$ & 7 & 1.49 & $r . v$ & r & $1 . r T$ & $r . \leqslant 1$ & 1 & $1 . \varepsilon V$ & $r .79$ & 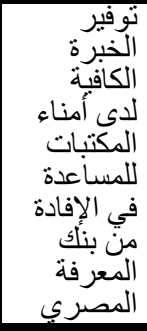 & \\
\hline
\end{tabular}




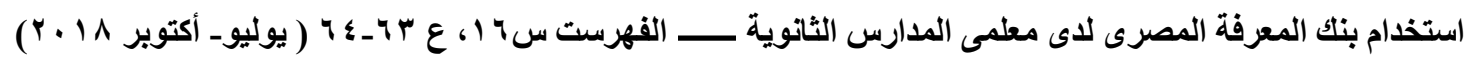

وكان لتوفير الدورات التدريبية حول التفعيل والاستخدام المرتبة الرابعة بالنسبة للطلبة

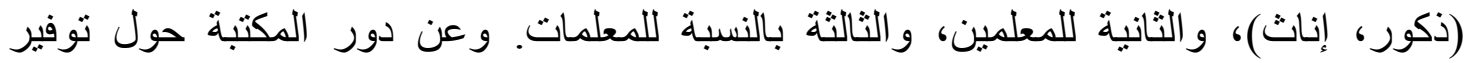

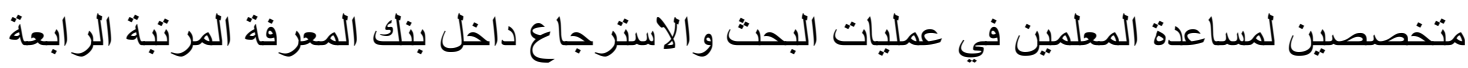

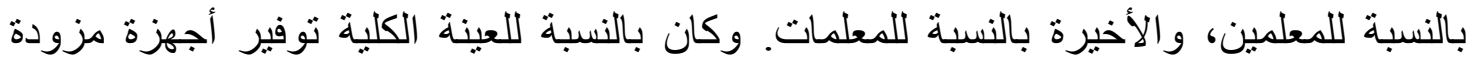

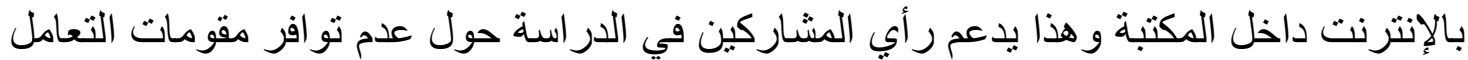

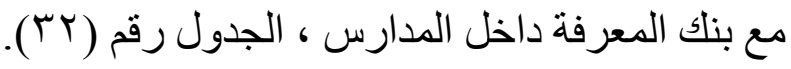

r/ / / ا المعوقات ( الصعوبات ) حول استخدام بنك المعرفة :

على الرغم من أن بنك المعرفة المصري "EKB" يوفر عددًا من المميزات إلا أن هذا لا

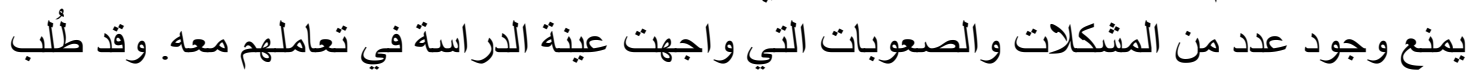

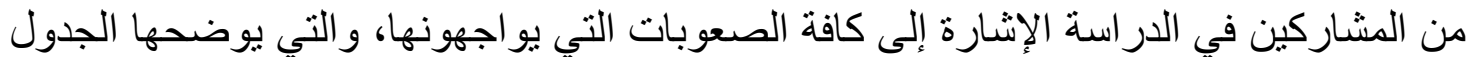

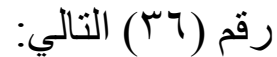

جدول (־َ) المعوقات والمشكلات التي تواجه أفراد عينة الدراسة

\begin{tabular}{|c|c|c|c|c|c|c|c|c|c|c|c|c|c|}
\hline \multicolumn{3}{|c|}{ معلمات } & \multicolumn{3}{|c|}{ مطمين } & \multicolumn{3}{|c|}{ طبة إناث } & \multicolumn{3}{|c|}{ طلبة نكور } & \multirow{2}{*}{ والمشككلات عينة الدراتة } & \multirow[t]{2}{*}{ r } \\
\hline الأهنية & معيراف & متوسط & تالزثيبة & معياري & متوسط & الأهيثية & معيلراف & متوسط & ترتهيب & معيلري & متوسط & & \\
\hline 1 & $1 . r 0$ & $r . \leqslant r$ & 。 & $1 . r 9$ & T.TV & V & 1.71 & r.rv & 9 & $1 . \Gamma \Lambda$ & $r . r$ & 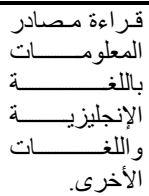 & $T$ \\
\hline 1. & $1 . \varepsilon$. & 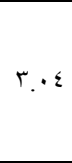 & V & $1 . K \pi$ & r.OT & $\varepsilon$ & 1.71 & $r .70$ & 1 & $1 . \mathrm{r}^{\prime}$ & $r . \leqslant \wedge$ & 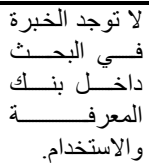 & $\bar{Y}$ \\
\hline Kr & $1 . r$. & r.97 & 1 & 1.10 & r.OV & ir & $1 . r 1$ & r... & 1 & $1 . \Gamma \Lambda$ & $r .19$ & 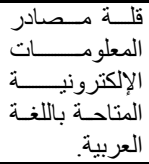 & $\Gamma$ \\
\hline 11 & 1.10 & r... & 9 & $.9 Y$ & r. rq & $r$ & $1 . r V$ & r.Tr & 。 & $1 . \varepsilon V$ & Tצ' & اللمعلومــــــــــــــة & $\varepsilon$ \\
\hline$\pi$ & $1 . \varepsilon r$ & r.TV & Ir & $1 . r 1$ & T.RT & $\wedge$ & $1 . \wedge \varepsilon$ & r.r. & $\wedge$ & $1 . \varepsilon r$ & r.1 & 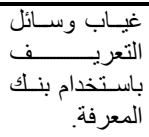 & 0 \\
\hline 0 & 1.7 & $r . \leqslant \wedge$ & 1 & $1 . v$ & $\varepsilon . \cdot T$ & r & 1.01 & r. & $r$ & 1.r4 & r.r & 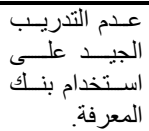 & 7 \\
\hline
\end{tabular}




\begin{tabular}{|c|c|c|c|c|c|c|c|c|c|c|c|c|c|}
\hline$\varepsilon$ & 1.07 & r.or & 1. & $1 . r T$ & T.r. & 11 & l.v. & 5.19 & $\varepsilon$ & $1 . r \Lambda$ & r.r. & 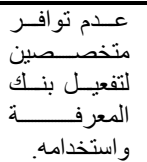 & $\bar{v}$ \\
\hline$r$ & $1 . \leqslant 1$ & $\varepsilon .{ }^{\prime} . \tau$ & r & $(, r)$ & $r .90$ & 9 & $1.0 \mathrm{~V}$ & $r . r q$ & 1. & $1.0 \xi$ & r.9A & 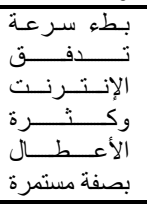 & $\lambda$ \\
\hline r & 1.00 & T. & $\varepsilon$ & $1, r \varepsilon$ & $r . Y \varepsilon$ & 1 & l.r. & r.91 & r & $1 . \varepsilon r$ & r.\& & ضيق الوقت. & 9 \\
\hline$\wedge$ & $1 . \leqslant 0$ & T.TT & 11 & $1 . r \wedge$ & $r . r \mu$ & ir & $1.0 r$ & $r .4$ & 11 & $1 . \varepsilon$ & r.9v & 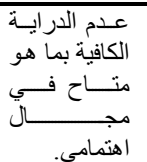 & 1. \\
\hline v & $1, r v$ & T.rT & $\wedge$ & 1.10 & $r . \varepsilon \wedge$ & $1 \varepsilon$ & l.v. & r.A. & 15 & $1, r \varepsilon$ & r.91 & 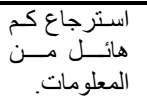 & 11 \\
\hline 9 & $1, r v$ & r.11 & ir & I.rA & r.IV & 。 & $1 . \varepsilon$. & $r . \leqslant 4$ & $1 \varepsilon$ & 1.54 & r. & 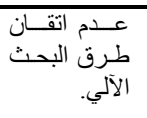 & $T$ \\
\hline $1 \varepsilon$ & I.rr & r.\&) & $1 \varepsilon$ & $1 . r 4$ & $r . r$ & 1. & $1 . \leqslant 1$ & $r . r)$ & V & $1 . \varepsilon r$ & r.10 & 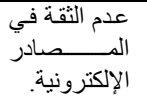 & 15 \\
\hline 1 & 1.15 & $\varepsilon . Y Y$ & $r$ & I.rY & r.AT & 7 & 1.7 & $r . \leqslant r$ & ir & $1, Y \varepsilon$ & r.9v & في العـدـد الكافـي & $1 \varepsilon$ \\
\hline
\end{tabular}

$$
\text { يتبين من الجدول رقم (Tr) ما يلي: }
$$

تعد عدم الخبرة في البحث داخل بنك المعرفة مع ضيق الوقت، بالإضافة إلى عدم التدريب الجيد على استخدام بنك المعرفة، في مقدمه الصعوبات التي تو اجه الطلبة و المعلمين الذكور تليها عدم توافر العدد الكافي من الحواسيب في المدارس بالنسبة للمعلمات كما يوضحها الجدول السابق، ويأتي ذللك كنتيجة طبيعية لعدم تو افر التدريب الجيد من قبل مدربين متخصصين فين وتوفير

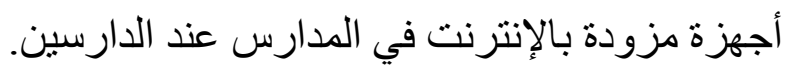
بينما كان عدم إتقان طرق البحث الآلي واسترجاع كنئ كم هائل من المعلومات بالنسبة للطلبة،

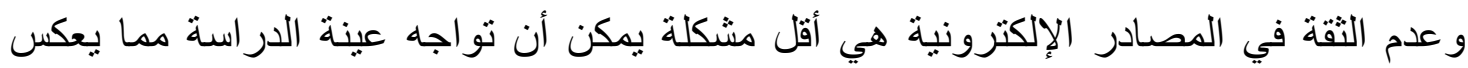
التنوع و التغطية التي يوفرها بنك المعرفة المصرية لمعظم الموضو عات في المجالات المختلفة. r/ / r r آراء ومقترحات العينة حول تحسين سبل الاستخدام والإفادة من بنك المعرفة :

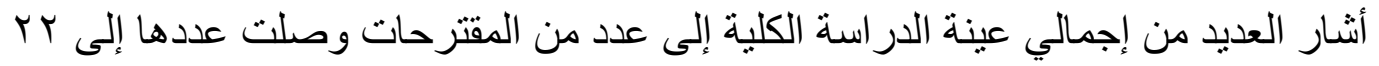

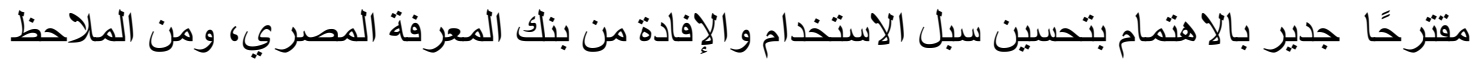
أن هذه الآر اء و المقترحات دارت حول المشكلات التي ترتبط بعدم التدريب الجيد على استخدام بنك المعرفة، وعدم تو افر المتخصصين للتفعيل والإفادة مع عدم تو افر العدد الكافي من الحواسيب 


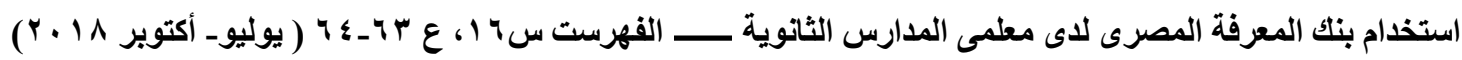

$$
\text { في المدارس. }
$$

وبناء على ذلك يشير الجدول رقم (rV ) التالي إلى كافة هذه المقترحات والآراء لعينة

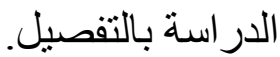

\section{جدل (TV) آراء ومقترحات عينة الدراسة}

\begin{tabular}{|c|c|c|c|c|c|c|c|c|c|}
\hline \multicolumn{2}{|c|}{ معلمات } & \multicolumn{2}{|c|}{ معلمين } & \multicolumn{2}{|c|}{ طلبة إناث } & \multicolumn{2}{|c|}{ طلبة نكور } & \multirow{2}{*}{ الآر اء و المقترحات عينة الدراسة } & \multirow[t]{2}{*}{ 5 } \\
\hline$\%$ & $\varepsilon$ & $\%$ & $\varepsilon$ & $\%$ & $\varepsilon$ & $\%$ & $\varepsilon$ & & \\
\hline - & . & - & - & 10.7 & V & $1 . . v 1$ & 7 & تشريب دوري داخلاب تدريب عملي المدارس. & $T$ \\
\hline ג. & r. & $0 \wedge .1$ & ro & 71.9 & I & $r 1 . \leqslant r$ & Ir & توفير أجهزة مزودة بالإنترنت في في & r \\
\hline$\leqslant\rceil . \wedge$ & $r r$ & $\leqslant 1.9$ & 11 & r..${ }^{\prime}$ & 1. & ד. 0. & r & وليست دور ات تدريبية حقيقية & $\bar{r}$ \\
\hline & & & & 7. V & r & דמיט & r & زلمعروضة المبة باللغة العربية. & $\varepsilon$ \\
\hline rદ. & 17 & 11.7 & $\wedge$ & $\varepsilon . \varepsilon$ & $r$ & ד. ט. & r & 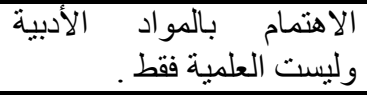 & 0 \\
\hline ro.o & 14 & rV.r & 17 & 7. $V$ & r & r.ov & r & واللغتشين الإنجليزين مستوى لمساعدة الطعلاب فين & 7 \\
\hline 19.1 & 9 & $9 . r$ & $\varepsilon$ & $r . r$ & 1 & דז.0 & r & إعلانات بالتلفزيون الفكرة من الجر ائد. & $\bar{v}$ \\
\hline • & · & - & • & $\varepsilon . \varepsilon$ & r & 1.94 & 0 & 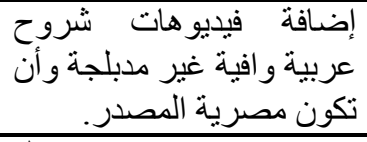 & $\Lambda$ \\
\hline . & • & . & - & r. & 1 & r.ov & r & الموقع الموقع واءوة وجودة تشغيل من قبل & 9 \\
\hline r. & IV & $\varepsilon \varepsilon . r$ & 19 & ז.ז" & 10 & $v .1 \leq$ & $\varepsilon$ & وذى وداءة متخصصية عالية . مدربين & 1. \\
\hline $1 \varepsilon .9$ & V & $1 \varepsilon$. & 7 & 7.. & r & $1 . . v 1$ & 7 & عمل ندل ندو المعرفة ومحاضر ات. & 11 \\
\hline . & . & . & • & • & • & ד ט. & r & وستشنارين المستخدمين وفي الموقع عند & $T$ \\
\hline $1 Y . \wedge$ & 7 & V. & r & Yr. & 1. & דץ.0 & r & تفعبل و لوحتخات و إرشادات حولك المعرفة. & $1 T$ \\
\hline 1.0 & $\varepsilon$ & 11.7 & 0 & 11.1 & 0 & & & 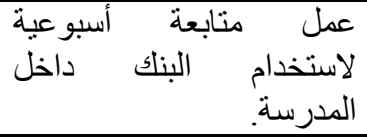 & $1 \varepsilon$ \\
\hline r. & IV & T. & $1 \varepsilon$ & r.Tו & 7 & $v .1 \leq$ & $\varepsilon$ & للتخريب العملي. فترة زمنية كافية & 10 \\
\hline$\varepsilon . \mu$ & r & 11.7 & 0 & 10.7 & V & $\cdot$ & $\cdot$ & تلطفير لتعلم كيفية التسجيل & 17 \\
\hline
\end{tabular}




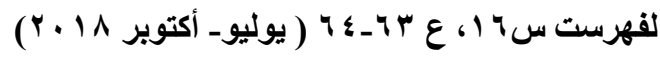

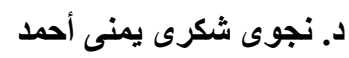

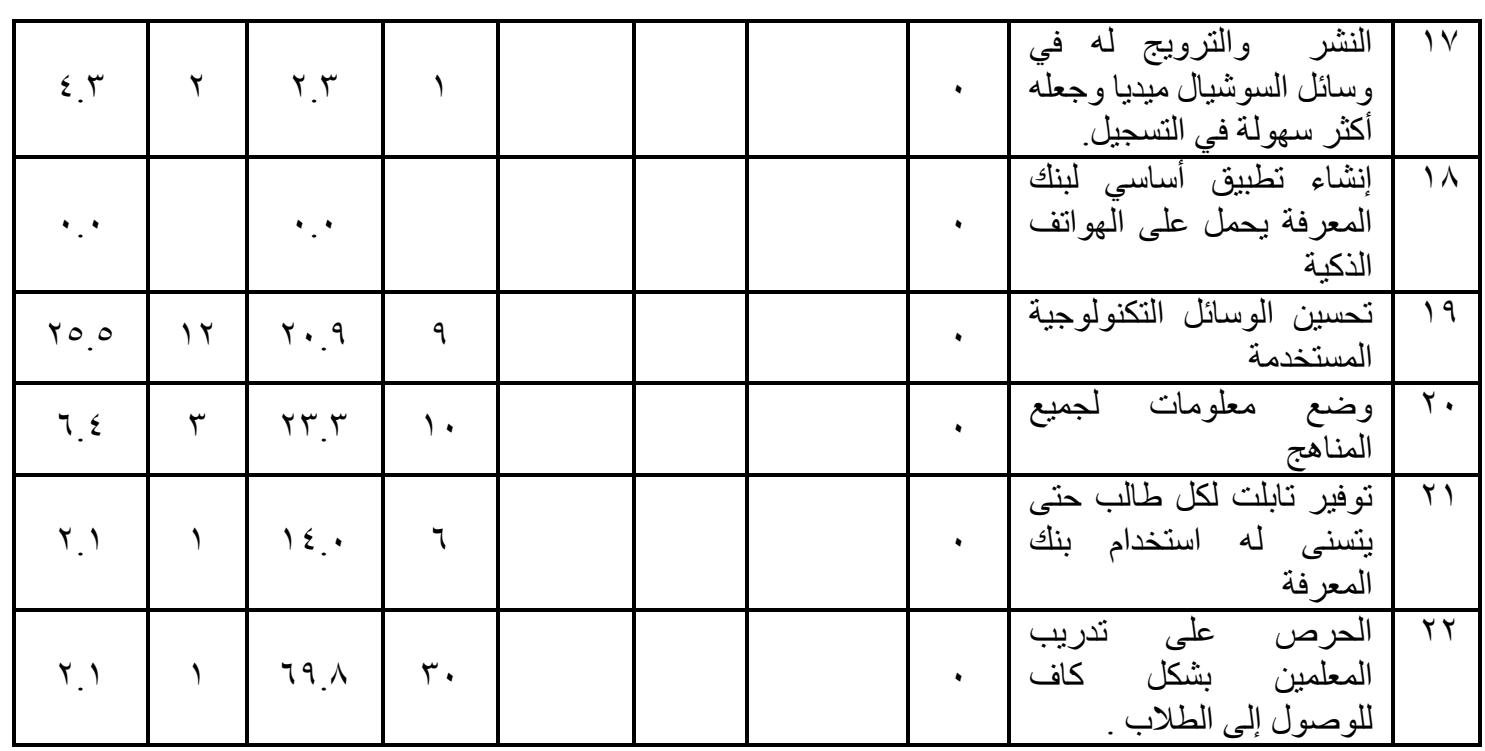




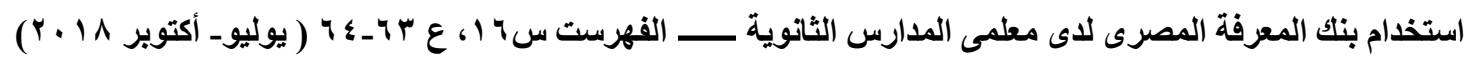

\section{نتائج الاراســـــة}

يمكن عرض أبرز النتائج التى توصلت إليها هذه الدراسة والتى تجيب عن التساؤلات

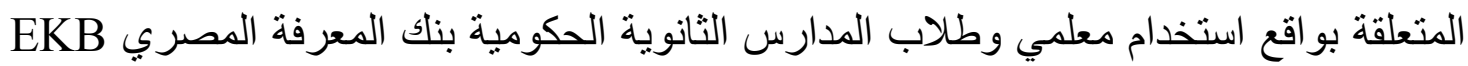
في محافظة القاهرة، و التى تبرز فيما يلي :

ا ـ ما واقع استخدام المعلمين وطلاب المدارس الثانوية لبنك المعرفة المصري (EKB) في

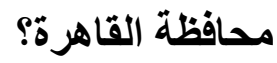

1/ يتبين من الدراسة أن السواد الأعظم من الطلبة (الذكور ـ الإناث) لم يقوموا بالتسجيل،

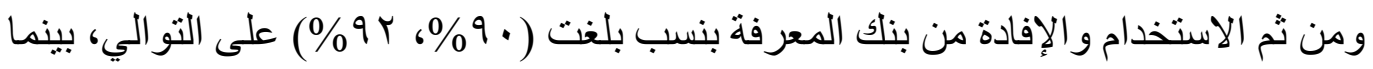

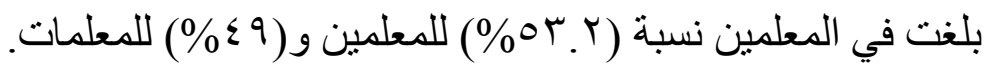
I / Yكمن السبب الرئيسي في عدم التسجيل والاستخدام، ومن ثم الإفادة من بنك المعرفة

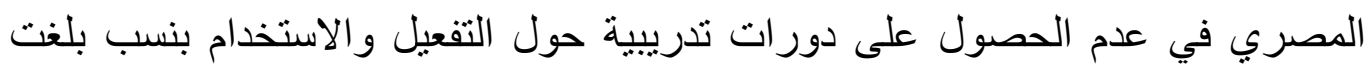

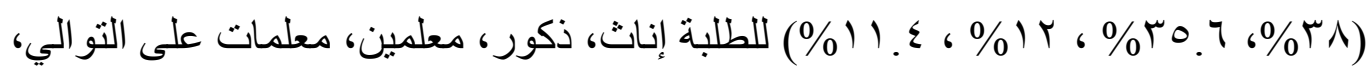
يليه مباثرة عدم تو افر مقومات التعامل معه في المدارس عينة الدر اسة "عدم تو افر أجهزة

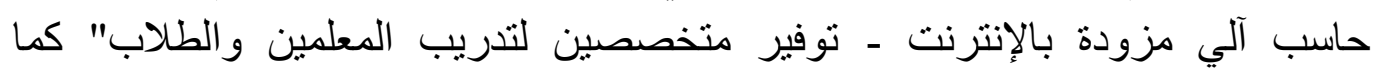

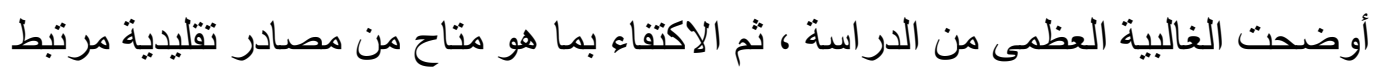

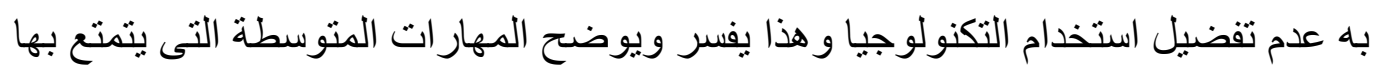
المعلمون و المعلمات في التعامل مع الحاسب الآلي.

Y ـ ما هي دوافع استخدام المعلمين والطلاب لبنك المعرفة المصري (EKB)؟

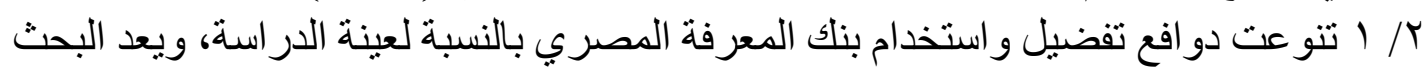

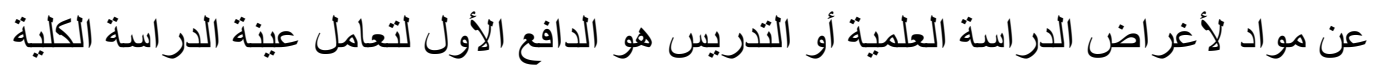

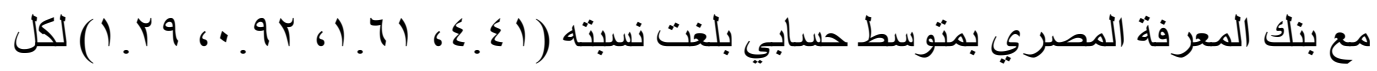
من الطلبة ذكور، إناث، معلمين، معلمات على التوالي، ثم يليه ملاحقة التطور ات في مجال

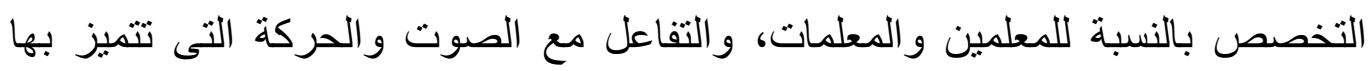
المصادر الإلكترونية داخل بنلك المعرفة بالنسبة للطلبة، ثم حداثة المعلومات التى يتميز بها ولثا

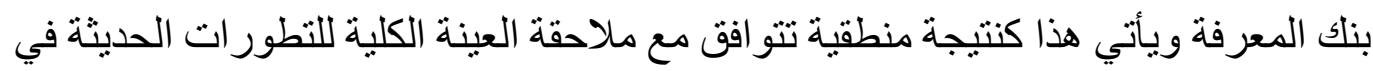

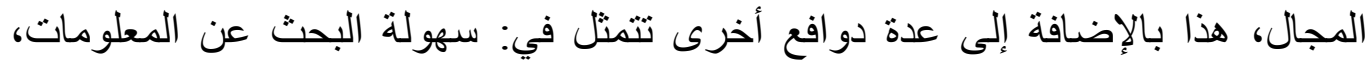

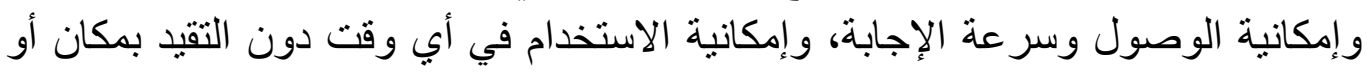

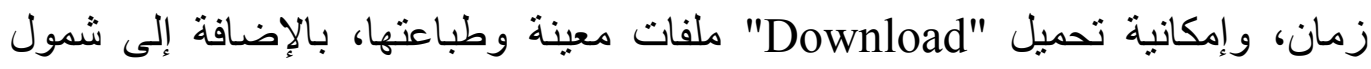

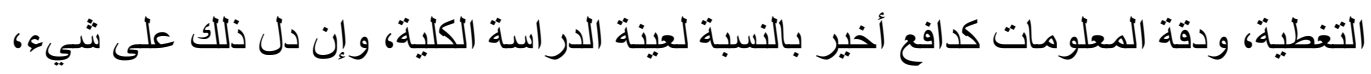

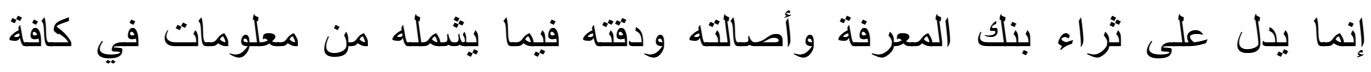
التخصصات الموضو عية . 
بـ ما أشكال مصادر المعلومات الأساسية في بتك المعرفة المصري التي تستخدم من قبل

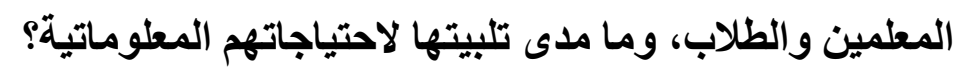

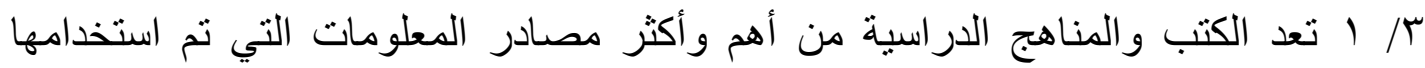

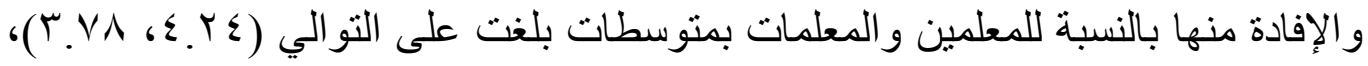

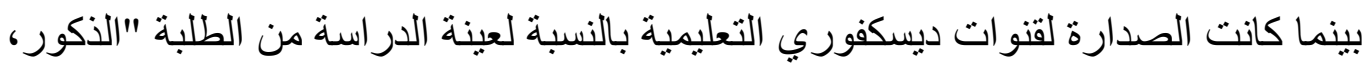

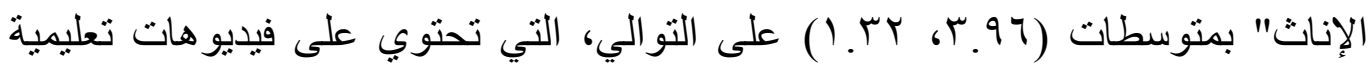

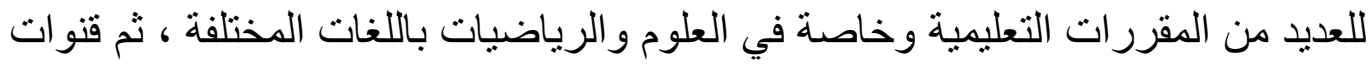

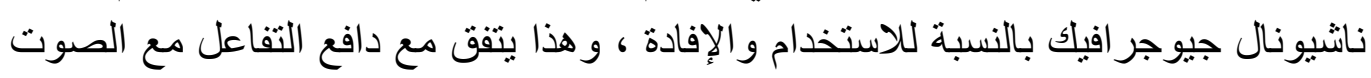

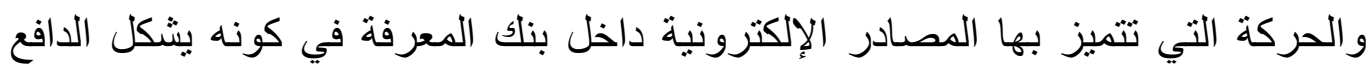

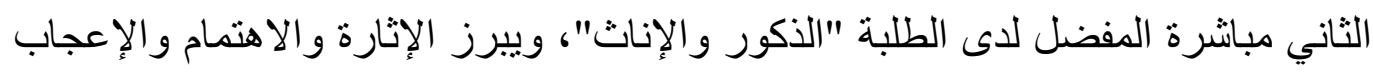
بهذه التكنولوجيا الجديدة في المقرر ات التعليمية.

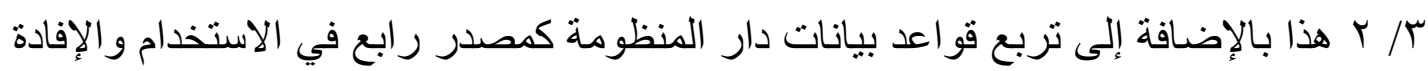

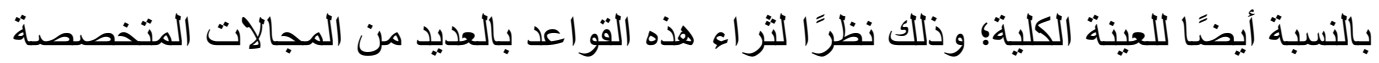
المختلفة التي يلجأ إليها المعلمون والطلبة للحصول على غايتهم العلمية مما بدل على ثرائها العلمي و أهميتها البحثية لهم.

ץ/ ץ ثم توالت العديد من المصادر الإلكترونية التي تم استخدامها والإفادة منها بالنسبة لعينة الدر اسة من الكتب المتخصصة ،و الدوريات العربية ،و الكتب المرجعية ،وموسو عة بريتانكا

$$
\text { الأكاديمية . الازية }
$$

ץ/ ؟ و أخيرًا شكلت الدوريات الأجنبية بالنسبة للطلبة "الذكور، والإناث" المصدر الأخير في

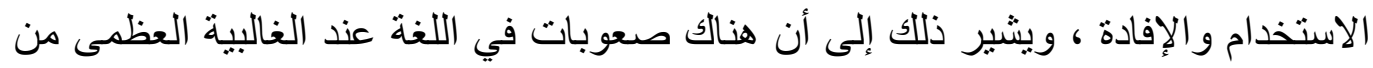
الطلبة "الذكور والإناث". بينما احتلت الدوريات المصرية المركز الأنير الأنير في الاستخدام

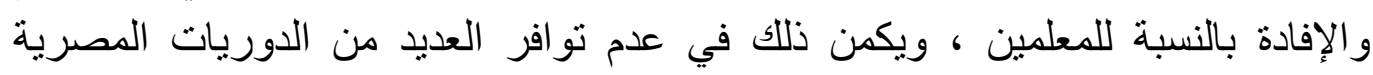

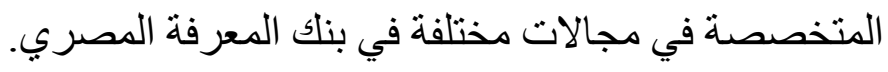

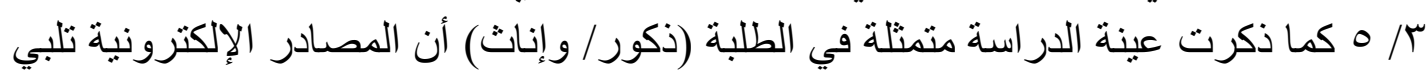

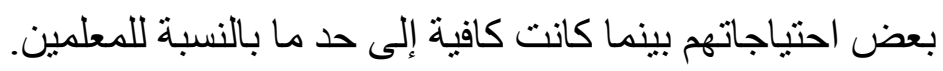

ع - ما مدى توافر مقومات التعامل مع بنك المعرفة المصري داخل المدارس الثانوية في محافظة

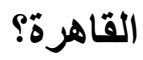

ع/ ا توصلت الدراسة إلى عدم توافر مقومات التعامل مع بنك المعرفة المصري (EKB) داخل المدارس عينة الدراسة من حيث نوافر أجهزة حاسب آلي مزودة بالإنترنت،

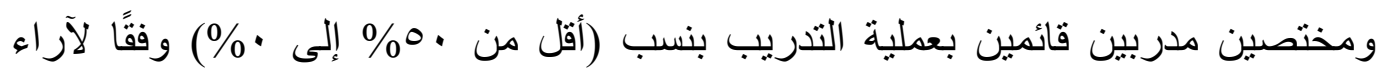
الغالبية العظمى من المشاركين في الدراسة. 


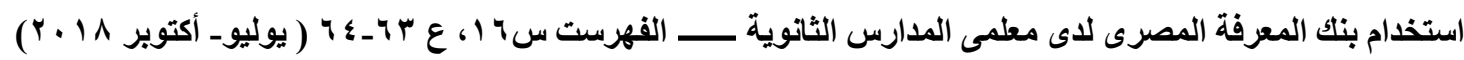

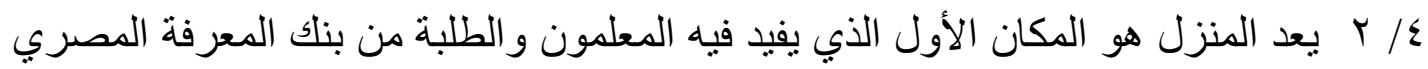

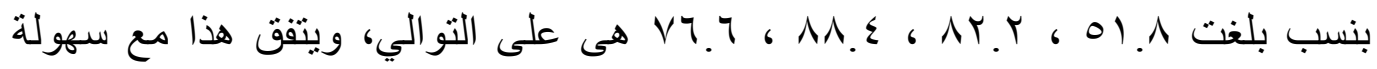
الاتصال بالإنترنت الذي لم يعد يتطلب الاتصال به العديد من التعقيدات.

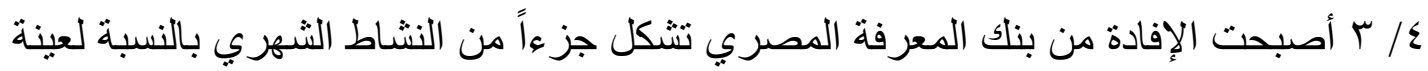

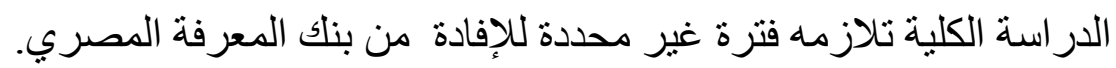

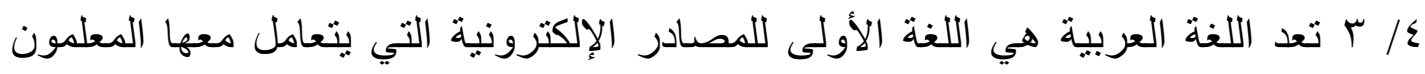

$$
\text { و الطلاب داخل المدارس عينة الدر اسة. }
$$

هـ هل هناك دور تثهض به مكتبات المدارس الثانوية في محافظة القاهرة لتفعيل ولرفع مستوى التهن

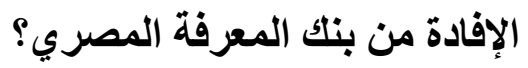

/ 1 الباين دور المكتبة الرئيسي بالنسبة للمشاركين في الدراسة، و إن كانت نقطة التقاء هذا

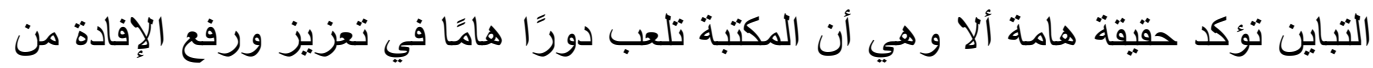

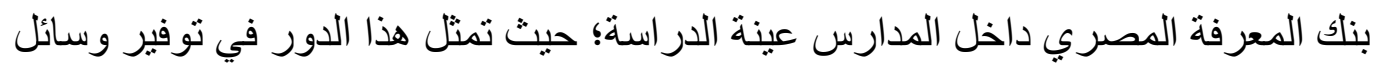
إرشادية حول كيفية التسجيل في بنك المعرفة، وتوفير الخبرة الكافية لدى أمناء المكتبات للمساعدة في الإفادة من بنك المعرفة، ولعل ذللك يبرز أهمية الدور الذي يقوم بـه أخصائي

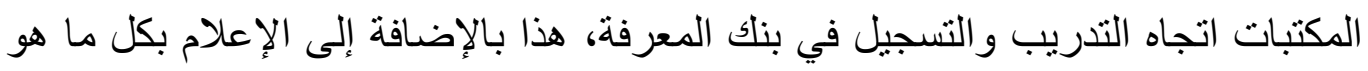

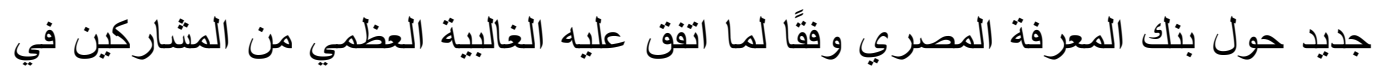
الدراسة، كذلك توفير بعض دورات التدريبية حول التفعيل والاستخدام وخاصة بالنسبة

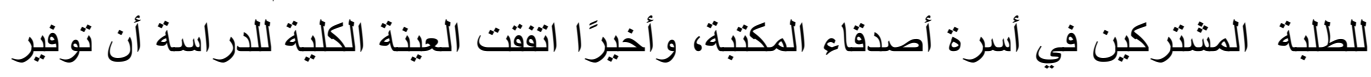

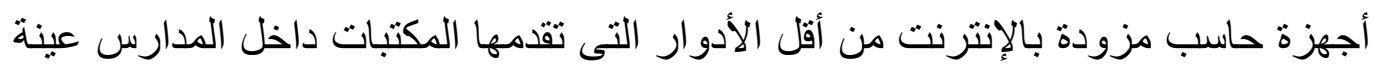

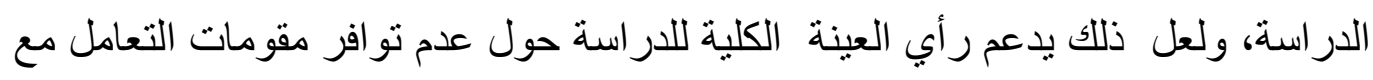
بنك المعرفة المصري داخل المدارس الحكومية في محافظة القاهرة.

7- ما المعوقات / الصعوبات التي تحد أو تقلل من استخدام بنك المعرفة المصري لأى

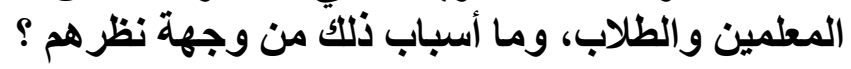

// / تعد عدم الخبرة في البحث داخل بنك المعرفة مع ضيق الوقت بالإضافة إلى عدم التى التدريب الجيد على استخدام بنك المعرفة، في مقدمه الصعوبات التي نواجه الطلبة و المعلمين الذكور تليها عدم توافر العدد الكافي من الحواسيب في المدارس بالنسبة فئة فئسة للمعلمات ، ويأتي ذلك كنتيجة طبيعية لعدم توافر التدريب الجيد من قبل فيل مدربين متخصصين وتوفير أجهزة مزودة بالإنترنت في المدارس عند فئن الدارسين.

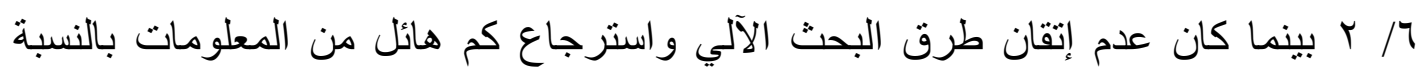

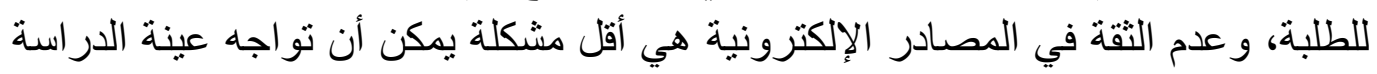


مما يعكس التنوع و التغطية التي يوفر ها بنك المعرفة المصرية لمعظم الموضوعات في المجالات المختلفة.

\section{V- مـا أهم مقترحات المعلمين والطلاب لتطوير الإفادة من بنك المعرفة المصري:}

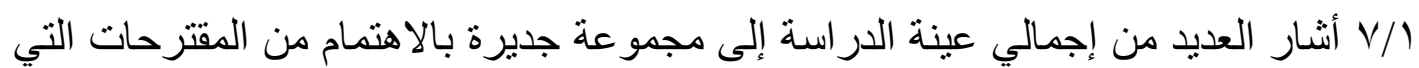

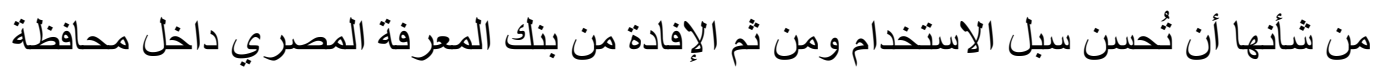

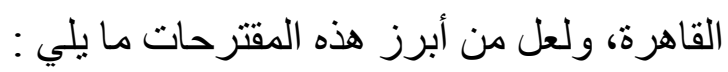
• توفير حصص شهرية للطلاب لتعلم كيفية التسجيل و الاستخدام. • توفير أجهزة حاسب آلي في المدارس مزودة بالإنترنت. • وجود متخصصين مدربين وذو كفاءة عالية. • الحرص على تدريب المعلمين بشكل كاف للوصول عدود إلى الطلاب. • عمل ندوات ومحاضر ات حول بنلك المعرفة. • النشر و الترويج له في وسائل السوشيال ميديا وجعله أكثر سهولة في التسجيل. • عمل متابعة أسبو عية لاستخدام البنك داخل المدارس.

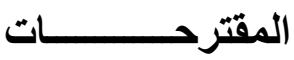

وضعت الباحثة مجمو عة من المقترحات التى من شأنها تعزيز الاستخدام ثم الإفادة من بنك المعرفة المصري داخل المدارس الثانوية الحكومية في محافظة القاهرة ، وباقي المحافظات الأخرى وتتلخص هذه المقترحات في التالي: ( ) ضرورة توفير شبكات داخلية بالفصول الدراسية من خلال خادم رئيسي لكل مدرسة

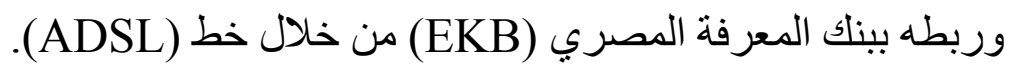
r برورة توفير سبورة تفاعلية داخل كل فصل در اسي. ع) توفير تابلت لكل طالب داخل المدرسة، لتسهيل الإفادة من بنك المعرفة فئة المصري. ع) توفير الأجهزة الحديثة والمعدات اللازمة داخل معمل الحاسب الآلي و المكتبة في المدارس.

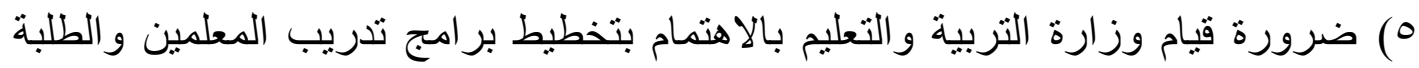

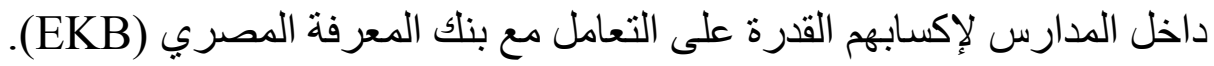

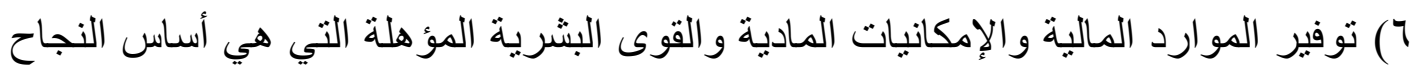
لأي خدمة يتم تقديمها. P بث الوعي في الوسط التعليمي حول أهمية بنك المعرفة المصري (EKB) و الاستفادة القصوى منه في إنجاز المهام العلمية المختلفة. A) ضرورة القيام بإنشاء دليل خاص بالمكتبة، وأن يتضمن تعريف المستفيد بكيفية التسجيل داخل بنك المعرفة المصري. 


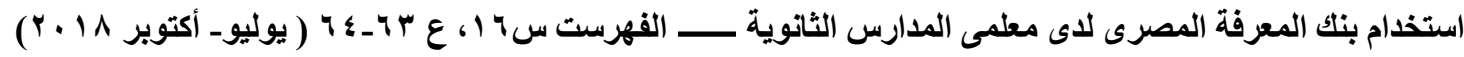

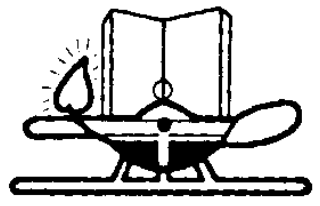

كلية الآداب
جامعة عين شمس المستو

قسم: المكتبات والمعلومات

\section{استبانـــ}

الأستاذ الفاضل، الأستاذة الفاضلة

$$
\text { تحية طيبة وبعد، أحسية }
$$

أقدم لكم جزيل شكري مقدماً على أجابتكم على الأسئلة التي تنتاولها طها هذه الاستبانة؛ و التي تتصل باستخدام بنك المعرفة المصري من قبل المعلمين وطلاب المدارس الثانويـة في محافظلة

وتهدف الباحثة من الاستبانة إلى التعرف على السمات الثخصية و المهنية لمجتمـع الدر اسـة

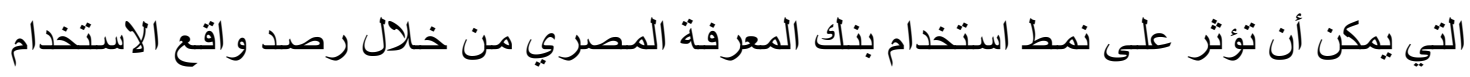

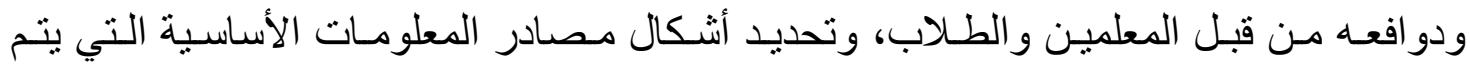

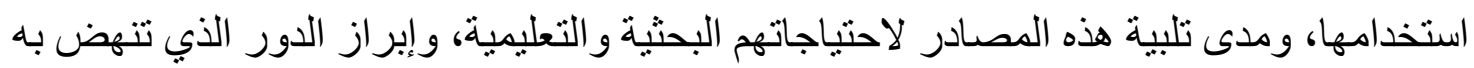

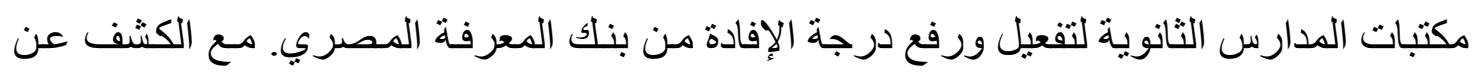

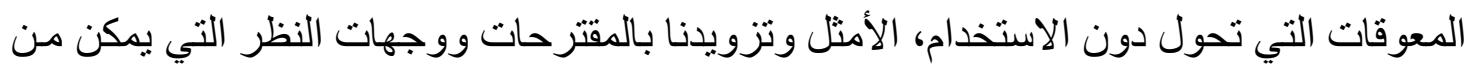
خلالهما تطوير وتعزيز أقصى إفاده ممكنة منه.

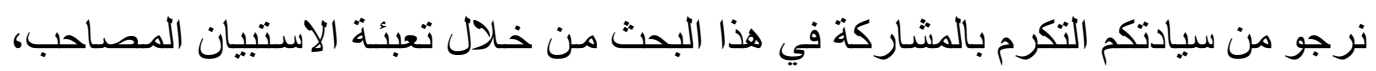

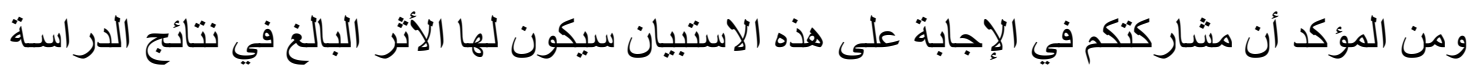
علمًا بأن إجابتك سوف تؤخذ بعين النظر ، ولن تستخدم إلا لغرض البحث العلمي دون سو اه.

$$
\text { ولسيادنكم كل تقدير و عرفان،، }
$$

\section{الباحثة}

د. نجوى شكري يمني أحمد

مدرس علم المعلومات و المكتبات

كلية الآداب - جامعة عين شمس علمس 


$$
\text { رجاء التفضل بوضع علامة ( ل ) أمام العبارة المناسبة }
$$

وفي حالة الإجابة عن الأسئلة متعددة البدائل يمكن اختيار أكثر من بديل

المحور الأول: البيانات الثخصية والمهنية:

() الاسم (اختباري) :

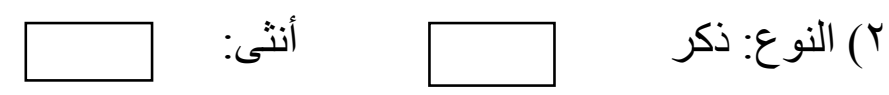

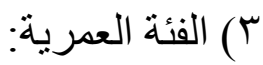

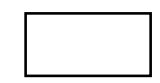

$$
\begin{aligned}
& \text { ب- sن • - }
\end{aligned}
$$

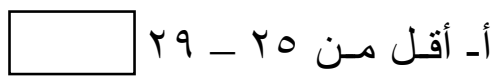

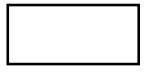

$$
\text { د- من • } 09
$$

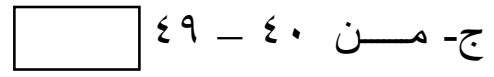

ع) الخبرة في التدريس:

ب- من ا1 إلى .r سنة

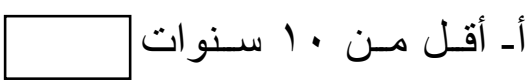

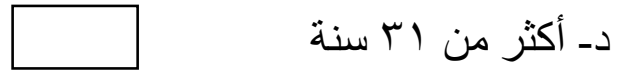

ج- بيـن اب و • س سـنة 0) المؤ هل : .

ج) دبلومة در اسات عليا ب

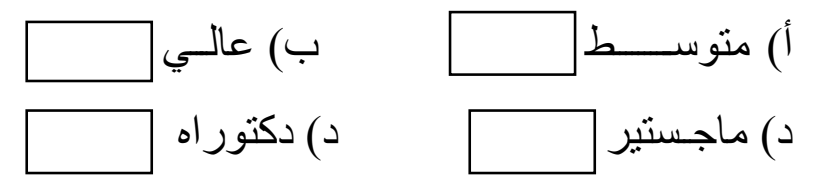

7) تاريخ الحصول عليه: .........

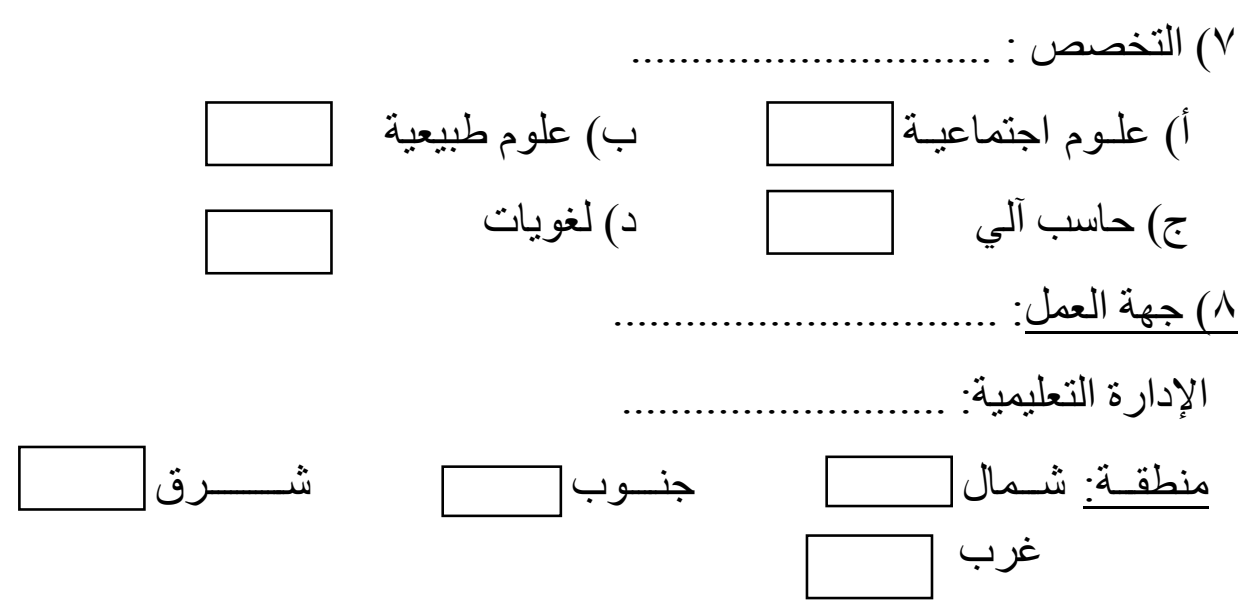




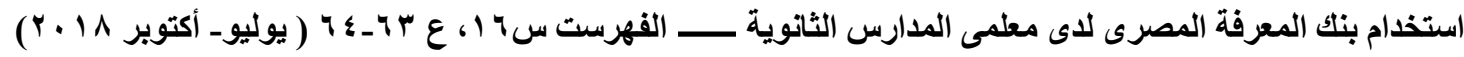

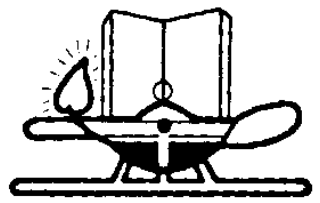

كلية الآداب

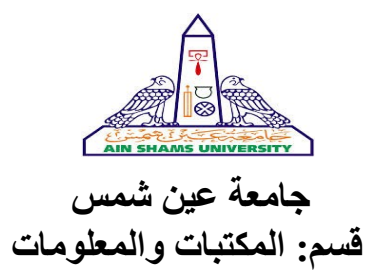

استبانــــ

عزيزى الطالب، عزيزتي الطالبة

أقدم لكم جزيل شكري مقدمًا على إجابتكم على الأسئلة التي تتناولها هذه الاستبانة؛ و التي

تتصل بتقديم صورة و اضحة المعالم لاستخدام بنك المعرفة المصري من قبل المعل المعلمين وطلاب

المدارس الثانوية في محافظة القاهرة.

ونظرًا لأهمية هذه الدر اسة في رسم استر اتيجية مستقبلية لاستخدام بنك المعرفة المصري

(EKB)

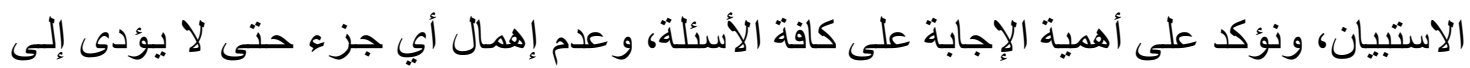

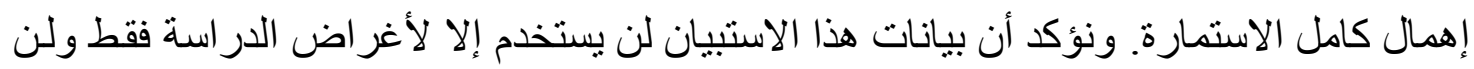

الباحثة

د. نجوى شكري يمني أحمد

مدرس علم المعلومات و المكتبات

كلية الآداب - جامعة عين شمس علم 


$$
\text { رجاء التفضل بوضع علامة ( ل ) أمام العبارة المناسبة }
$$

وفي حالة الإجابة عن الأسئلة متعددة البدائل يمكن اختبار أكثر من بديل

المحور الأول: البيانات الثخصية

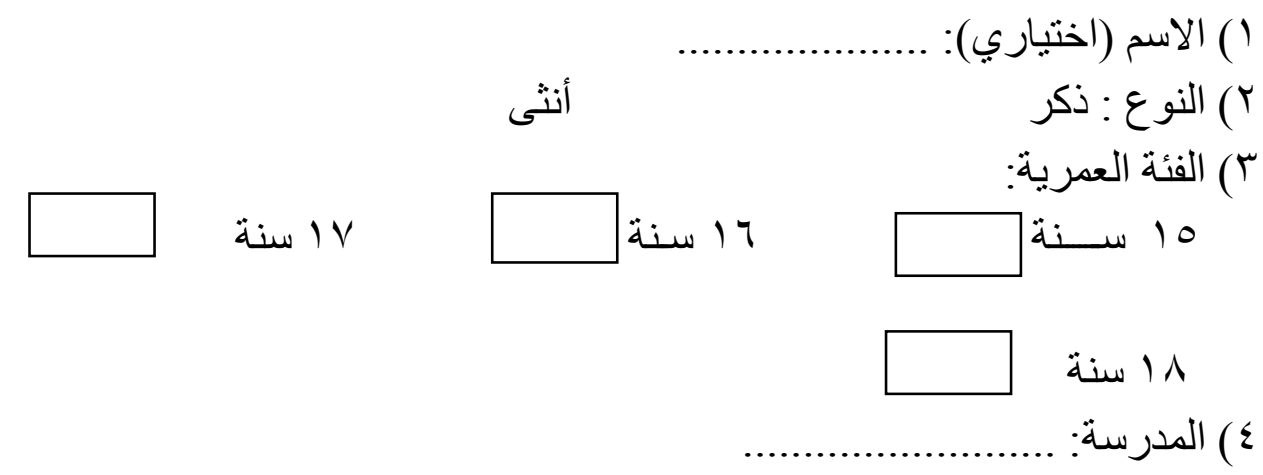




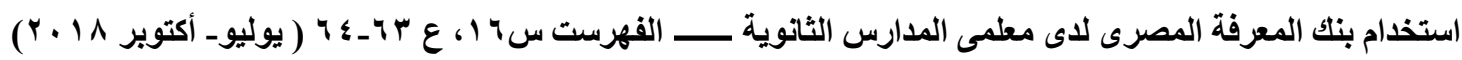

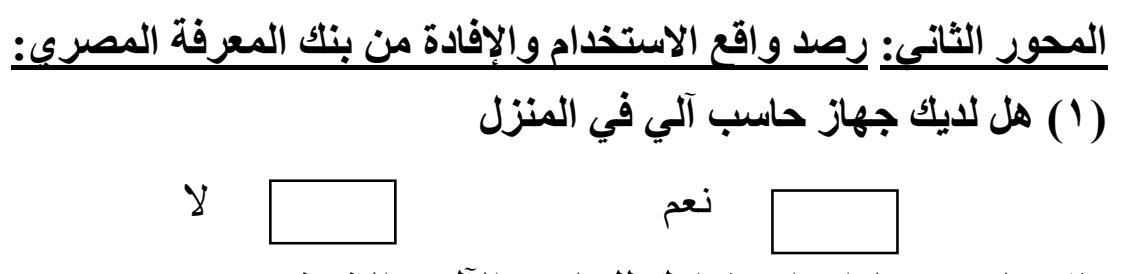

(Y) ما هي مهارات استخدامك للحاسب الآلي والإنترنت:

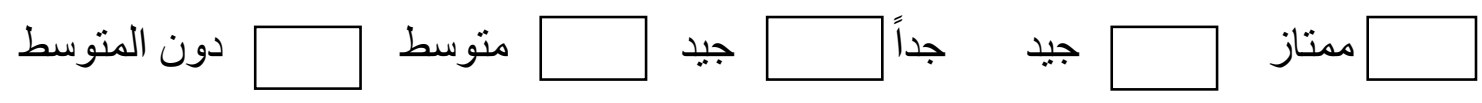

(r) هل قمت بالتسجيل واستخدام بنك المعرفة المصري؟

口 نعم (أجب على أسئلة الاستبيان بدءاً من السؤال رقم (0)

$$
\text { لا ل أجب على السؤ ال التالي) }
$$

( ع) في حالة الإجابة بـ ( لا ) ما السبب في عدم تسجيلك أو استخدامك لبنك المعرفة

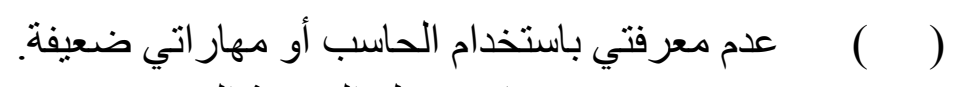

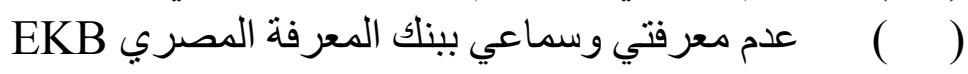

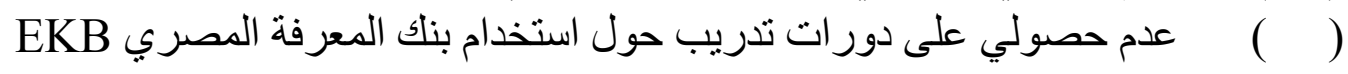

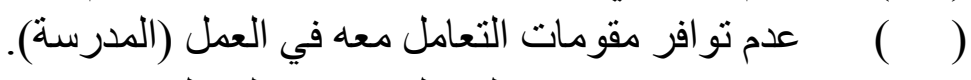

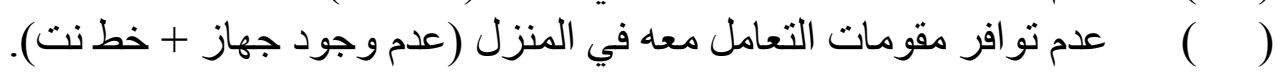

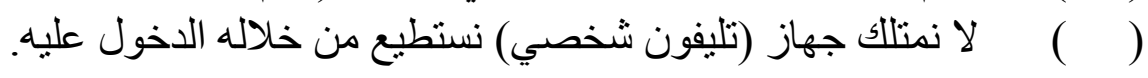

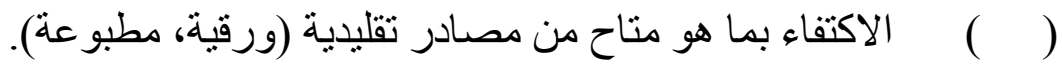

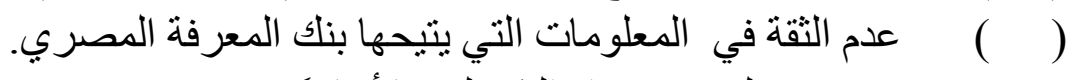

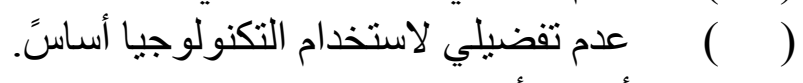

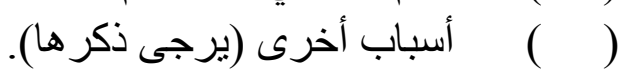

(0) ما هي سبل اكتسابك لمهارات التعامل مـع بنك المعرفة المصري "يمكن اختيار أكثر من

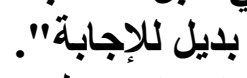

( ) بنفسك عن طريق التجربة و الخطأ.

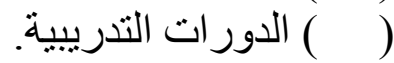

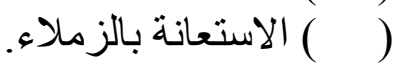

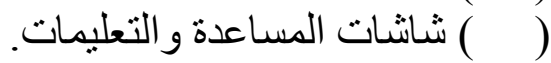

( ) (المو اقع التعليمية الموجودة على المعلى الإنترنت.

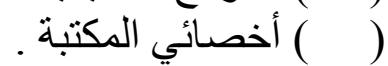

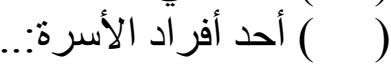

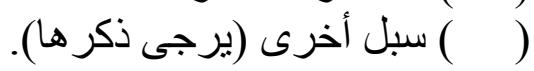


(") ما هي دوافع استخدامك وتفضيلك لبنك المعرفة المصري؟ "يمكن اختيار أكثر من بديل".

\begin{tabular}{|c|c|c|c|c|c|c|}
\hline ن ن ادرا & 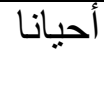 & إلى حد & مهم & مداً & دو افع الاستخدام و التفضيل & $\hat{r}$ \\
\hline & & & & & البحث عن مو اد لأغر اض الدر اسة العملية. & $T$ \\
\hline & & & & & 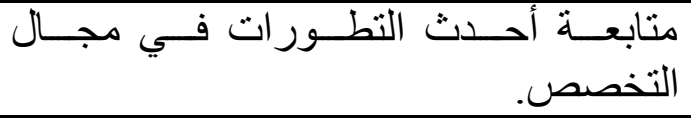 & r \\
\hline & & & & & التسلية و الترفيه. & $r$ \\
\hline & & & & & حداثة المعلومات. & $\varepsilon$ \\
\hline & & & & & البحث عن مو اد لأغر اض التدريس. & 0 \\
\hline & & & & & سهولة الاستفسار عن المعلومات (الإفادة). & 7 \\
\hline & & & & & الاطلاع و الثقافة العامة. & $\mathrm{V}$ \\
\hline & & & & & 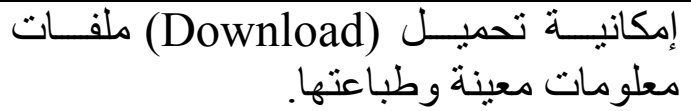 & $\Lambda$ \\
\hline & & & & & 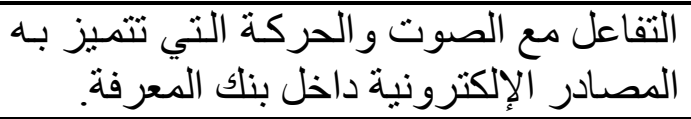 & 9 \\
\hline & & & & & توفير الوقت و الجهد. & 1 . \\
\hline & & & & & التعليمية. معرفـة مـا هـو جديـد في التكنولوجيـات & 11 \\
\hline & & & & & إمكانية الوصول وسر عة الإجابة. & Ir \\
\hline & & & & & شمول التغطية ودقة المعلومات. & 14 \\
\hline & & & & & تحقيق التعلم الذاتي. & $1 \varepsilon$ \\
\hline & & & & & إمكانية استخدامه في أي مكان وفي أي وقت. & 10 \\
\hline & & & & & مجانية الاستخدام. & 17 \\
\hline & & & & & ذات صلة تو بدر مصادر معلومات أخرى مطبوعة & IV \\
\hline
\end{tabular}

$$
\text { أسباب أخرى (يرجى ذكر ها) . - (ير) }
$$




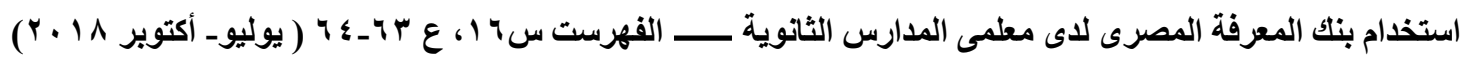

ما المصادر الإكترونية التي استخدمتها وأخذت منها بالفعل وما درجة إفادتكم منها.

\begin{tabular}{|c|c|c|c|c|c|c|}
\hline نادر & أحيات & مالى حدا & كثيرا & كثيرا & المصادر الإلكترونية & $\hat{r}$ \\
\hline & & & & & الكتب و المناهج الدر اسية & 1 \\
\hline & & & & & الكتب المتخصصة & r \\
\hline & & & & & الدوريات الأجنبية & $\bar{r}$ \\
\hline & & & & & الدوريات العربية & $\xi$ \\
\hline & & & & & قو اعد بيانات دار المنظومة & 0 \\
\hline & & & & & الدوريات المصرية & 7 \\
\hline & & & & & دوريات إلكترونية & V \\
\hline & & & & & الكتب الدر اسية. & $\Lambda$ \\
\hline & & & & & 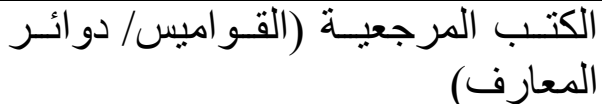 & 9 \\
\hline & & & & & موسو عة بريتانيكا الأكاديمية & 1 . \\
\hline & & & & & قنو ات ديسكفوري التعليمية & 11 \\
\hline & & & & & قنو ات ناثيونال جيوفر افيك & IY \\
\hline & & & & & قو اعد بيانات & 14 \\
\hline & & & & & قنو ات تعليمية & $1 \varepsilon$ \\
\hline
\end{tabular}

أسباب أخرى (يرجى ذكر ها)

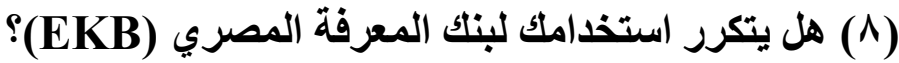

$\checkmark()$

( ) نعم ( )

إذا كانت إجابتك بنعم?

(9) ما معدل استخدامك له اله

( ) ( ) ( )

( ) بوميًا ( )

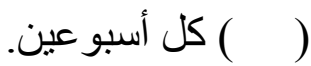

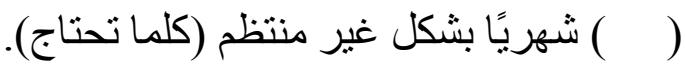

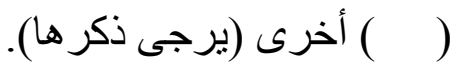

( • (1) ما الوقت الأي تستغرقه عادة في الاستخدام والإفادة من بنك المعرفة المصري؟

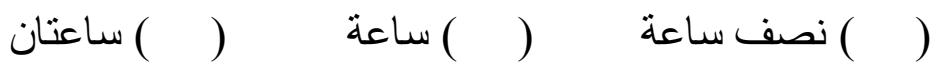




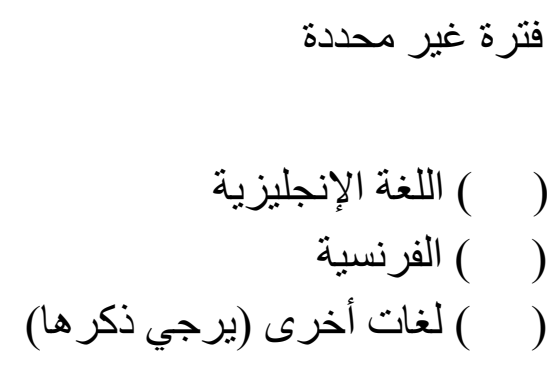

r ( )

(1 (1) ما لغة المصادر التي تفيل منها عادة؟

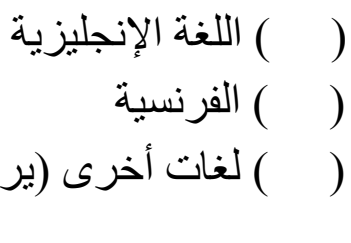

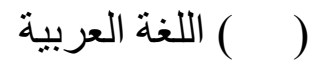
( ) ( ) (الألمانية العزية ( ) ( ) (الإيطالية

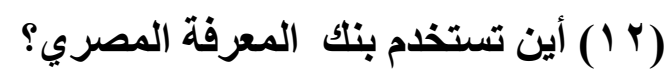
( ) معامل الحاسوب في المدرسة. ( ) من خلال الحاسوب في المكتبة المدرسية.

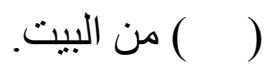

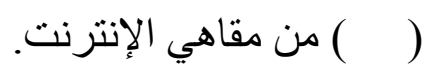
( ) من أماكن أخرى (يرجى ذكر ها).

(T ( ) مـدى تلبيـة المعلومـات / مـصادر المعلومـات الإكترونيـة في بنـك المعرفـة المـصرية لاحتياجاتك المعلوماتية.

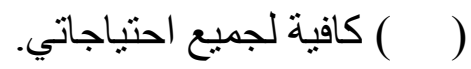

$$
\begin{aligned}
& \text { ( ) ( ) كافية لمعظم احتياجاتي. }
\end{aligned}
$$

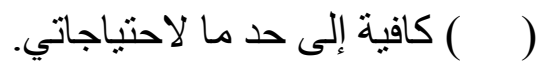

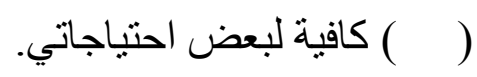

$$
\begin{aligned}
& \text { ( ) غير كافية على الإطلاق. }
\end{aligned}
$$

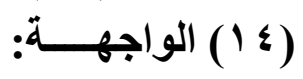

ـ إلى أي مدى تتميز واجهة التعامل و التشغيل بسهولة الاستخدام داخل بنك المعرفة

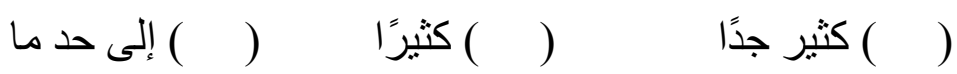

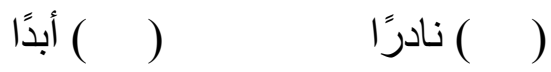

ـ هل يحتاج المستخدم إلى وسيط لاستخدام و اجهة التعامل (بنك المعرفة المصري).

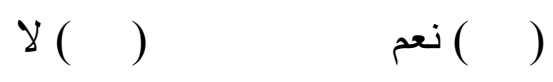

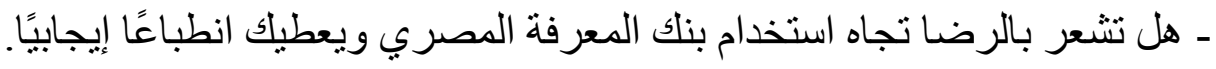

$$
\begin{aligned}
& \text { ( ) كثيرًا جدًا }
\end{aligned}
$$

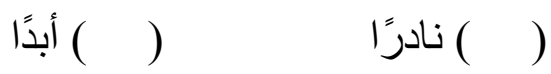




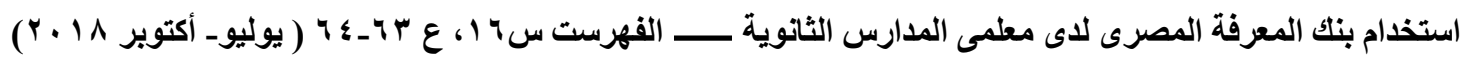

(0) هل سبق وأن حضرتم دورة تدريبية حول تفعيل واستخدام بنك المعرفة المصري؟

$$
\begin{aligned}
& \text { لا ( ) نعم () ( ) } \\
& \text { (7 } 1 \text { ) في حالة الإجابة بـ ( لا ) ما سبب ذلك؟ }
\end{aligned}
$$

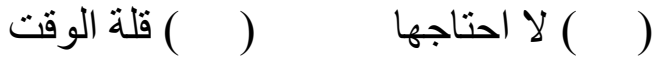

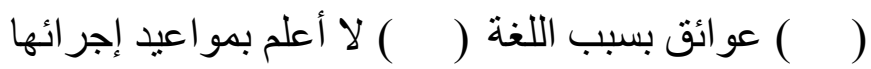

$$
\begin{aligned}
& \text { أسباب أخرى (يرجي ذكرها ) }
\end{aligned}
$$

( إذا كاتت الإجابة بـ ( نعم ) ما الجهة التي قامت بعملية التدريب؟

(1 ( ) هل يمكن تقيم مستوى هذه الدورات التدريبية؟

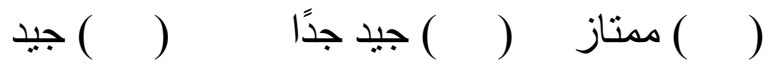

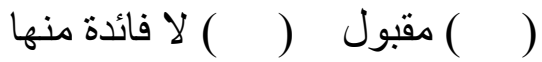

(9 (1) هل واجهتكم صعوبات أثثاء متابعتكم لبرامج التدريب؟

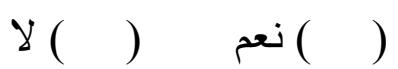

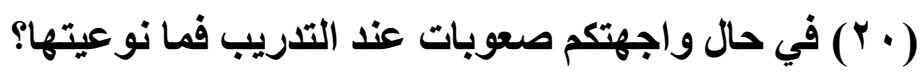

( ) الفترة الزمنية للتدريب غير كافية.

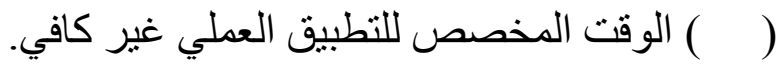

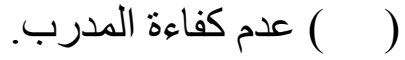

( ) صعوبات تقنية (عدد الأجهزة ـ الثبكة ـ الإنترنت لا تعمل أثناء التدريب).

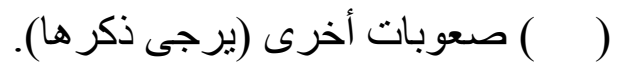

$$
\begin{aligned}
& \text { (Yl) } \\
& \text { ( ) الاستعانة بأحد الأساتذة المتخصصين في مجال الحاسب. }
\end{aligned}
$$

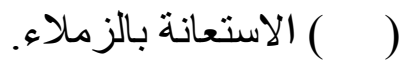

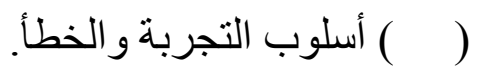

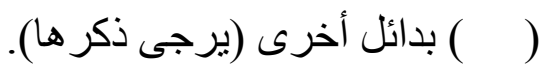

(Y ) من وجهة نظرك إلى أي مدى تثوافر مقومات التعامل بنك المعرفة داخل المدارس؟

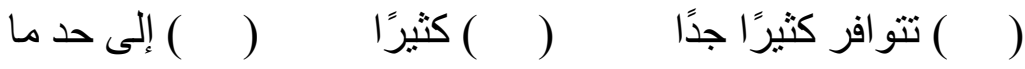

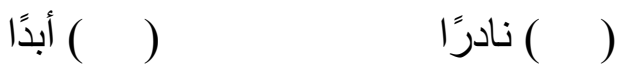




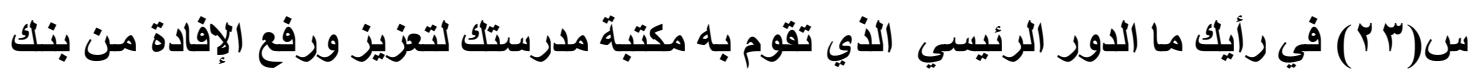
المعرفة المصري.

\begin{tabular}{|c|c|c|c|c|c|c|}
\hline نادر ا & أحيانا & 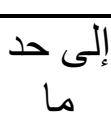 & كثيرا & كذانيرا & دور المكتبة & م \\
\hline & & & & & تقوم بإعلامك بكل مـا هو جديد حول بنك & $T$ \\
\hline & & & & & 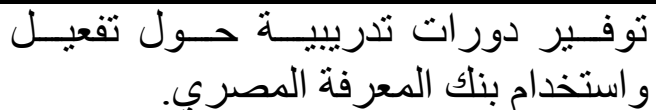 & $r$ \\
\hline & & & & & 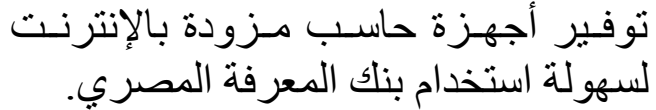 & $r$ \\
\hline & & & & & 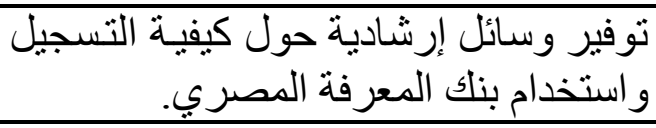 & $\varepsilon$ \\
\hline & & & & & 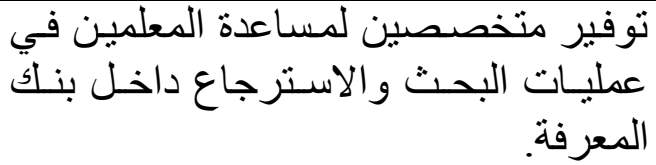 & 0 \\
\hline & & & & & 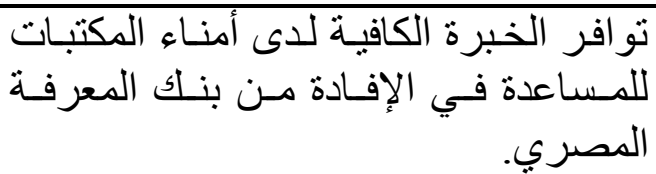 & 7 \\
\hline
\end{tabular}

أخرى (يرجى ذكر ها) 


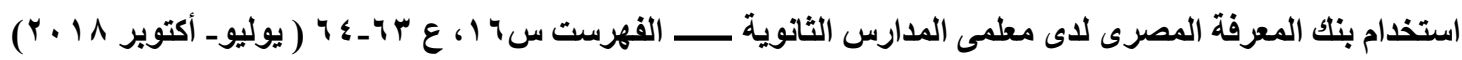

( ₹ Y ما المعوقات (الصعوبات) والمشكلات التي تواجهك في استخدام بنك المعرفة المصري؟

\begin{tabular}{|c|c|c|c|c|c|c|}
\hline نادرًا & أحيانًا & إلى حد & كثيرًا & كتًَ جيرًا & المعوقات أو الصعوبات & r \\
\hline & & & & & 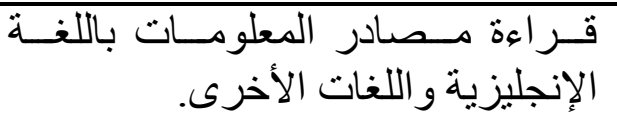 & 1 \\
\hline & & & & & لالمعرفة توجد الخبرة في البحث داخل بنك & r \\
\hline & & & & & 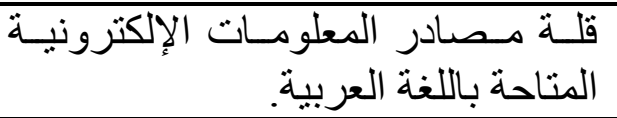 & $\mu$ \\
\hline & & & & & المناسبة. صــوبة الوصـــول إلــى المعلومــة & $\varepsilon$ \\
\hline & & & & & الميّاب وفة وسـائل التعريـف باسـتخدام بنـك & 0 \\
\hline & & & & & المعرفة التدريب الجيد على استخدام بنك & 7 \\
\hline & & & & & 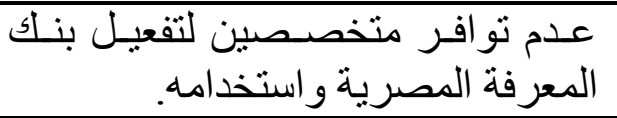 & $\bar{V}$ \\
\hline & & & & & عدم المعرفة الكافية بطريقة الاستخدام. & $\Lambda$ \\
\hline & & & & & للاستخدام. وجـود أجهـزة كمبيوتـر كافيـة & 9 \\
\hline & & & & & 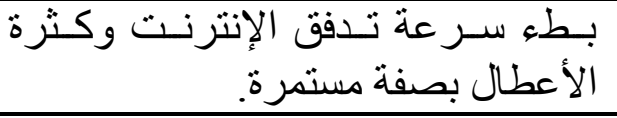 & $1 \cdot$ \\
\hline & & & & & ضيق الوقت. & 11 \\
\hline & & & & & مجال اهتمامي. الدر ايـة الكافيـة بمـا هـو متـاح في & Tr \\
\hline & & & & & 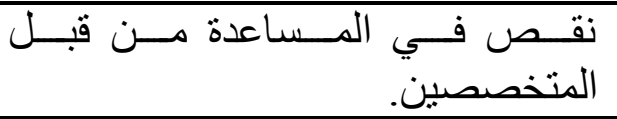 & $T$ \\
\hline & & & & & استرجاع كم هائل من المعلومات. & $1 \varepsilon$ \\
\hline & & & & & عدم إتقان طرق البحث الآلي. & 10 \\
\hline & & & & & عدم التقة في المصادر الإلكترونية. & 17 \\
\hline & & & & & في المدارس. تو افر العدد الكافي من الحو اسبب & IV \\
\hline & & & & & كافية. وجود مصدادر معلومـات مطبو عـة & 11 \\
\hline
\end{tabular}




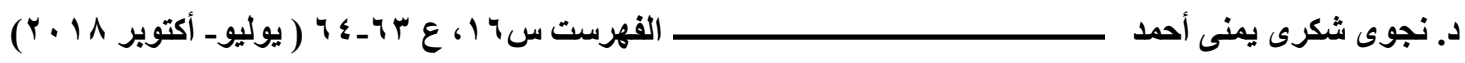

$$
\text { صعوبات أخرى (يرجى ذكر ها ) . }
$$

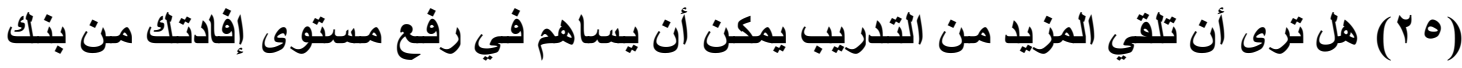

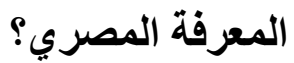

$$
\text { لا ن ( ) ( ) ( ) }
$$

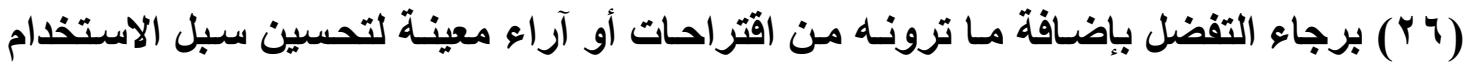
والإفادة من بنك المعرفة المصري.

$$
\text { شكرًا جزيلاً لتعاونكم }
$$




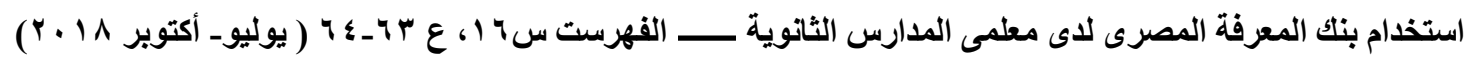

(1) www.EKB.eg .

(2) www.discovery education. Ekb.eg..

(3) https://www.facebook.com/EgyptianKnowledgeBank/ .

(4) www.ahram.org.eg.

(5) Joan M. Reitz. On line dictionary for libray and information science - data access (15/2/2018) .- Available at : http://lu.com/odlis/index.cfm.

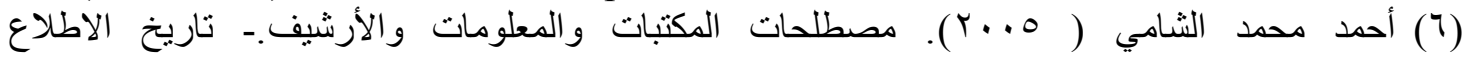

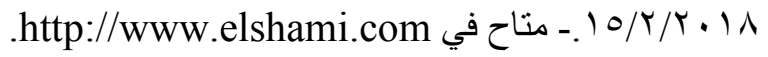

(7) ISO. ISO9242: Ergonomic Requirements for office work with visual Display terminals, Genece : International organization for standardization , 1997.

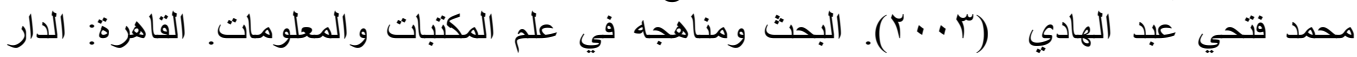

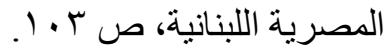

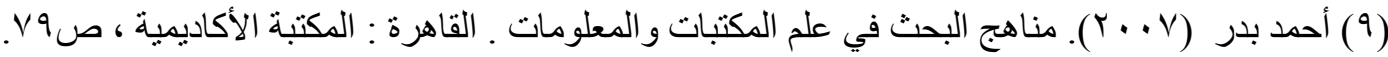

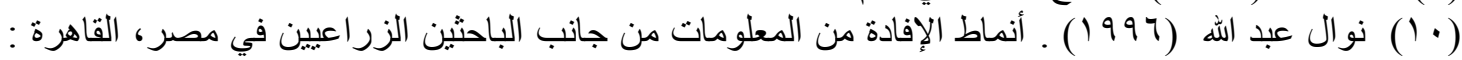

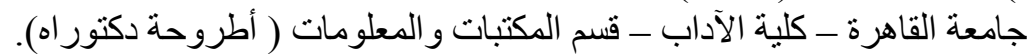

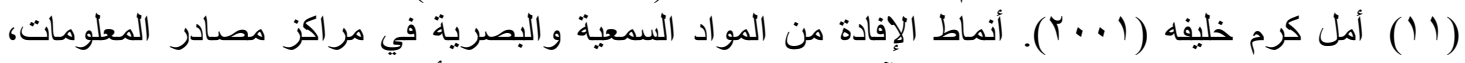

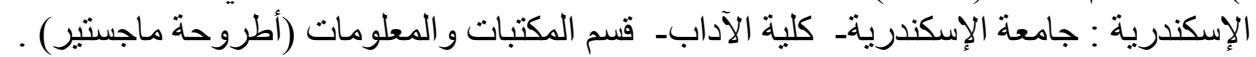

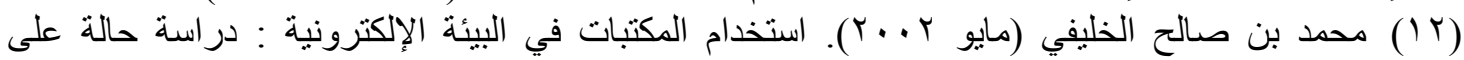

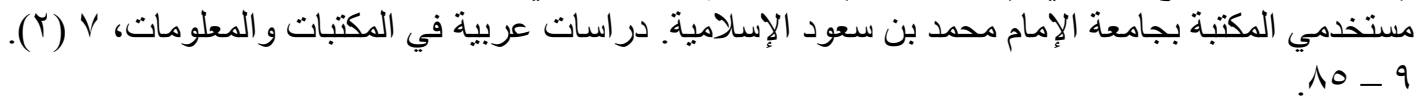

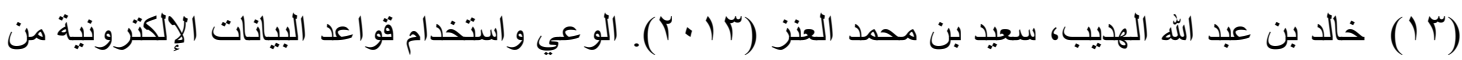

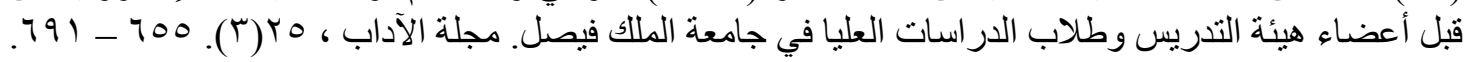

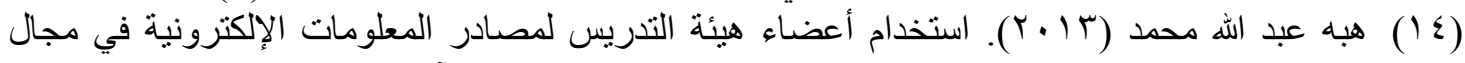

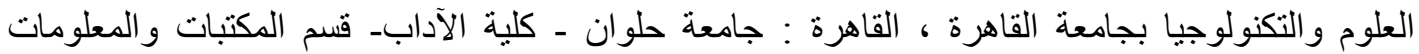

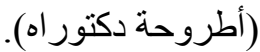

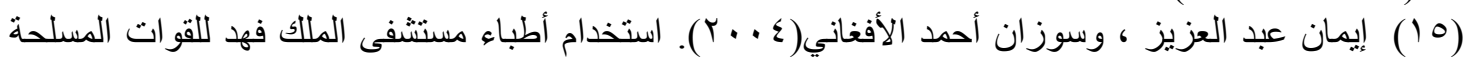

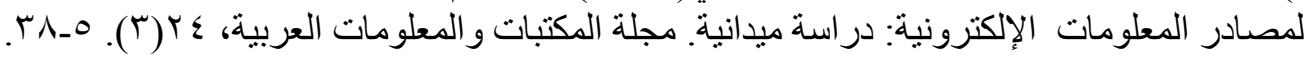

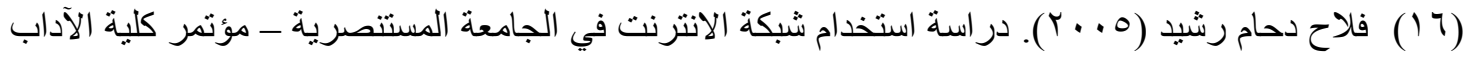

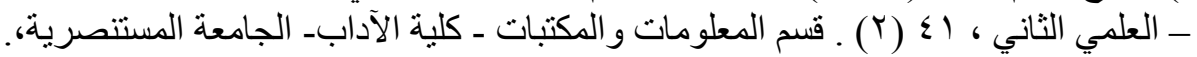

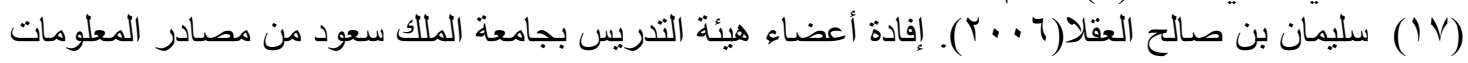

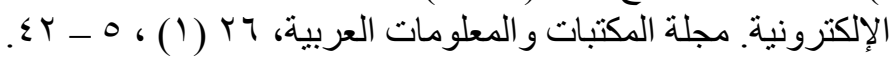

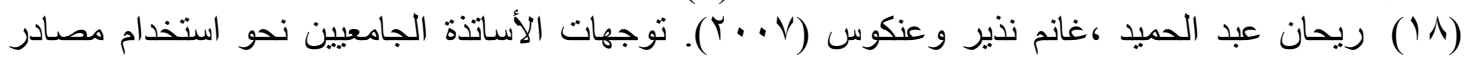
المعلومات الإلكترونية: دراسة ميدانية بكلية العلوم الإنسانية والاجتماعية بجامعة منتوري قسنطينة.

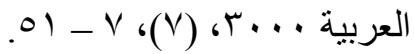

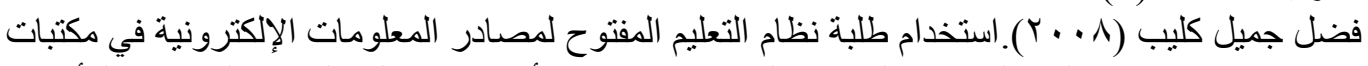

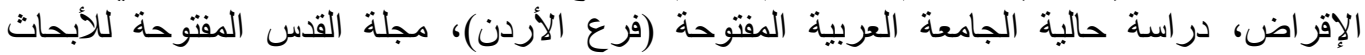

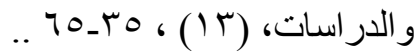

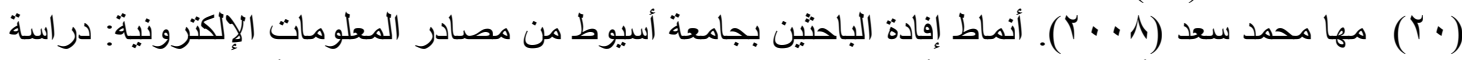

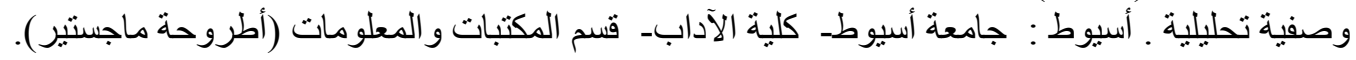




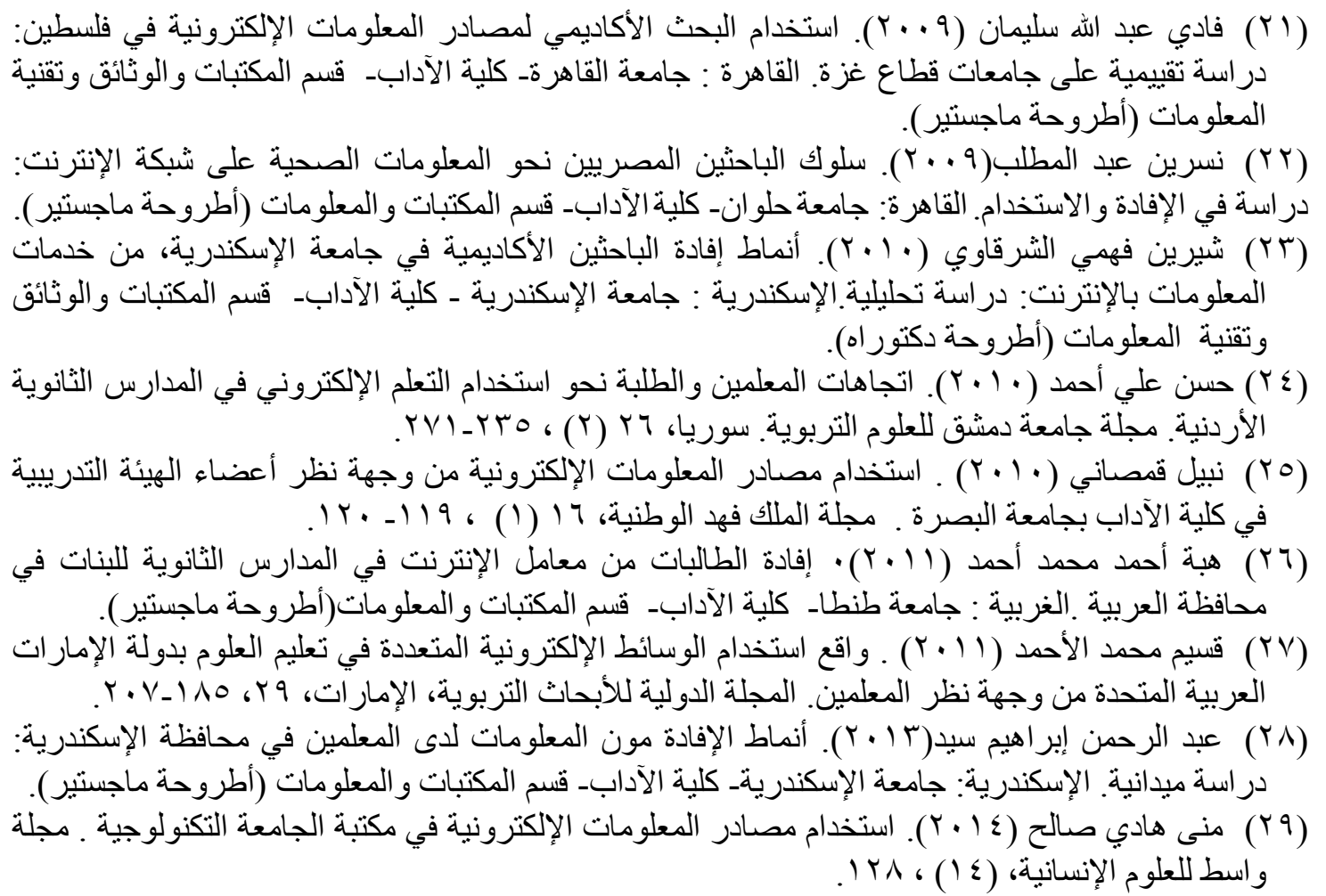

(30) dams, Judith n. and Bonk, (march 1995)Sharor C. Electronic Information Technologies and Resources: Use by University Faculty Preferences for Related Library Services College \& Research Libraries. Vol. 56, No. 2 pp 119-131.

(31) Lazinger, Susan S., bar0ilan, (June 1997) Judit and periz, Dulna. Internet Use by Faculty Members in Various Disciplines. A Comparative Case Study, Journal of American Society for Information Science. Vol. 48, No. 6, pp. 496-507.

(32) Kemp J. \& Waterton, P. (1997). CTCL 1996 survey on library internet services. Occasional paper series. ERIC No. ED419549.

(33) Vander Meer, P. and Ogthers. (2003). Are Library Users Also Computer Users? A Survey of Faculty and Implications for Services. The Public-Access Computer Systems Review, Vol. 8, No. 1.

(34) Curtis, K., Weller, A. and Hurd, J. (2010). Information-seeking behavior of health sciences faculty: the impact of new information technologies. Bulletin of the Medical Library Association, Vol. 85, No 4, [[ 402-412.

(35) Brad MacDonald, Robert Dunkelberger. (2012). Full- Text Database Dependency: An Emerging Trend Among Undergraduate Library Users? Research Strategies, Vol. 16, No4, March 1998, pp. 301-307.

(36) Max Plank, Diann Rusch-Feja, Uta Siebeky. (2014)Evaluation of Usage and Acceptance of Electronic Journals: Results of an Electronic Survey of Max Planck Society Researchers including Usage Statistics from Elsevier, Springer and Academic.

(37) Tenopir, C \& Lias Ennis(2017), A Decade of digital reference services. Reference \& User Quarterly. V. 41, No. 3, p. 265-273. 